STEPHANIE AARONSON

BRUCE FALLICK

ANDREW FIGURA

JONATHAN PINGLE

W I L L I A M W A S C HER

Board of Governors of the Federal Reserve System

\title{
The Recent Decline in the Labor Force Participation Rate and Its Implications for Potential Labor Supply
}

THE LABOR FORCE PARTICIPATION rate is defined as the percentage of the noninstitutional working-age population (those aged 16 and over) reporting themselves as either working or actively looking for work. This statistic is constructed from data collected as part of the Current Population Survey and published monthly by the Bureau of Labor Statistics (BLS). Its longer-run trend is an important determinant of the supply of workers to the U.S. economy. For much of the past four decades, the participation rate has trended upward, rising from less than 60 percent in the early 1960s to more than 67 percent by the late 1990s. However, after peaking at 67.3 percent in the first quarter of 2000 , the participation rate fell steadily to under 66 percent by early 2005 and has edged up only to just above 66 percent since then.

As figure 1 shows, such a decline in labor force participation is nearly unprecedented in the postwar experience. Although the upward trend between the mid-1960s and the mid-1990s was occasionally interrupted by relatively brief periods of little change, few episodes of persistent outright decline are evident in the data. Indeed, even after the upward trend from the earlier period is removed (using, for example, a Hodrick-Prescott filter

We are grateful to Leslie Carroll for superb research assistance and to Gary Burtless, Lawrence Katz, Joseph Lupton, Kevin Moore, Karen Pence, Daniel Sichel, Paul Smith, and especially Joyce Zickler for helpful comments and discussions. The views expressed in this paper are those of the authors and are not necessarily shared by the Federal Reserve Board or other members of its staff. 
Figure 1. Aggregate Labor Force Participation Rate, 1948-2005 ${ }^{\mathrm{a}}$

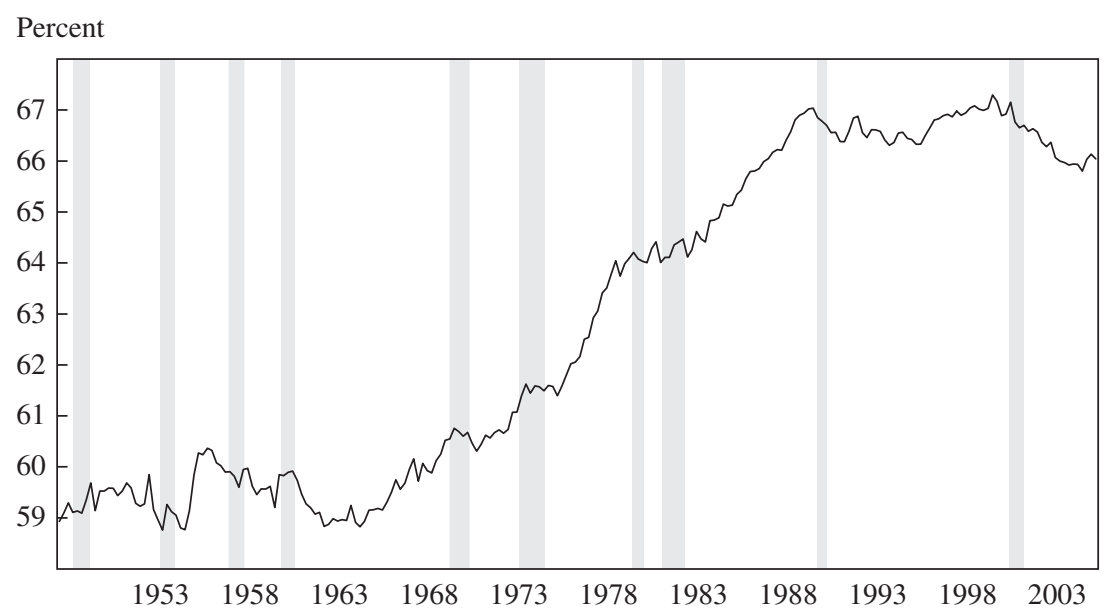

Source: Bureau of Labor Statistics.

a. Data in all figures adjusted by the authors as described in the text. Shaded areas indicate recessions. Data in this figure are seasonally adjusted.

or a linear spline, not shown), the decline in the participation rate in recent years seems large and unusually protracted by historical standards.

A key question is whether the decline in the participation rate since 2000 primarily reflects cyclical forces - the tendency for individuals to withdraw from the labor force during periods of reduced job opportunities-or longer-lasting structural influences. Indeed, the answer to this question bears importantly on the interpretation of recent macroeconomic developments. If the weakness in participation since 2000 is largely cyclical in nature, the current unemployment rate could be significantly understating the degree of slack in the labor market - and perhaps overstating the potential upside pressures on wage and price inflation; moreover, the outlook for longer-term economic growth would be buoyed by a higher labor force participation trend. ${ }^{1}$ If instead much of the decline results from structural developments in the labor market, the unemployment rate may be giving the appropriate signal of current economic slack, and the implications for potential economic growth would be less favorable.

1. See, for example, Bradbury (2005). 
From one standpoint the cyclical story seems quite reasonable. The downturn in the participation rate lines up closely with the weakening in overall economic activity that began in early 2001. With the exception of those over age 55, it occurred across demographic groups and coincided with a deterioration of households' perceptions of labor market conditions. Moreover, the failure of the participation rate to rebound after the 2001 recession could be a consequence of unusually weak labor demand in the subsequent recovery. However, this evidence is by no means definitive, and the persistence of a low participation rate during the recent period of more rapid employment gains has increasingly led observers to question whether other factors might be at work as well. ${ }^{2}$

This paper undertakes a comprehensive review of recent developments in labor force participation and attempts to parse the recent decline into its cyclical and structural components. After a brief overview of the data, we examine the effects of changing demographics on the aggregate participation rate and review the facts and past research on a number of other potential influences, including trends in human capital accumulation, relative wages, family structure, and income support programs. We then use a cohort-based model of the participation rate that attempts to account for these factors to estimate and project forward the underlying trend in the participation rate. Next we supplement the model-based results with analyses of recent changes in labor force participation using state-level data, gross labor force flows, and information on the incidence and duration of labor force attachment. Finally, we report briefly on two other components of the aggregate supply of labor: the size of the working-age population and the length of the average workweek.

Several important findings emerge from our analysis. As one might suspect, our results suggest a role for both cyclical and structural factors in explaining the recent decline in the labor force participation rate. In particular, the hot economy of the late 1990s-perhaps coupled with new legislation that encouraged or required welfare recipients to enter the labor force-appears to have pulled additional workers into the labor market, thus raising the participation rate at the same time that it pushed the unemployment rate down to about 4 percent. As the economy turned down in early 2001, the participation rate dropped back and remained low, mirroring

2. See, for example, Aaronson, Park, and Sullivan (2006), Himmelberg and McConnell (2006), and Toossi (2005). 
the extended period of employment decline and persistent lack of job opportunities that followed the recession.

However, important structural and demographic developments appear to have been at work as well. First, the aging of the baby-boom cohort has been raising the share of the population in older age groups, for which participation rates have historically been much lower than for younger groups, and this compositional change has been putting downward pressure on the aggregate participation rate. Second, participation rates for newer cohorts of adult women appear to have flattened out after more than three decades of steady rise, while new cohorts of men continue to be less inclined to participate in the labor market than their predecessors. Third, we find that teenagers and young adults are remaining in school longer and are reducing their labor force attachment whether in or out of school. Finally, and partly offsetting these other influences, older workers are increasingly delaying retirement or reentering the labor force following retirement, a development that seems to reflect better health, longer life spans, and changes to Social Security rules.

On balance, the results suggest that most of the decline in the participation rate during and immediately following the 2001 recession was a response to business cycle developments. However, the continued decline in participation in subsequent years and the absence of a significant rebound in 2005 appear to derive from other, more structural factors. Indeed, the participation rate at the end of 2005 was close to our model-based estimate of its longer-run trend level, suggesting that the current state of the labor market is roughly neutral for the participation rate. Finally, projections from the model suggest that many of these structural factors will continue to put downward pressure on the participation rate for some time, so that any future cyclical fluctuations in participation will take place around a declining trend. This continued downtrend, coupled with slower projected population growth and an apparent downtrend in the average workweek, suggests that trend growth of aggregate hours will slow further in coming years.

\section{The Data}

The official labor force statistics published by the BLS come from the Current Population Survey (CPS), a survey of roughly 110,000 individuals aged 16 and older in the civilian noninstitutional population, conducted 
monthly by the U.S. Census Bureau. We use these published data along with the underlying CPS micro data to analyze movements in labor force participation. We also use data from the Annual Demographic Supplements to the CPS, which are conducted in March of each year.

Because the CPS survey instrument has changed over time, inconsistencies in the data may arise. Most important for our purposes is that, in 1994, the Census Bureau redesigned the CPS and introduced computerassisted interviewing techniques. A primary goal of the redesign was to reduce the potential for misclassification of an individual's labor force status, by improving and clarifying the definitions of the labor force concepts and by revising the wording and sequencing of the questions. ${ }^{3}$ The new questionnaire also better distinguishes between permanent and temporary layoffs and between active and passive job search behavior, in order to correctly identify the unemployed.

Research shows that the redesigned CPS identifies more individuals as being in the labor force than did the old survey. Parallel surveys that the BLS conducted before and after the introduction of the new survey instrument indicate that the redesign raised the measured aggregate labor force participation rate by about 0.4 percentage point ${ }^{4}$ However, the effects of the redesign varied for different subgroups of the population: for example, the measured participation rate of females aged 16 and over rose significantly, but that of men aged 20-54 fell. ${ }^{5}$

Multiplicative and additive factors have been derived that can be used to adjust the participation rate so that it is comparable over time. ${ }^{6}$ Because these factors are constants, they simply shift the series upward before 1994. The multiplicative factor allows for the possibility that the magnitude of the adjustment varies with the share of individuals in the labor market. However, neither factor allows for the possibility that the impact of the redesign varies in response to other potential influences, such as the business cycle. Unfortunately, little is known about how the effects of the redesign vary with the state of the labor market. The parallel survey covered only one and

3. Polivka and Rothgeb (1993).

4. To assess the impact of the new collection procedures, a parallel CPS survey using the new procedure was conducted from July 1992 through December 1993. In addition, households in the parallel survey were interviewed using the old procedures from January through May 1994.

5. See Polivka and Miller (1998).

6. Polivka and Miller (1998). 
a half years, during which the unemployment rate fell from 7.7 percent to 6.5 percent. In addition, although it might be possible to infer the likely cyclical sensitivity of any single feature of the redesign from the change to the question itself, the fact that so many changes were made at once makes the ultimate impact difficult to discern. ${ }^{7}$

This paper uses the multiplicative factor to adjust the data from the basic monthly CPS before 1994, thus making the level of the series more consistent over time. ${ }^{8}$ However, given the lack of information on the impact of the redesign on the cyclical behavior of the participation rate, we do not try to make any further adjustments. In addition, we do not make any adjustments to the data from the March supplement. The Census Bureau did not redesign the CPS supplements in 1994, although interviewers did switch to the computer-assisted techniques used for the basic monthly survey. Also, responses to the supplemental questions could have been influenced by changes to the basic survey, although we know of no study that has explored this issue.

\section{The Effects of Demographic Change on the Aggregate Participation Rate}

Changes in the demographic structure of the population have been shown to have had important influences on a variety of labor market indicators. ${ }^{9}$ For the aggregate labor force participation rate, the most important demographic development now under way is probably the rising share of older Americans in the population, a result of both the aging of the baby-boom cohort and the significant increases in life expectancy that have occurred in recent decades. As table 1 shows, the share of the population between

7. For example, the new survey was designed to better distinguish between passive and active search methods. If the use of these methods varies over the business cycle, the impact of the survey on measured unemployment, and hence the participation rate, would vary in a predictable way. However, although the revised sequence of unemployment questions eliminated passive searchers, it also expanded the pool of individuals who were asked the job search questions and increased the likelihood that an interviewee would report multiple search activities, one of which could turn out to be active (Polivka and Rothgeb, 1993).

8. In addition to the 1994 redesign, the basic monthly CPS has been subject to a number of additional adjustments: the Census Bureau updated the population weights in 1989, 1997, 1999, 2000, 2003, 2004, and 2005 and introduced a new compositing procedure in January 1998. These changes primarily affect the size of the labor force rather than the participation rate. Nonetheless, we have adjusted the data in order to make them more comparable over time.

9. Examples include Perry (1971), Wachter (1977), Welch (1979), and Shimer (1999). 
Table 1. Age Composition of the Population Age 16 and Over, 1965-2015 Percent of total ${ }^{\mathrm{a}}$

\begin{tabular}{lrrrrrr}
\hline Age (years) & 1965 & 1975 & 1985 & 1995 & 2005 & $2015^{\text {b }}$ \\
\hline $16-19$ & 10.2 & 10.7 & 8.3 & 7.3 & 7.2 & 6.3 \\
$20-24$ & 9.8 & 12.1 & 11.6 & 8.9 & 9.0 & 8.5 \\
$25-34$ & 16.9 & 20.1 & 22.8 & 20.7 & 17.3 & 17.5 \\
$35-44$ & 18.8 & 14.7 & 17.6 & 21.0 & 19.0 & 16.2 \\
$45-54$ & 17.2 & 15.4 & 12.6 & 15.6 & 18.6 & 17.3 \\
$55-64$ & 13.2 & 13.0 & 12.2 & 10.5 & 13.3 & 16.2 \\
65 and over & 13.8 & 14.1 & 15.0 & 16.0 & 15.5 & 18.1 \\
\hline
\end{tabular}

Source: U.S. Census Bureau.

a. Columns may not sum to 100 because of rounding. b. Projected.

the ages of 25 and 44 fell sharply between 1995 and 2005, while the share of the population between 45 and 64 increased. Moreover, the Census Bureau projects that the share of the population aged 65 and over will rise to more than 18 percent by 2015 .

The influence of this population aging on the aggregate participation rate arises because of the typical life-cycle patterns of labor force participation illustrated in figure 2. For males the average participation rate in 2005 ranged from about 45 percent for teenagers to close to 90 percent for those in their late twenties and early thirties. Participation rates then edge down by age 40 and drop off sharply beginning at about age 55 . For females the pattern is similar, albeit a bit less pronounced. Even so, the average participation rate falls from about 65 percent between the ages of 55 and 59 to less than 10 percent at age 70 and above.

More formally, low-frequency movements in the aggregate participation rate can be decomposed into the influence of demographic changes in the population and the influence of changes in labor supply behavior within the various demographic groups. One useful decomposition of the aggregate labor force participation rate into the contributions of the participation rates and population shares of various demographic groups is based on the following identity:

$$
R_{t}-\bar{R}=\sum_{j}\left[\left(\overline{R_{j}}-\bar{R}\right) \times S_{j, t}+\left(R_{j, t}-\overline{R_{j}}\right) \times \overline{S_{j}}+\left(R_{j, t}-\overline{R_{j}}\right) \times\left(S_{j, t}-\overline{S_{j}}\right)\right],
$$

where $R$ denotes a participation rate, $S$ denotes a population share, $t$ indexes years, $j$ indexes demographic groups, and overbars denote means over time. In this way the deviation of the aggregate participation rate in 
Figure 2. Labor Force Participation Rates by Age in 2005

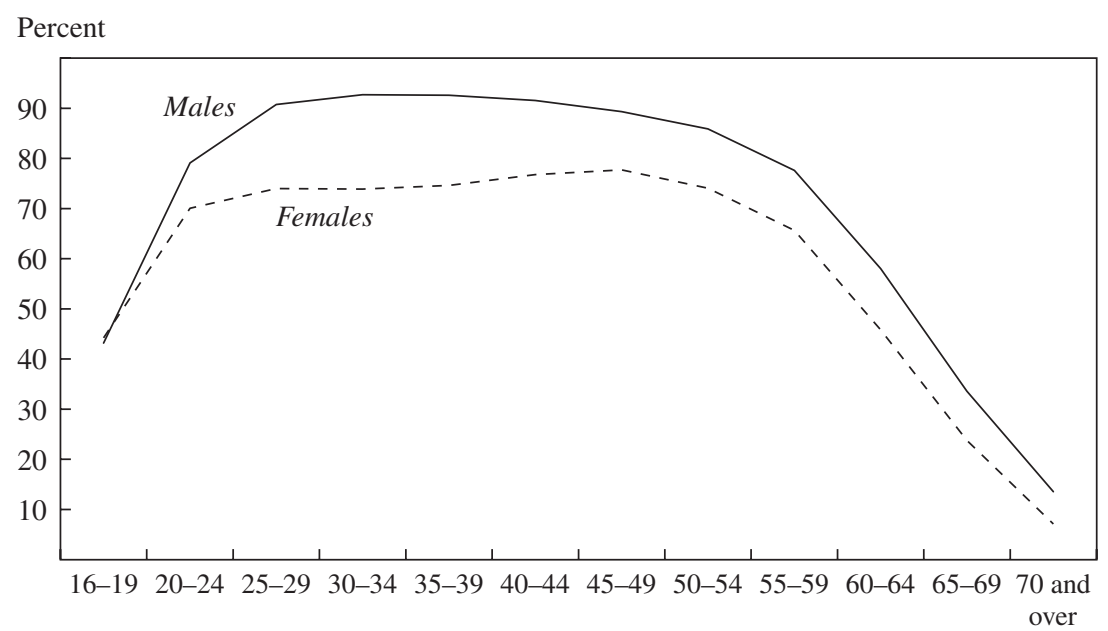

Age (years)

Source: Bureau of Labor Statistics.

any year from its sample mean can be decomposed into the contributions of the typical difference between each demographic group's participation rate and the overall rate, weighted by the group's population share; the deviation of each group's participation rate from its own mean, weighted by the group's average population share; and an interaction term, which turns out to be negligible. Changes over time in the first term can be interpreted as the contribution of changes in a group's population share to the change in the overall participation rate, and changes over time in the second term can be interpreted as the contributions of changes in the group's participation rate to the change in the overall rate.

Table 2 reports the contribution of changes in each age group's population share to the overall change in the participation rate over various time periods. As shown in the bottom row of the first column, the overall change in the age distribution accounted for about 0.6 percentage point of the 2.4-percentage-point rise in the aggregate participation rate between 1980 and 1995. Although changes in the population share of several age groups made sizable negative or positive contributions to the aggregate rate over this period, this demographic boost largely reflected the rising share of the population in their prime working years. 
Table 2. Contribution of Changing Population Shares to the Change in the Aggregate Labor Force Participation Rate, 1980-2010

Percentage points

\begin{tabular}{lrrr}
\hline Age (years) & $1980-95$ & $1995-2005$ & $2005-10^{\mathrm{b}}$ \\
\hline $16-19$ & 0.33 & -0.04 & 0.04 \\
$20-24$ & -0.33 & 0.01 & -0.01 \\
$25-34$ & -0.15 & -0.57 & 0.00 \\
$35-44$ & 1.06 & -0.35 & -0.36 \\
$45-54$ & 0.41 & 0.41 & -0.02 \\
$55-64$ & 0.19 & -0.10 & -0.24 \\
65 and over & -0.89 & 0.21 & -0.27 \\
$\quad$ Total change accounted for by & & & -0.87 \\
$\quad$ changing population shares & 0.62 & -0.42 & $\ldots$ \\
$\quad$ Total change in aggregate labor & & & $\ldots$ \\
$\quad$ force participation rate & 2.36 & -0.44 & \\
\hline
\end{tabular}

Source: Authors' calculations using data from the Bureau of Labor Statistics. Data are adjusted by the authors as described in the text.

a. Contributions are the sum of the relevant disaggregated categories from a decomposition based on twenty-eight distinct agesex groups.

b. Projected.

c. See the discussion later in the paper.

The second column of table 2, which reports these contributions over the past decade, indicates that the net effect of demographic change has reversed sign in recent years. In particular, the declining share of the population between the ages of 25 and 44, age groups for which labor force participation tends to be high, put downward pressure on the aggregate participation rate between 1995 and 2005, and only about half of this effect was offset by an increase in the group aged 45-54, which also has a relatively high participation rate. An increase in the share of 55- to 64-yearolds also acted to reduce the aggregate participation rate over this period, although this contribution was roughly offset by a small decline in the weight of the 65-and-over age category. The last column shows the effect of prospective changes in the age distribution. Given census projections of a decline in the relative size of the 35-44 and 45-54 age groups and an increase in the relative size of the 55-64 and 65-and-over age groups, demographics will contribute more negatively to the aggregate participation rate over the next five years.

To illustrate the size of the demographic effect relative to the actual changes in the participation rate, figure 3 shows a constructed measure of participation that allows the aggregate participation rate to vary only with changes in the population weights - that is, holding age-sex-specific 
Figure 3. Influence of Population Shares on the Aggregate Participation Rate, 1995-2015

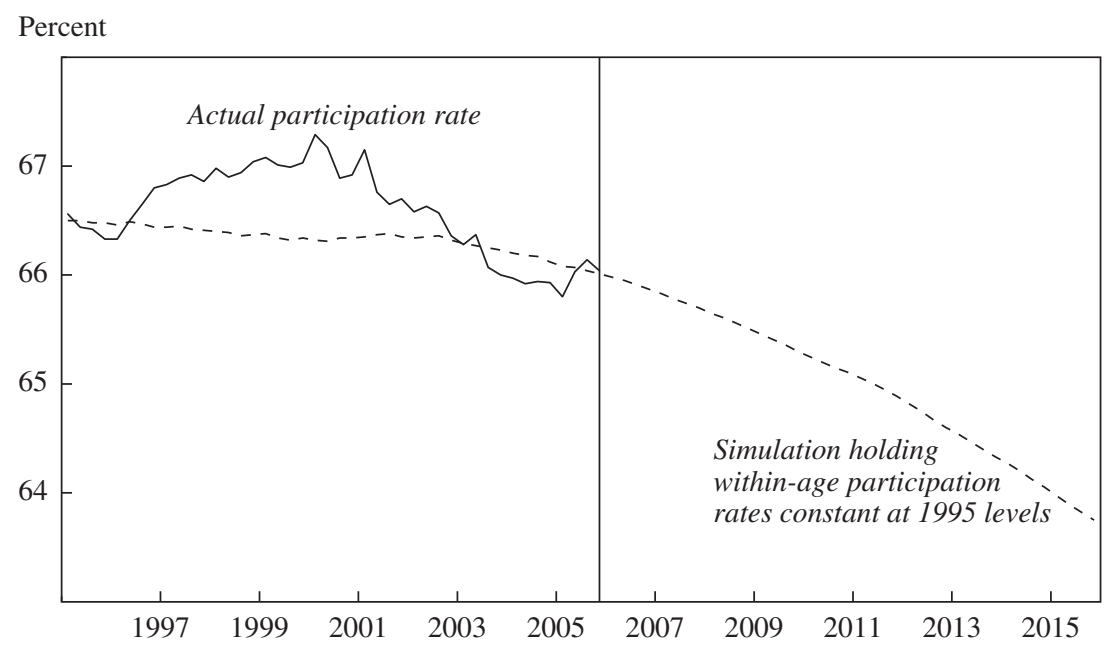

Source: Bureau of Labor Statistics data and authors' calculations. a. Points to the right of the vertical line are projections.

participation rates constant at their 1995 levels. This simulated participation rate is shown through 2015 (based on census population projections), and actual movements in the participation rate are shown through 2005 . The figure indicates that much of the variability in the actual participation rate over the past decade, including the decline between 2000 and 2005, was due to movements in age-sex-specific participation rates. Nevertheless, the importance of demographic shifts in the age structure of the population is clearly evident as well, especially after 2002. Moreover, demographic changes will likely be an increasingly important factor holding down the participation rate in coming years. Absent changes in the participation rates of individual age-sex groups, the aging of the population implicit in the census projections will reduce the aggregate participation rate by more than 2 percentage points between 2005 and 2015 .

\section{Potential Sources of Changes in Participation Rates by Age and Sex}

Although demographic change is one explanation for the declining participation rate, the above decomposition suggests that other forces have 
Table 3. Labor Force Participation Rates by Age and Sex, 1977-2005

Percent

\begin{tabular}{lccccc}
\hline Age (years) and sex & 1977 & 1985 & 1995 & 2000 & 2005 \\
\hline Males & & & & & \\
$16-17$ & 50.0 & 44.9 & 43.5 & 41.0 & 30.6 \\
$18-19$ & 72.1 & 68.7 & 65.7 & 65.0 & 57.9 \\
$20-24$ & 84.1 & 83.6 & 82.9 & 82.6 & 79.1 \\
$25-29$ & 94.2 & 93.6 & 92.5 & 92.5 & 90.7 \\
$30-34$ & 96.0 & 95.2 & 93.7 & 94.2 & 92.7 \\
$35-39$ & 95.6 & 94.8 & 92.4 & 93.2 & 92.5 \\
$40-44$ & 94.7 & 94.2 & 92.0 & 92.1 & 91.5 \\
$45-49$ & 92.7 & 92.8 & 90.7 & 90.2 & 89.3 \\
$50-54$ & 88.8 & 88.2 & 86.4 & 86.8 & 85.8 \\
$55-59$ & 82.6 & 79.1 & 77.3 & 77.0 & 77.6 \\
$60-61$ & 74.0 & 68.5 & 65.4 & 66.0 & 65.5 \\
$62-64$ & 54.3 & 45.9 & 44.9 & 47.0 & 52.5 \\
$65-69$ & 31.2 & 25.9 & 26.7 & 30.3 & 33.5 \\
70 and over & 14.6 & 11.2 & 11.5 & 12.1 & 13.5 \\
Females & & & & & \\
$16-17$ & 43.2 & 43.1 & 42.8 & 40.9 & 33.9 \\
$18-19$ & 61.9 & 63.3 & 61.1 & 61.3 & 55.9 \\
$20-24$ & 66.7 & 71.9 & 70.0 & 73.1 & 70.0 \\
$25-29$ & 62.5 & 72.0 & 74.7 & 76.7 & 73.9 \\
$30-34$ & 57.6 & 70.9 & 74.8 & 75.5 & 73.8 \\
$35-39$ & 60.0 & 72.3 & 76.2 & 75.7 & 74.6 \\
$40-44$ & 60.2 & 72.5 & 78.0 & 78.7 & 76.7 \\
$45-49$ & 58.5 & 68.3 & 77.2 & 79.1 & 77.7 \\
$50-54$ & 54.2 & 61.3 & 70.7 & 74.1 & 74.0 \\
$55-59$ & 49.9 & 52.3 & 59.4 & 61.4 & 65.6 \\
$60-61$ & 40.8 & 41.8 & 46.0 & 49.0 & 53.7 \\
$62-64$ & 29.6 & 29.8 & 32.5 & 34.1 & 39.9 \\
$65-69$ & 44.8 & 13.7 & 17.2 & 19.5 & 23.7 \\
70 and over & 4.4 & 5.2 & 5.8 & 7.1 \\
\hline Source: Bureau of Labor Statistics, Current Population & Survey. Data are adjusted by the authors as described in the text.
\end{tabular}

Source: Bureau of Labor Statistics, Current Population Survey. Data are adjusted by the authors as described in the text.

been at work as well. In particular, participation rates for specific age-sex categories have changed noticeably over time, and understanding the sources of these changes is important to our interpretation of the decline in the overall participation rate in recent years. Table 3, which reports participation rates for twenty-eight different age-sex categories in selected years, illustrates some of the key patterns in the data. Here we highlight the most important of these long-run patterns and review the key facts and research on some of their likely determinants. We also discuss how the behavior of the participation rate in the recent economic downturn and recovery has differed 
from those in the past. We emphasize that this discussion is not intended to be exhaustive or rigorous, but rather illustrative of the types of considerations we took into account when formulating the model described below.

\section{Youths}

One important development contributing to the long-run participation rate trend has been the decline in the participation rates of youths since the late 1970s. As can be seen in table 3, the participation rate for 16- and 17-year-old males fell from 50 percent in 1977 to 31 percent in 2005, while that for 16- and 17-year-old females fell from 43 percent to 34 percent over the same period; participation rates for 18- and 19-year-olds show a similar decline. For both sexes the decline was especially sharp after 2000. Labor force participation among 20- to 24-year-olds has also fallen since 2000, although there is less evidence of a longer-run downtrend, especially for women (for whom it appears participation may actually have risen since 1977).

Because schooling is an important activity for young people, the changing pattern of school enrollment is an obvious potential source of change in their labor force attachment. In fact, the proportion of teenagers in school has risen from about 60 percent in the late 1980s to nearly 75 percent in 2005, and the school enrollment rate for 20- to 24-year-olds has increased from about 20 percent to more than 30 percent over the past twenty years. ${ }^{10}$ Viewed over the longer run, these higher enrollment rates likely reflect, at least in part, the significant increase in the economic returns to education in recent decades. In addition, Daniel Aaronson, Kyung-Hong Park, and Daniel Sullivan note that college tuitions, net of grants and education tax benefits, have fallen, on balance, over the past decade, which, coupled with the general expansion of community colleges, has made college attendance more accessible to a greater segment of the youth population. ${ }^{11}$ Regardless of its source, the fact that students are less likely to work than nonstudents points to rising enrollment rates as a factor contributing to the decline in youth labor force participation in recent years.

10. An important contributor to the rise in enrollment for teenagers has been an increase in the proportion of teenagers enrolled in school during the summer. Of the approximately 15-percentage-point increase in the enrollment rates of teenagers between the late 1980 s and 2005, roughly 6 percentage points is attributable to the increase in schooling during the summer quarter (June, July, and August).

11. Aaronson, Park, and Sullivan (2006). 
Figure 4. Labor Force Participation Rates by Enrollment Status, Ages 16-24, 1985-2005

Percent Percent

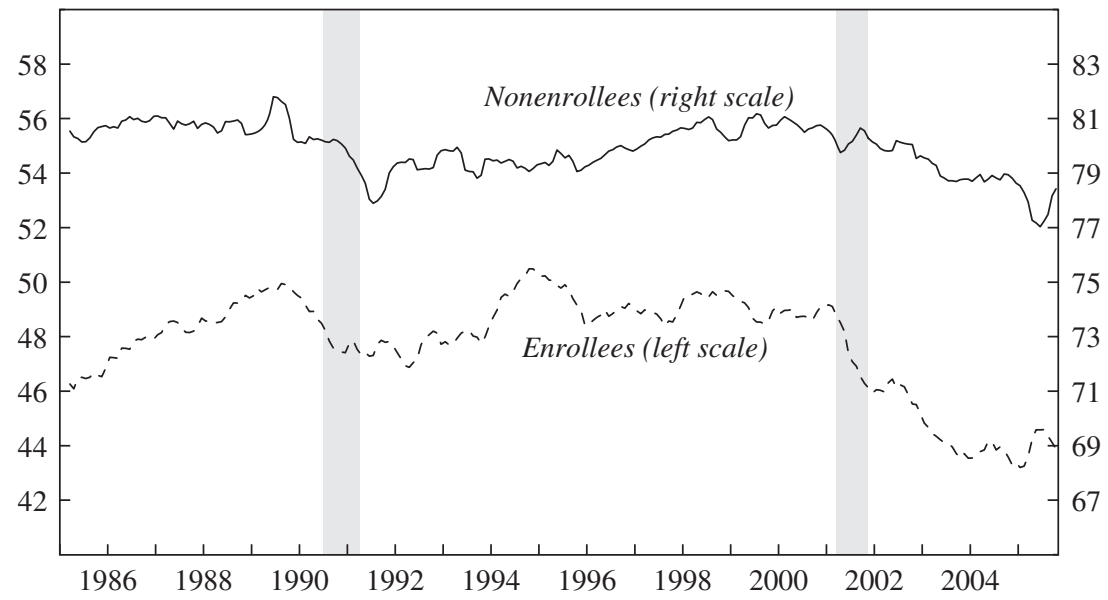

Source: Bureau of Labor Statistics and authors' calculations.

a. Data are five-month centered moving averages of the seasonally adjusted series. Shaded areas indicate recessions.

However, rising enrollment accounts for only a portion of that decline. As figure 4 shows, labor force participation rates of both enrollees and nonenrollees have fallen in recent years, and a decomposition of the decline in participation into the contribution of the change in enrollment patterns (holding the participation rates of enrollees and nonenrollees constant) and the contribution of the change in enrollee and nonenrollee participation rates indicates that these within-group changes are at least as important as the increase in enrollment. Indeed, of the 8-percentage-point drop in the labor force participation rate of teenagers between 2000 and 2004, 1.6 percentage points can be attributed to the rise in school enrollment rates, while 5.1 percentage points is due to participation declines among enrollees, and 1.4 percentage points owed to participation declines among nonenrollees. For 20- to 24-year-olds, the contributions are more evenly spread: of the 2.8-percentage-point decline in the participation rate for this age group between 2000 and 2004, 0.8 percentage point reflects the increase in school enrollment rates, another 0.8 percentage point derives from the decline in the participation rate among students, and 1.2 percentage points is the result of the decline in the participation rate of nonenrollees. 
Of course, in addition to boosting enrollment, increased returns to schooling may have reduced the participation rate of enrollees as the rewards for engaging intensively in schooling became more pronounced. Alternatively, increases in family wealth may have decreased the incentives for enrolled youths to work. However, the historical behavior of enrollee participation shown in figure 4 suggests that these effects have not been particularly strong, at least until recently.

Finally, low real wages for unskilled workers may have lessened the attractiveness of work for both enrollees and nonenrollees. In addition, Aaronson, Park, and Sullivan raise the possibility that low-skilled women who entered the labor force in response to welfare reform may have crowded inexperienced teenagers and young adults out of jobs. ${ }^{12}$ However, the same authors conclude that the decline in youth participation has been largely due to increases in family wealth and higher returns to schooling rather than to factors related to the demand for labor. ${ }^{13}$ Consistent with this interpretation, the share of 16- to 24-year-olds not in the labor force who report that they "do not want job now" has risen steadily over the past decade, from below 80 percent in 1994 to about 86 percent in 2000 and nearly 90 percent in 2005.

That said, some of the recent decline in the participation rate of youths is likely due to cyclical factors. Labor force attachment among young persons, who typically have accumulated little work experience or careerspecific education, tends to be more sensitive to the business cycle than that among other demographic groups. This is not surprising: human capital theory suggests that individuals who are the least specialized in regard to market and nonmarket activities should be the most sensitive to changes in the relative returns to these activities. ${ }^{14}$ In addition, the returns

12. Aaronson, Park, and Sullivan (2006). Previous literature has also found some substitutability between women and youths. See, for example, Grant and Hamermesh (1981) and Berger (1983).

13. In downplaying the contribution of labor demand to recent declines in teen participation, Aaronson, Park, and Sullivan note that teen wages have changed little relative to adult wages in the past two decades and that recent increases in employment in industries that employ significant numbers of teens have outpaced the national average.

14. Becker (1993) shows that workers with greater firm-specific capital are less likely to leave a firm in response to temporary changes in demand. Analogously, individuals with greater market-specific capital or skills should be less likely to pursue nonmarket activities in response to a drop in the relative returns to market work. Indeed, Benhabib, Rogerson, and Wright (1991) show that the change in market hours worked in response to a temporary change in market productivity should be positively related to the elasticity of substitution between market and nonmarket work. Greater specific human capital or skills (either market 
to the acquisition of both education and experience are likely to be relatively high for youths, and thus it may be especially advantageous to substitute between these two forms of human capital acquisition in response to temporary changes in their relative costs or benefits. Indeed, Harris Dellas and Plutarchos Sakellaris report evidence that school enrollment is negatively related to the business cycle, although they also note that this cyclicality has diminished over time. ${ }^{15}$ Nevertheless, the fact that enrollment itself responds cyclically makes distinguishing the long-run from the cyclical influences on participation more difficult.

The first panel of figure 5 graphs the quarterly participation rate of 16- to 24-year-olds for the nearly five years following the last business cycle peak in the first quarter of 2001, along with the average participation path during and after the four previous recessions. To provide a rough estimate of the cyclical component of participation, the data are detrended using a HodrickPrescott filter and indexed to their level at the peak. ${ }^{16}$ The shaded region demarcates the maximum and minimum paths of the detrended participation rate attained in any of the previous cycles in each quarter. As can be seen, the decline in the participation rate following the early-2001 business cycle peak was more prolonged than in any previous cycle, and, relative to the peak, the participation rate was as low at its nadir as in any previous cycle. Moreover, the recovery in participation has been weaker than in past experience. Even in the weakest of the previous recoveries, the participation rate of young people had fully recovered nineteen quarters after the peak. In the current episode it remains about 1 percentage point lower. Given the dispersion of the participation rate path in past cycles, it seems possible that some of the recent decline in the participation rate of youths reflects a stronger-thanusual cyclical response to the weak labor market in the early part of this

or nonmarket) should lead to a greater probability of a corner solution-devoting all of one's time to market or to nonmarket work-and thus should contribute negatively to the elasticity of substitution between market and nonmarket work.

15. Dellas and Sakellaris (2003). The most natural interpretation is that such cyclicality reflects variation in the opportunity cost of schooling. Dellas and Sakellaris also point out that the human capital model would predict enrollment to be procyclical if students are credit constrained or if the cost of schooling is also procyclical (for example, if real net tuition is influenced by changes in asset returns from endowments).

16. Of course, the decomposition between trend and cycle depends on the magnitude of the smoothing parameter chosen for the Hodrick-Prescott filter, and thus the results presented here are intended to be illustrative rather than a precise decomposition. We chose a high value for this parameter to prevent the filter from following the data too closely at the end of the sample. 
Figure 5. Cyclical Comparisons of Labor Force Participation Rates by Sex and Age Groupa

Both sexes, ages 16-24

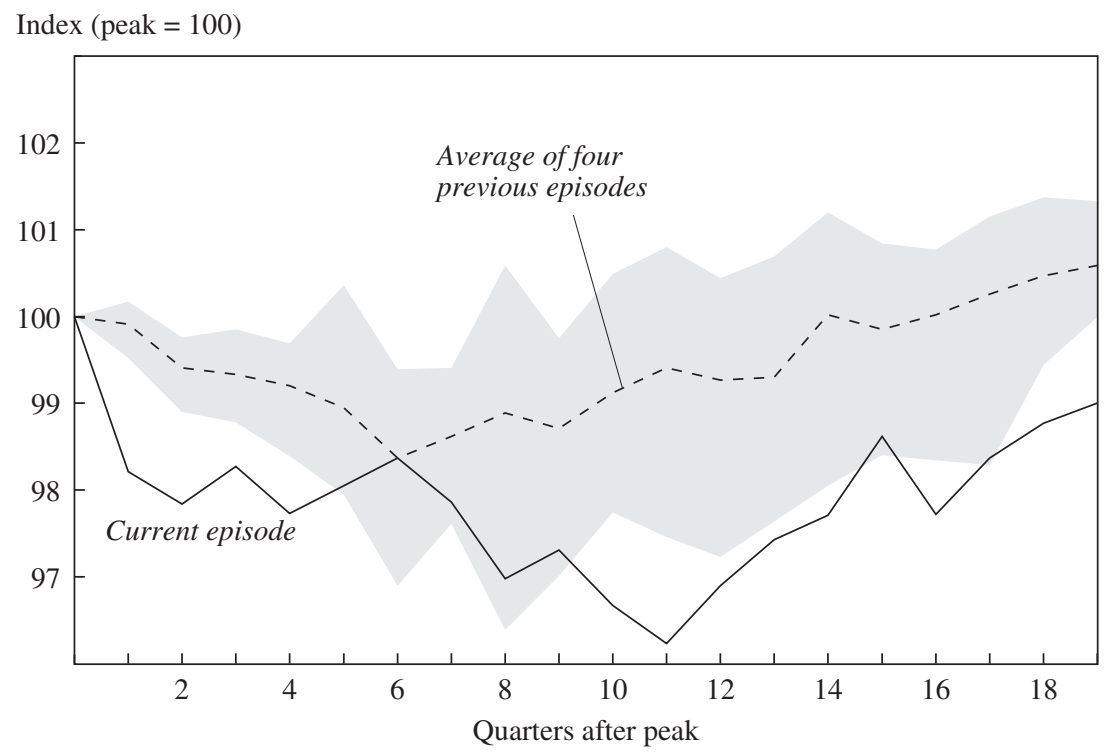

Men, ages 25-54

Index $($ peak $=100)$

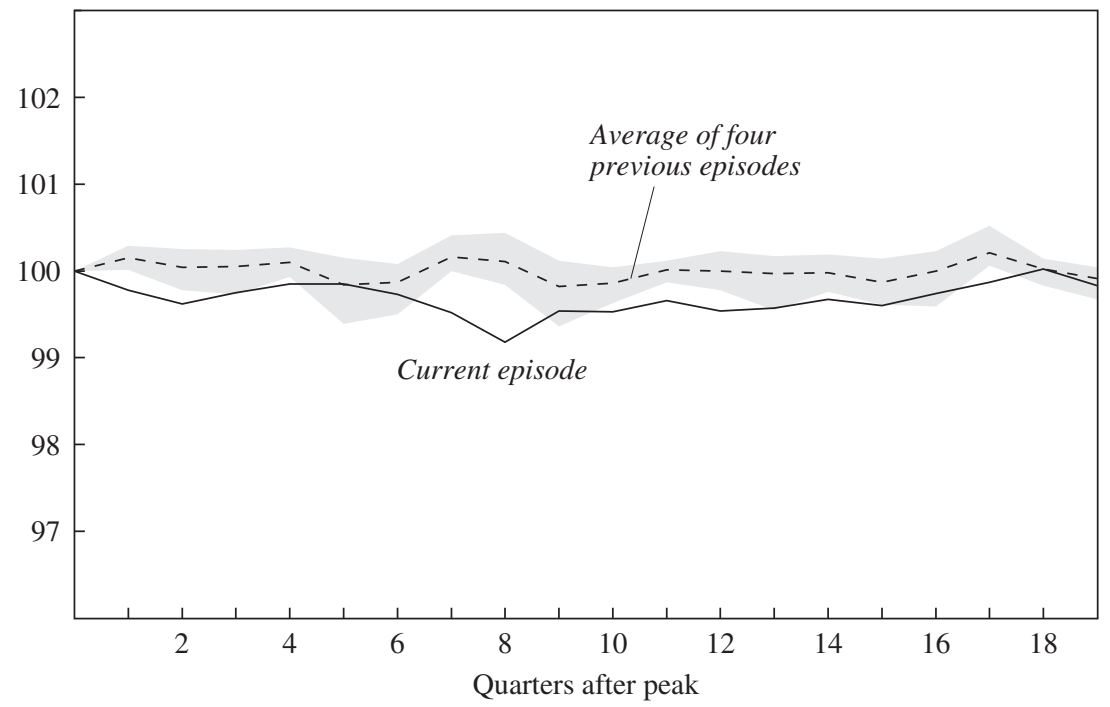


Figure 5. Cyclical Comparisons of Labor Force Participation Rates by Sex and Age Group ${ }^{\text {al Continued) }}$

Women, ages 25-54

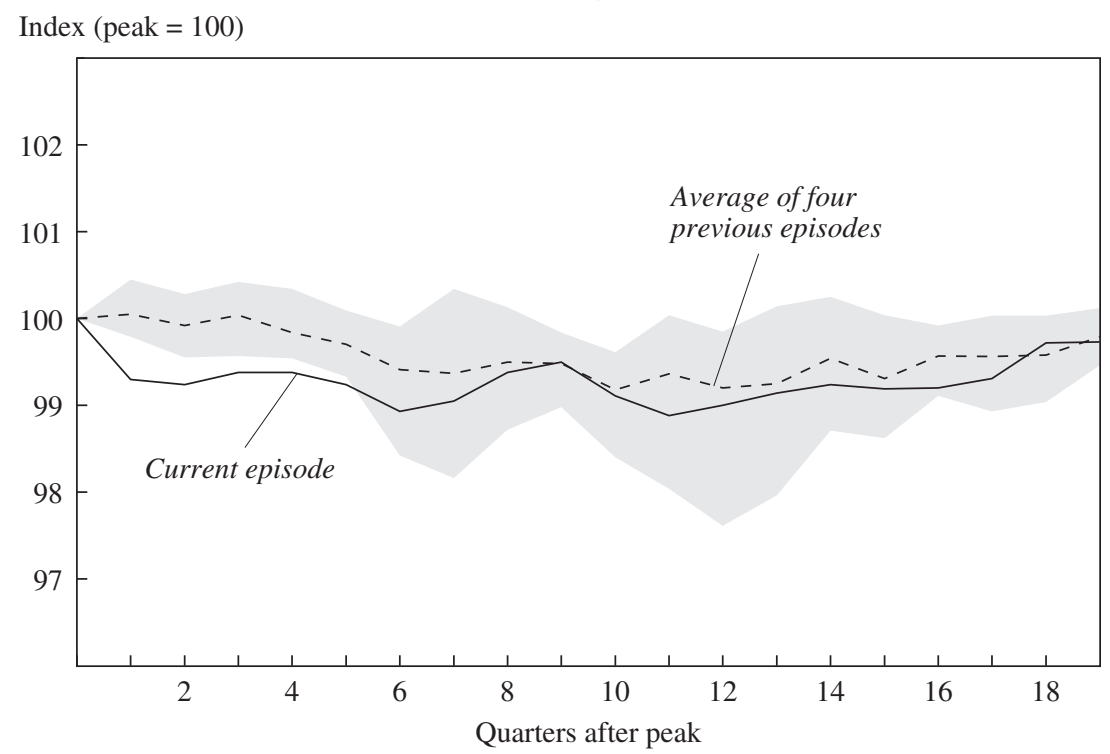

Both sexes, ages 55 and over

Index $($ peak $=100)$

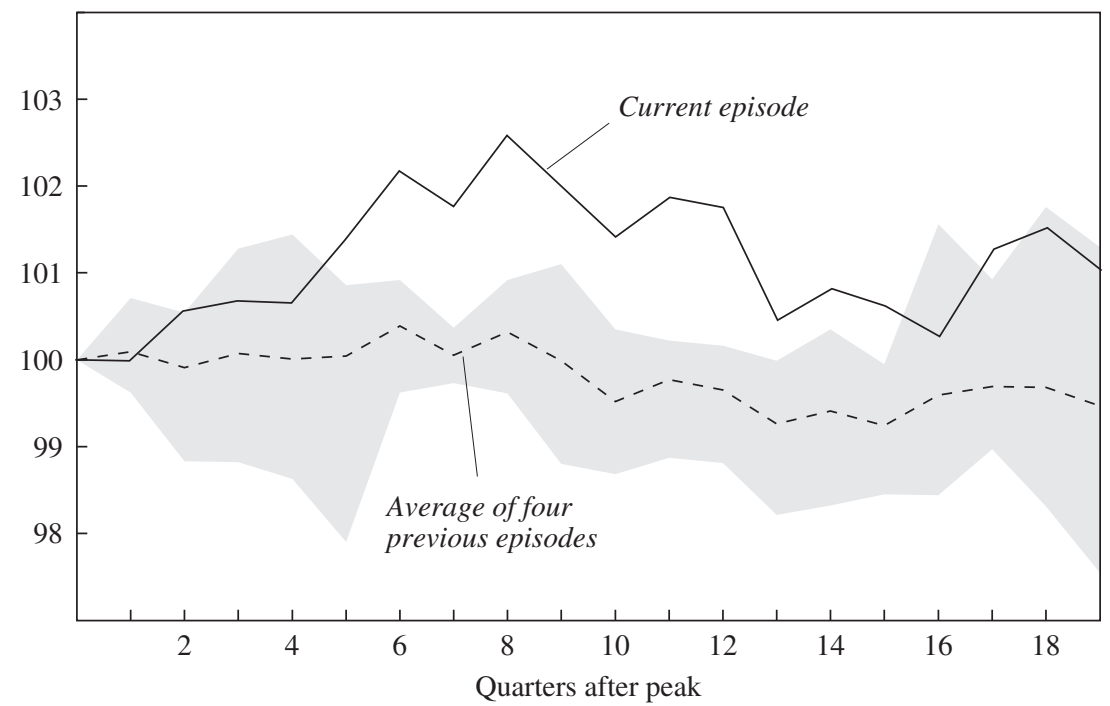

Source: Authors' calculations using data from the Bureau of Labor Statistics.

a. Peak of current episode is 2001:1; peaks of previous episodes are 1969:4, 1973:4, 1981:3, 1990:3. Shaded areas denote range of observed values in previous episodes. 
Figure 6. Labor Force Participation Rates by Sex, Ages 25-54, 1960-2005

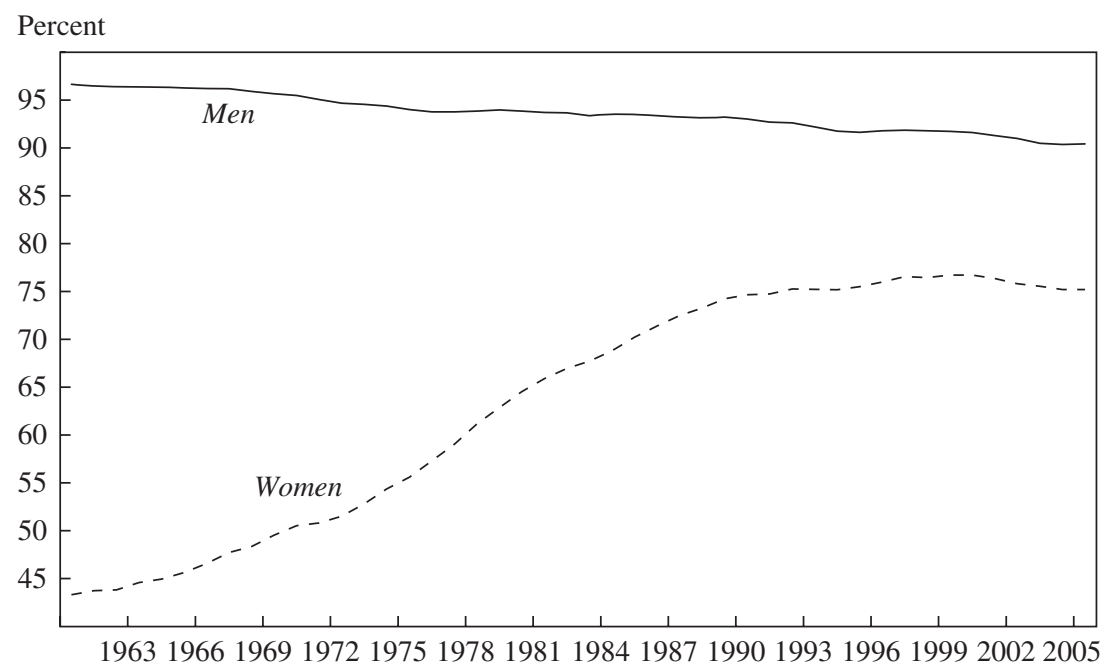

Source: Bureau of Labor Statistics.

decade. However, even apart from such a response, the Hodrick-Prescott filter shows a downward trend in youth participation in recent years.

\section{Prime-Age Individuals}

For the age categories that represent the principal working years, the patterns of labor force attachment differ importantly by sex. As indicated in figure 6, for women between the ages of 25 and 54, participation rates rose fairly steadily between the early 1960s and the mid-1990s but leveled off thereafter. For men in this age range, the participation rate has been trending downward slowly for some time, and the movements in recent years appear to be a continuation of that trend rather than a break.

The earlier increases in the participation rate of adult women likely stem from numerous structural factors such as tastes, reproductive and contraceptive technology, wealth, education, social attitudes, and the development of the retirement, welfare, and financial systems. It seems likely that new generations internalized many of these changes more easily than did mature cohorts, who had already made "sticky" choices (shifting the 
Figure 7. Changes in Female Labor Force Participation Rate by Age and Birth Year

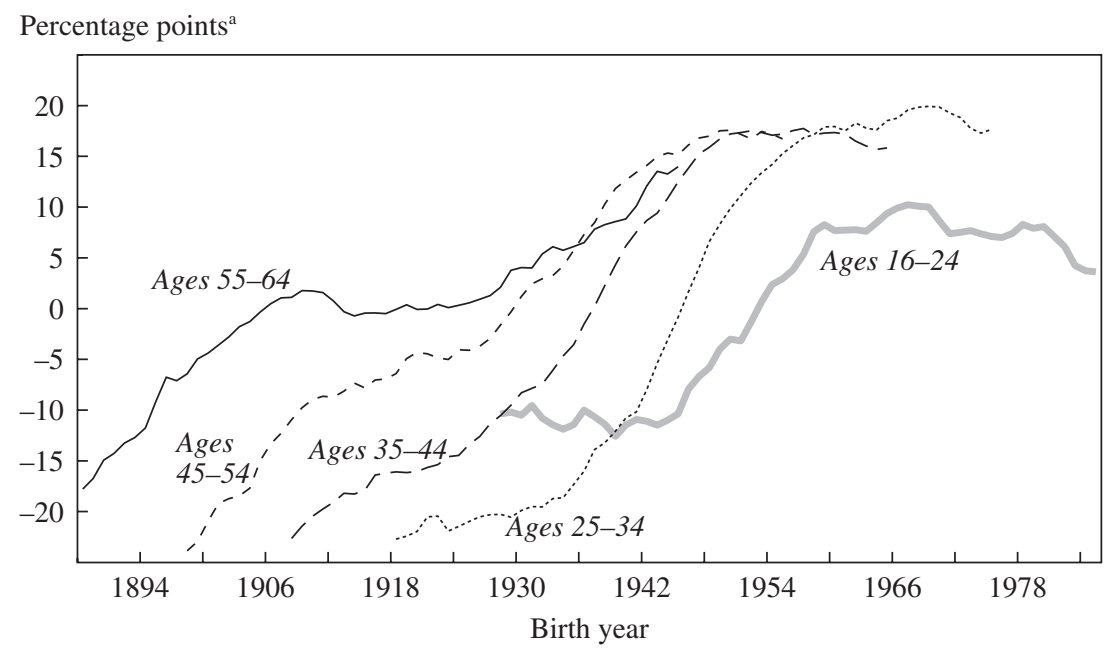

Source: Authors' calculations using data from the Bureau of Labor Statistics. a. Values are deviations from age-specific means.

entire age profile up or down). However, some of these factors also worked their way into the decisions of individuals in midlife, effectively altering the slope of the age profile as well.

Indeed, much of the change in the aggregate female participation rate appears to have resulted from progressively higher average participation rates of successive cohorts. For example, until the late 1980s successive cohorts of 35- to 44-year-old women had higher participation rates than their predecessors. Participation rates of successive cohorts of 45- to 54-year-olds stopped rising about ten years later, in the late 1990s. This pattern suggests that the participation rate in each of these age groups at a given time is at least partly related to which birth cohort is passing through that age range at that time.

Figure 7 illustrates this point more generally. Each line shows the participation rate of women of a single age group over time. However, instead of the year of observation, the horizontal axis shows the birth year for the middle age of the group. In this way the lines are shifted so that each birth cohort is vertically aligned with itself at different ages. The participation rate of the 45- to 54-year-old group appears to exhibit three 
changes in slope, corresponding to the cohorts born around 1910, 1925, and 1945 , in the vicinity of years 1960,1975 , and 1995 , respectively. The first two of these line up well with the 55- to 64-year-old group. The cohort associated with the third slope change (those born around 1945) is not quite old enough to be observed in the 55- to 64-year-old group. But that third slope change can be seen when that cohort was 35-44 years old. Similarly, the participation rate of the youngest age group flattens out around 1980, with the cohort born around 1960, and this same flattening can be seen when that cohort is $25-34$ years old. These coincidences suggest that birth cohort plays a significant role in determining the pattern in participation of an age group over time, and that the evolving trend in the average labor force attachment of successive cohorts has been an important factor in the leveling off in the participation rate for adult women in recent years. From this standpoint our analysis suggests that, going forward, one should not expect rising participation among adult women to offset a continued downtrend in participation for adult men.

Not all of the changes in slope line up, of course. For example, the steep portion of the line for the 16- to 24-year-old group begins around 1965 (corresponding to birth year 1945), but the steep portion of the line for the 25- to 34-year-olds begins well before this same cohort entered that age group. Clearly, there have been developments in participation that are not well represented by the aging of birth cohorts and which may, for example, be better described as changes in the shape of the age profile.

One factor that may influence both the average participation rate of a cohort and the shape of that cohort's age profile is educational attainment. The percentage of women in a cohort with a high school diploma and that of women in a cohort with a college degree have both trended upward; indeed, more-recent cohorts of women are now more likely than their male counterparts to have completed high school or college. As noted above, individuals are less likely to work when they are enrolled in school, and so one would expect more-educated cohorts to have relatively lower participation rates in their school-intensive years. Beyond the traditional school ages, however, education increases the opportunities for and the returns from employment, and this has both substitution and income effects. The substitution effect of greater education would tend to increase a cohort's participation. However, the higher incomes available to cohorts with more education may make them more likely to retire earlier, or may enable more intermittent labor force attachment. 
Three other observable factors seem particularly relevant to the level and age profile of women's participation rates. First, the presence of young children in the family has tended, on average, to reduce women's labor force participation. Thus changes in the prevalence of young children at different ages-reflecting changes in both the overall level and the timing of fertility-are likely to have changed the shape of the age profile of participation for women. In particular, women have increasingly tended to delay marriage and child bearing, and this tendency by itself might be expected to have depressed participation rates among women in their thirties and early forties, while raising participation for younger women. On the other hand, it seems likely that as societal attitudes and institutions have adapted to the greater prevalence of working mothers, the influence of the presence of young children on the labor force participation of women at various ages would have changed over time. Indeed, among women with a child under age 6 , the share in the labor force has increased from about 40 percent in the mid-1970s to more than 60 percent in the past decade.

Second, the data suggest that welfare reform may have had a noticeable influence on changes in the labor force attachment of single mothers over the past decade. The participation rate for single-mother welfare recipients rose sharply toward that of single-mother nonrecipients in the late 1990s, following welfare reform (specifically, the implementation of the Temporary Assistance for Needy Families program) and in conjunction with the improvement in labor market conditions. Since 2000, however, the participation rate has fallen more sharply for welfare recipients than for nonrecipients, although recipients remain more likely to work than before the reform. This pattern suggests that welfare reform may have increased both the average level and the cyclical sensitivity of women's labor force attachment. ${ }^{17}$

17. Other policy changes, such as changes in marginal tax rates and the earned income tax credit, may also have affected women's labor supply. However, although some estimates indicate that women have relatively high (compared with men) elasticities of labor supply with respect to taxes (Hausman, 1985), the effects of tax reform are often not easy to see in the data. For example, in examining the impact of the 1981 and 1986 tax reforms, Bosworth and Burtless (1992) find evidence that the labor supply of women did increase relative to trend during the 1980s, but that the increase was greatest for low-income women, who benefited little from the reforms. Similarly, the dramatic expansion of the earned income tax credit over the past two decades appears to have reduced the labor force attachment of married women, but to have increased the participation of single women with children (Eissa and Hoynes, 2004, 2005). 
Third, the relative wages of women have generally increased since the early 1980s, as more women found employment in a greater variety of professional occupations and as a reduction in discriminatory practices occurred..$^{18}$ In addition to proxying for the draw of greater economic opportunities more generally, higher relative wages for women tend to shift the relative mix of labor supply within families from men to women. ${ }^{19}$

Turning to the role of cyclical factors, many adult women have acquired human capital specific to both market and nonmarket activities. Those with more market experience may find it worthwhile to remain in the labor market even in the face of negative demand shocks, whereas those for whom nonmarket work is more productive may choose to leave the labor force for at least some period of time. In addition, cyclical changes in family income may play a role in the participation rate decisions of women (the "added worker" effect). Thus the aggregate cyclical response for women is not easily predictable from the theory. However, empirical research suggests that adult women on the whole are sensitive to changes in the relative returns of market work, ${ }^{20}$ and as the third panel of figure 5 shows, their participation rate appears somewhat procyclical, although much less so than that of youths. Relative to earlier recessions, the participation rate of prime-age women declined more steeply just after the 2001 peak and subsequently tended to hover a little below the average experience. Although not definitive, this pattern suggests that there is nothing particularly unusual about the cyclical behavior of women's labor force participation in recent quarters.

The participation rate for men in their prime working years has declined, on balance, since the late 1970s, although it held steady during the strong labor market of the mid- to late 1990s. After turning down again during the 2001 recession, it has been fairly flat since 2002. One potentially important factor driving the long-term decline in men's labor force participation has been the declining real wage for low-skilled workers. For example, Chinhui Juhn finds that changes in wages can explain nearly all of the decline in participation of low-skilled men between the early 1970s and the late 1980s, ${ }^{21}$ and Finis Welch argues that the decline in the participation

18. Goldin (2006).

19. See, for example, Juhn and Murphy (1997), Devereux (2004), Blau and Kahn (2005), and Mulligan and Rubinstein (2006).

20. Killingsworth and Heckman (1986).

21. Juhn (1992). 
of low-skilled men relative to high-skilled men corresponds closely to the decline in their relative wages. ${ }^{22}$

By the 1990s, however, real wages for low-skilled men had stopped declining. At the same time, labor force participation among prime-age men flattened out, and, according to Juhn, Kevin Murphy, and Robert Topel, ${ }^{23}$ the dispersion in participation across skill levels closed a bit. Similarly, real wages have changed little since the end of the 2001 recession, which again seems consistent with the flat participation rate for prime-age men as a whole. However, despite the absence of any significant reversal in skill premiums in recent years, the participation rate among men with less than a high school education has continued to rise, while that for men with more education has been falling. Thus, in the past few years, it seems that other factors have been driving the pattern of participation among prime-age men. ${ }^{24}$

One possible influence, particularly for individuals toward the upper end of the 25- to 64-year-old age range, has been the increased generosity of Social Security Disability Insurance (SSDI) benefits over time, relative to declining or stagnating wages for low-wage workers. Numerous studies have reported a relationship between SSDI and the long-run downward trend in participation among men. ${ }^{25}$ David Autor and Mark Duggan have also shown that applications for SSDI are sensitive to labor demand shocks. ${ }^{26}$

Even so, whether disability insurance has had an important negative influence on male participation rates in recent years is less obvious. The only major policy change in the past decade was a law designed to increase the labor force participation of SSDI beneficiaries. ${ }^{27}$ In addition, although

22. Welch (1997).

23. Juhn, Murphy, and Topel (2002).

24. Changes in tax policy are unlikely to have had much of an impact on the participation of men over this period. Studies of the effects of the 1981 and 1986 tax reforms have generally found small effects for men (Bosworth and Burtless, 1992), and the impact of the tax cuts implemented in 2001 and 2002 also seems likely to be small. Similarly, the existing research suggests that the expansion of the earned income tax credit has had at most a small positive impact on male labor force participation (Eissa and Hoynes, 2004).

25. See, for example, Parsons (1980), Bound (1989), Haveman, de Jong, and Wolfe (1991), and Bound and Waidmann (1992).

26. Autor and Duggan (2003).

27. Social Security Administration (2004). The Ticket to Work and Work Incentives Improvement Act was signed into law in 1999. Also, in 1997 Congress prohibited eligibility for individuals whose drug or alcohol addiction contributed to their impairment. This resulted in a one-time drop in recipiency as these individuals were removed from the rolls. 
the proportion of the working-age population receiving SSDI has increased in recent years, the percentage of individuals giving disability as a reason for limited work has been relatively stable. Taken together, these data appear to point to an increase in the proportion of disabled individuals receiving benefits, rather than to an increase in the proportion of individuals with a work-limiting disability. ${ }^{28}$

Research into cyclical influences on recent prime-age male participation rates suggests that the human capital of adult men is quite specialized and that their participation rates are relatively insensitive to temporary changes in the relative returns to market work. ${ }^{29}$ The bottom left panel of figure 5 shows that, on average, the prime-age adult male participation rate has been relatively flat following business cycle peaks and that this pattern varies little from cycle to cycle (the shaded area indicating the range between the minimum and the maximum response is narrow). Nonetheless, the pattern following the most recent business cycle peak is a little different. Participation declined more steeply than usual early in the downturn — as it did for women — and remained relatively low for several years. However, over the past year the participation rate for primeage men has moved back toward the average experience. In any event, because the magnitude of the deviation is fairly small, most of the recent decline in adult male participation seems likely to have been a continuation of the longer-term structural downtrend.

\section{Older Individuals}

Finally, participation rates for older individuals have been increasing over time. As table 3 shows, participation rates for older men held steady or declined between 1977 and 1995 and then moved upward, with an especially sharp increase registered after 2000. For older women the

28. Of course, if the income provided by SSDI creates a disincentive to work, or if SSDI recipients tend to have more severe disabilities than nonrecipients, an increase in the share of disabled individuals receiving disability benefits could be associated with a reduction in labor force participation even without an increase in the share of individuals reporting a work-limiting disability. In fact, SSDI recipients are less likely to be in the labor force for at least one week during the year than are disabled individuals who do not receive SSDI: about 5 percent of SSDI recipients versus about 30 percent of disabled nonrecipients. Nonetheless, given the low participation rate even among the disabled who are not SSDI recipients, the increase in recipient status is not enough to have a noticeable effect on the aggregate participation rate.

29. Pencavel (1986). 
increase appears to have started somewhat earlier, but the general pattern is similar.

For both sexes the labor force participation decisions of older persons hinge on their need and ability to finance retirement. Individuals in poorer health or who are better positioned to retire at an earlier age would be expected to have a lower attachment to the labor force at older ages. Aside from educational attainment, which is likely to be associated with higher average levels of income and wealth, among the most important factors affecting the ability to finance retirement are the parameters of the Social Security program, the availability of private pension benefits, health, and life expectancy. ${ }^{30}$

In particular, in any forward-looking model of labor supply in which workers do not rely entirely upon Social Security to finance their retirement, one would expect a longer expected life span to increase the number of years a person chooses to work, in order to save more toward retirement and to reduce the number of years of retirement that need to be financed. In addition, to the extent that life expectancy is correlated with better health more generally, older individuals would, on average, be physically able to work longer into their lives as life expectancy increases. In fact, life expectancy for men at age 65 has increased steadily over time and now stands at nearly 17 years. For women, life expectancy at age 65 leveled off in the 1980s and early 1990s, but it has since risen noticeably, to more than 20 years.

Given the relatively large amounts of specialized human capital accumulated by older individuals, their labor supply decisions should be relatively immune to temporary changes in the returns to market work, and as the lower right panel of figure 5 shows, the labor force participation rate of older individuals is fairly flat during recessions. However, cyclical changes in wealth may contribute to cyclical changes in participation (although these changes would be countercyclical, rather than procyclical). Indeed, one explanation that is sometimes offered for the increase in the labor force participation of older persons following 2000 is that the decline in stock prices, especially relative to expectations formed during the long bull market, has led many older individuals to delay their retirement.

30. For an overview of the economic influences on the labor force attachment of older individuals, see Burtless (1999) and Burtless and Quinn (2001). For an analysis of recent changes to Social Security programs and rules, see Loughran and Haider (2005). 
Several researchers have explored the role of wealth in retirement decisions. ${ }^{31}$ Most of these studies do find that the unexpected positive shock to wealth associated with the stock market boom led to some additional retirements. However, as Courtney Coile and Phillip Levine point out, the impact on the aggregate participation rate was probably small, both because relatively few individuals have enough of their savings in stocks for market movements to significantly affect their assets, and because many of those who do have substantial wealth holdings are not on the margin in making their retirement decisions. ${ }^{32}$ Given the apparent responsiveness of retirement to the stock market run-up in the 1990s, some individuals might have had to delay their retirement in light of the decline in equity values and the subsequent low returns. But given the small share of the population that is likely to be affected at the margin by these stock market fluctuations, this explanation seems unlikely to explain the recent rise in participation rates among the elderly. ${ }^{33}$

\section{Putting the Pieces Together: A Cohort-Based Model of Labor Force Participation}

To investigate the questions raised in the above discussion, we have developed a model that attempts to account for the influences on labor

31. See, for example, Gustman and Steinmeier (2002), Coronado and Perozek (2003), Sevak (2005), and Coile and Levine (2006).

32. Coile and Levine (2006). None of these studies includes wealth held passively in defined-benefit pension plans, because the retirement benefits paid out from these plans do not vary with their asset value. However, the recent stock market decline has reduced the solvency of many such plans, and as many as 10 percent of all defined-benefit plans are now frozen (PBGC, 2005; Watson Wyatt, 2005), meaning that participants are no longer accruing benefits (although in most cases the plans have been replaced with definedcontribution plans). An individual's retirement decision could be influenced by a change in the asset value of a defined-benefit plan large enough to alter the perceived default probability of the plan, although these termination probabilities are still fairly low.

33. In addition, according to data from the Survey of Consumer Finances, many families that owned both corporate equity and a home experienced a decline in the value of their stock portfolio but a rise in the value of their home between 2001 and 2004. In this sense the sharp rise in housing prices in recent years suggests that changes in a broader measure of wealth that includes housing might imply less upward pressure on labor force participation than changes in a measure based solely on stock market wealth. However, the extent to which individuals view housing wealth as a retirement asset is a subject of considerable debate (see, for instance, Venti and Wise, 2001). 
force participation of observed structural factors, unobserved structural factors, and cyclical factors for the twenty-eight age-sex categories of the population shown in table 3 . We model the participation rate for each agesex group as a function of a set of observed variables $(X)$ that we believe are relevant to a particular group's participation decisions (including a measure of the business cycle), a fixed age effect $(\alpha)$ that captures the propensity of each age group to participate in the labor force, and fixed cohort effects $(\beta)$ that capture the influence of different birth cohorts as they pass through the relevant age group.

In this specification the birth cohort and age effects are intended to capture unobserved structural factors affecting labor force participation. Thus the age effects define a baseline age profile of participation for an arbitrary birth cohort, and the cohort effects then shift this baseline up or down to reflect different birth cohorts' differing propensities to participate over their lifetime. Of course, the actual life-cycle pattern of participation is unlikely to be constant across cohorts (or, equivalently, the relative propensity of any two birth cohorts to participate is unlikely to be constant for each age level). As various economic and social factors evolve, one would expect the age profile of participation to evolve as well. The set of observed variables that we include in the model attempt to account for this evolution by capturing the influence of the economic and social changes discussed in the previous section on the labor force attachment of particular age groups.

Because average participation rates and age profiles of participation have historically been so different for men and women, we model participation separately by sex. Thus, for each sex there are fourteen separate equations of the form

$$
\log L F P R_{g, t}=\log \alpha_{g}+\lambda_{g} \log X_{g, t}+\frac{1}{n_{g}} \sum_{b=1907}^{1989} C_{g, b, t} \log \beta_{b}+\varepsilon_{g, t} g=1 \text { to } 14,
$$

where $g$ indexes age groups, $t$ indexes calendar years, and $b$ indexes birth years. The $C_{g, b, t}$ are indicator variables that equal one if the corresponding cohort appears in that age group equation at time $t$, and $n_{g}$ is the number of ages in age group $g$. The set of observable variables $(X)$ and the coefficient vector $(\lambda)$ vary by age group, which allows the age profile of participation to evolve over time. For each sex the fourteen equations are estimated simultaneously using a restricted least squares estimator with a 
White-corrected covariance matrix. ${ }^{34}$ Counting both males and females, we estimate 342 parameters in 28 equations using data covering the period from 1977 to 2005.

\section{Structural Variables Relevant to the Participation Decision}

Consistent with the earlier discussion, the variables that we considered including in the model fall into three broad categories: those related to human capital, those related to financing nonparticipation, and those pertaining to family structure. Many of the variables we considered have moved broadly together over our sample period. For example, life expectancies, dependency ratios, and educational attainment have mostly risen over time, while fertility and the proportion of workers with defined-benefit pension plans have mostly fallen. Thus, choosing which variables to include and in just what fashion is a matter of judgment, and the coefficients on the included variables should accordingly be interpreted cautiously.

HUMAN CAPITAL. For males in the age groups ranging from 16 to 24 years old, we included an estimate of the return to a college education developed by Aaronson, Park, and Sullivan..$^{35}$ This variable is constructed from a regression of wages on a standard set of variables that includes different levels of schooling. For the remaining age groups of males and for all age groups of females, we experimented with two variables representing the average educational attainment of a cohort when the midpoint of that cohort was age $27 .{ }^{36}$ The first such variable is the share of individuals with a high school degree, and the second is the share with a college

34. See Greene and Seaks (1991) for a description of the estimator.

35. Aaronson, Park, and Sullivan (2006). We thank Daniel Aaronson for providing us with these estimates.

36. Data on educational attainment for the 25-29 age group-ages by which the vast majority of individuals have achieved their terminal degrees—are published back to 1940 . If all of the fourteen age groups that define our participation equations were similarly five years wide, measuring the educational attainment appropriate to each equation would be a simple matter of leading or lagging these attainments of 25- to 29-year-olds by the appropriate number of years. However, because several of our age categories are only two years wide, we attributed to each cohort the educational attainment of the 25- to 29-year-olds in the year in which the midpoint of that cohort was age 27 . We then averaged these values across the cohorts relevant to each of the age-specific participation equations in each year. For cohorts that were not yet 29 years old by the end of our sample period, we extrapolated their eventual educational attainment linearly by the average change in attainment over the previous eight cohorts. 
degree. ${ }^{37}$ However, given the substantial co-movement between these two variables, we included only college-level attainment in the model.

For women aged 18-61 (above the typical high school age but below the typical retirement age), we included in the model the ratio of median weekly earnings for full-time working women to those of full-time working men as a measure of the female-male wage gap. As noted earlier, to the extent that the historical increase in this ratio has been exogenous, it likely represents an expansion of women's labor market opportunities that would be expected to draw more women into the workforce and perhaps reduce the degree of specialization into market and home production within the household. However, we recognize that higher rates of female participation may themselves have contributed to a higher wage ratio through greater labor market experience and other human capital investments.

FINANCING NONPARTICIPATION. We included two variables as proxies for factors that potentially influence the labor force decisions of older individuals. First, we included a variable for sex-specific life expectancy as of age 65 , based on life tables published by the Census Bureau, as an estimate of future income needs. ${ }^{38}$ Longer life expectancy implies more years of retirement to finance, ceteris paribus. Second, we included a variable in the equations for older men to capture changes in the Social Security program over time, including changes in early-retirement rules, the retirement age, and the delayed retirement credit. ${ }^{39}$ For the $62-64$ age

37. In 1992 the questions on education in the CPS switched from asking about years of schooling to asking about highest degree or level of education attained. We bridged this change using methodology and data from Jaeger (1997) and Kominski and Siegel (1993).

38. These are not true forecasts of the longevity of an individual or cohort, in that they do not take into account how age-specific mortality rates may change as a cohort ages. Rather, in each year they are based on current mortality rates for individuals of various ages. Thus the life expectancy of a person aged 65 in any given year reflects the state of medical knowledge and technology, environmental factors, wealth, and other factors as of that year. Nevertheless, in broad terms this variable does take into account the advances in health over history.

39. The prospects for the generosity of the Social Security system and of private pension plans depend in large part on the ratio of potential retirees to likely workers, and it is the current and impending increases in this ratio that drive current concerns about the future of Social Security and Medicare. Accordingly, we constructed a "potential dependency ratio" facing a cohort as the ratio of the population over age 64 to the population aged 25-64 that, according to Census Bureau estimates and projections, a cohort saw or can expect to see at age 65 . However, we found that this variable did not add to the power of the model once the variable for life expectancy was included, and so we did not include it in the specification presented here. 
group this variable is defined as the average fraction of the primary insurance amount (PIA) a man would receive from Social Security if he were to retire before age 65 (so that a higher value for this variable is equivalent to a smaller penalty for retiring early). For the 65-69 age group this variable is the percentage increase in the PIA that a man would receive for each year he delayed retirement beyond age 65 (so that a higher value of the variable implies a greater reward for delaying retirement)..$^{40}$

We also included the disability award rate - the fraction of applications for benefits that were approved in each year-to represent the generosity of the federal disability insurance program and, in particular, the changes over time in the stringency of the criteria for being awarded disability benefits. Although this variable is not completely independent of other factors that influence participation - the composition of the applicant pool surely varies with the state of the labor market, for example-it is an improvement in this regard over using a measure of disability benefits recipiency. The disability program should be most relevant to middle-aged individuals, because younger persons are much less likely to be disabled and the elderly are covered by Social Security retirement benefits instead.

In addition, we experimented with several measures of aggregate household wealth as explanatory variables in our model, including total household net worth, stock market wealth, and housing wealth. However, none of these measures had reasonable explanatory power in the model equations, even for the age groups near or above the typical retirement age.

FAMILY STRUCTURE. We attempted to capture influences associated with family structure with two variables. In the equations for women aged 18-29, we included a variable for the percentage of the cohort that, when in each age group, had children younger than 6 years old. ${ }^{41}$ Not surprisingly, cohorts with a higher proportion of women with young children had

40. Changes in the earnings test during this period coincided with changes in the delayed retirement credit, and so our estimates may be somewhat influenced by the former despite their exclusion from the model. We also experimented with these variables in the equations for older women. However, the coefficients were never statistically significant, and their signs and magnitudes often made little sense.

41. The cutoff at age 29 seemed reasonable because the presence of young children at older ages more likely reflects delayed childbearing as a result of greater labor market attachment, a factor that is more intuitively captured by other variables in the model, rather than the direct influence of children on participation. We also omitted this "fertility" variable from the 16- to 17-year-old age group because it produced what seemed to us a spurious estimate: a greater incidence of young children raised labor force participation for that age group. 
substantially lower participation rates at those ages. However, as noted above, the influence of this variable on labor force participation seems likely to have changed over time in response to changing social norms and economic opportunity. If so, it would be desirable to allow the coefficients on the fertility variable to vary over time. For identification reasons, allowing the coefficient to vary freely is not possible, and simply constraining the coefficients to vary "slowly" over time seemed to us too ad hoc. Instead we used individual-level data from the CPS to estimate separately for each year an age group-specific coefficient on a variable for the presence of children less than 6 years old from a cross-sectional regression of participation. ${ }^{42}$ We then interacted these coefficients, which vary by year, with the fertility variable in our model. In this way the coefficient on the fertility variable is constrained to evolve over time in the same way as the cross-sectional coefficients. However, these interactions did not add to the explanatory power of the model, and thus we did not include them in the full version.

A related development has been the decline in the percentage of women in every age group below age 60 who are married. For obvious reasons, married women have long had lower participation rates than unmarried women. Still, the decline in marriage rates may be both a cause and a result of increased labor force participation. In contrast, marriage rates for women above age 65 have been rising steadily, primarily because of declining rates of widowhood. We included a variable for the percentage of women in the age group who are married, for each age group 18-61. We omitted this variable from the 16-17 age group because their marriage rates are too low to be a significant factor in determining their aggregate participation, and from age groups eligible for Social Security because of the complications that marriage introduces for Social Security benefits.

\section{Business Cycle Controls}

The business cycle is represented in the model by the contemporaneous and lagged deviations of employment in the nonfarm business sector from an estimate of its trend (we include two lags). The trend is derived from a Hodrick-Prescott filter, with the smoothness parameter set to 2800, a level

42. We thank Julie Hotchkiss for providing us with her data and programs, which we used for our preliminary investigations of this approach. A fuller description of this technique is described in Hotchkiss (2005). 
at which the trend tends to coincide with actual employment when the unemployment rate was at the Congressional Budget Office's (CBO) estimate of the NAIRU (the non-accelerating-inflation rate of unemployment). To prevent endpoint bias in the filter from unduly affecting the estimate of trend employment in recent years, we assumed that trend employment increased at an annual rate of $1 / 2$ percent after the fourth quarter of 2001 , the last quarter in which the filtered series was equal to actual employment. ${ }^{43}$

\section{Age and Cohort Effects}

The baseline age profile represented by the $\alpha$ parameters in equation 2 is assumed to be constant across time and is intended to capture a basic pattern of life-cycle behavior. The value of the age effect at each age is identified by the labor force behavior of the cohorts that appear in that age equation during the sample period.

Similarly, the cohort effects represented by the $\beta$ parameters in equation 2 are assumed to be constant across time. They are intended to capture the relative propensity of each birth cohort to participate in the labor force over its life span. Because the estimating equations are specified in terms of age groups, the same cohort appears (at different times) in several different equations. Constraining the cohort fixed effect for each birth year to be equal across the equations in which it appears identifies the cohort fixed effects up to a scale factor; that is, the relative propensity to participate over ages or across cohorts is well identified. However, the allocation of the overall level of the aggregate participation rate between cohort effects and age effects requires an arbitrary normalization, and we chose to normalize to 1 the cohort effect for those born in 1969 .

Although each birth year's cohort fixed effect is constrained to be equal across all age categories, in general we do not constrain the cohort effects to be related to each other in a particular way. Rather, each cohort effect is freely estimated. The youngest cohorts in our sample are an exception to this procedure because there are too few observations with which to

43. We chose the post-2001 growth rate to match the average change in employment from 2001:3 to 2005:4, because the unemployment rate in both quarters was about 5 percent. Because of concerns about the endogeneity of the unemployment rate to changes in labor force participation and the potential for correlated measurement errors in the two series (which are derived from the same survey), we did not use the unemployment rate gap directly. We explore the model's robustness to alternative specifications of the cyclical variable later in the paper. 
reliably estimate their cohort effects. In particular, in order to minimize the bias associated with estimating cohort effects using observations drawn primarily from a cyclically weak period, we constrained the evolution of the fixed effects for consecutive pairs of these recent cohorts so that the difference in the average propensity to participate between one cohort and the next is the same as for a set of cohorts that we observe over the last full business cycle. For men the oldest cohort so constrained is that born in 1978; for women it is the cohort born in $1976 .{ }^{44}$ In this way we link the cohort effects of the youngest cohorts, who do not appear in many age groups or years in our sample period, to those of older cohorts, who do appear in several age categories and in more than one stage of the business cycle.

\section{Results}

The age and cohort profiles form the backbone of our model, and so we start our exploration of the results with these. We then derive an aggregate trend for the labor force participation rate from these age and cohort profiles and compare it with the actual series. We then compare the model results with the actual data for the various age groups and, finally, report projections of the model and some alternative simulations. ${ }^{45}$

\section{Age and Cohort Profiles}

As explained in the previous section, the age (or cohort) profiles include both the age (or cohort) effects and the influence of the time-varying variables, except those included to capture cyclical changes in participation. To construct the cohort profiles, we calculate the trend participation rate for an age group in a year as

$$
\log T L F P R_{g, t}=\log \alpha_{g}+\lambda_{g} \log Z_{g, t}+\frac{1}{n_{g}} \sum_{b=1907}^{1989} C_{g, b, t} \log \beta_{b},
$$

44. Extending the constraint for men back to 1975 as well did not materially affect the results. We took advantage of this insensitivity to reduce the number of constraints and simplify the estimation procedure. The intent was to freely estimate as many parameters as possible, while balancing the risk of endpoint bias.

45. A table reporting the full set of estimated parameter values is available from the authors. 
where $Z$ excludes the cyclical variables from the $X$ vector in equation 2 . Then, for each age group, we trace out a cohort profile by plotting this trend over time, averaging across the birth cohorts that appear in that age group in each year. Thus the cohort profiles shown are a centered moving average of the true cohort profiles. The age profiles are computed in a similar fashion, except that the contributions of the cohort effects are omitted from the calculation, to remove the direct effects of the changing mix of cohorts in an age group over time. In principle, for each birth cohort one could trace out the trend as one moves from age group to age group. For purposes of presentation, however, we aggregate cohorts into five-year groups.

Figure 8 shows the cohort profiles for selected age groups. For each age group we show the calculation from equation 3 for the cohorts that appear in our data in each year. For men the cohort profiles are generally declining, as successive cohorts have lower propensities to participate in the labor force than their predecessors in each age group, with the notable exception of the oldest. Individuals in this group (which begins with cohorts born in 1908) exhibit an increasing propensity to participate that no doubt reflects greater expected longevity and better health rather than a latent increasingly favorable attitude toward work at retirement age. (Indeed, the estimated cohort effects themselves imply a fairly steady decline in labor force attachment over time.) Women share this feature at ages 65 and over. In addition, 18- and 19-year-old women, like 18- and 19 -year-old men, are increasingly less likely to participate in the labor force. In the middle age groups, however, successive cohorts of women display higher participation rates up to a peak, and in the younger cohorts the participation rate turns down.

Figure 9 shows average age profiles for selected groups of birth cohorts. Given the limited time span of our data and estimation period (1977-2005), not every cohort is represented in every age group. For example, persons born in 1935 are not observed in age groups younger than 40-44, and persons born in 1969 are not observed in age groups older than 35-39. Thus we do not observe values for all of the time-varying variables used in constructing the age profiles, and not every cohort contributes directly to the estimation of every part of the age profile. Rather than extrapolate the age profile of each group of birth cohorts beyond the data, in figure 9 we show the age profile for each group of birth cohorts only for that span of ages in which it is well represented in the data. Nevertheless, the figure highlights well how the age profiles have evolved over time. 
Figure 8. Estimated Participation Rate Trends by Age Group, 1977-2005

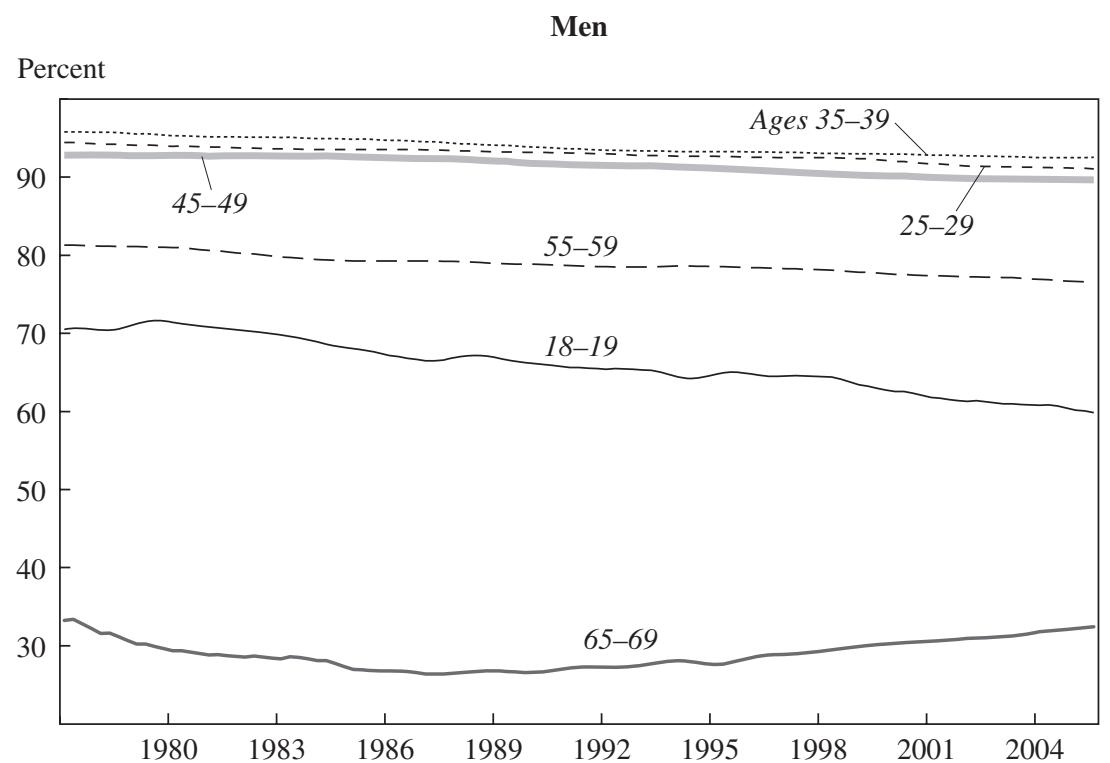

Women

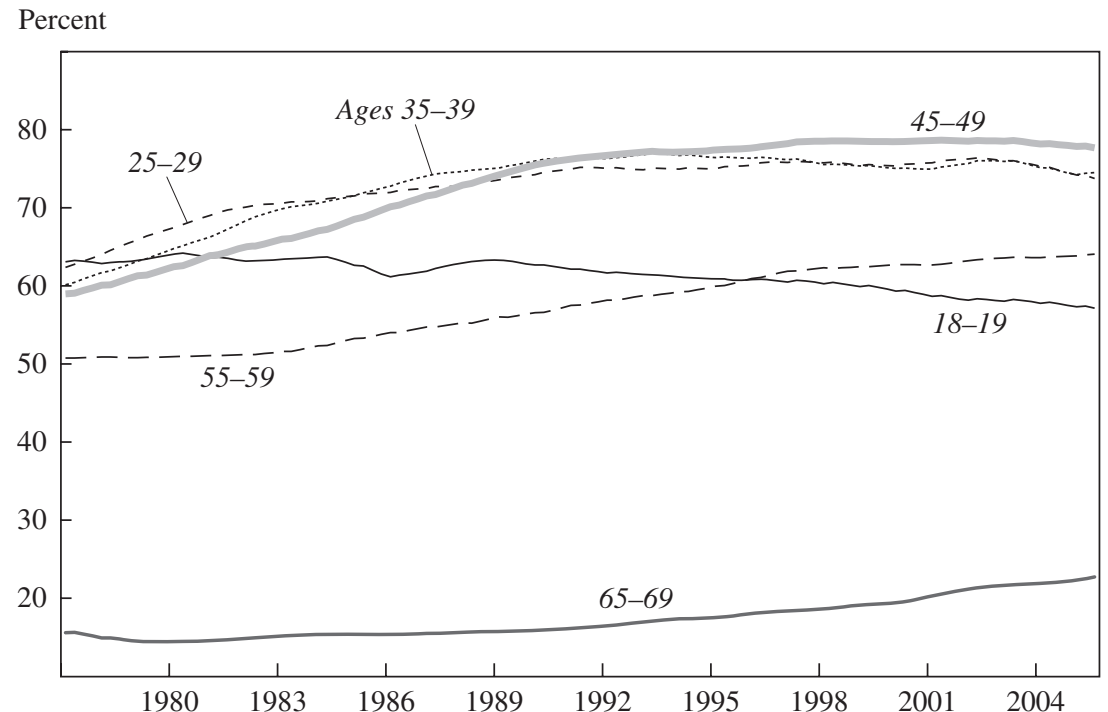

Source: Bureau of Labor Statistics data and authors' calculations. 
Figure 9. Age Profiles of Trend Participation Rate by Cohort

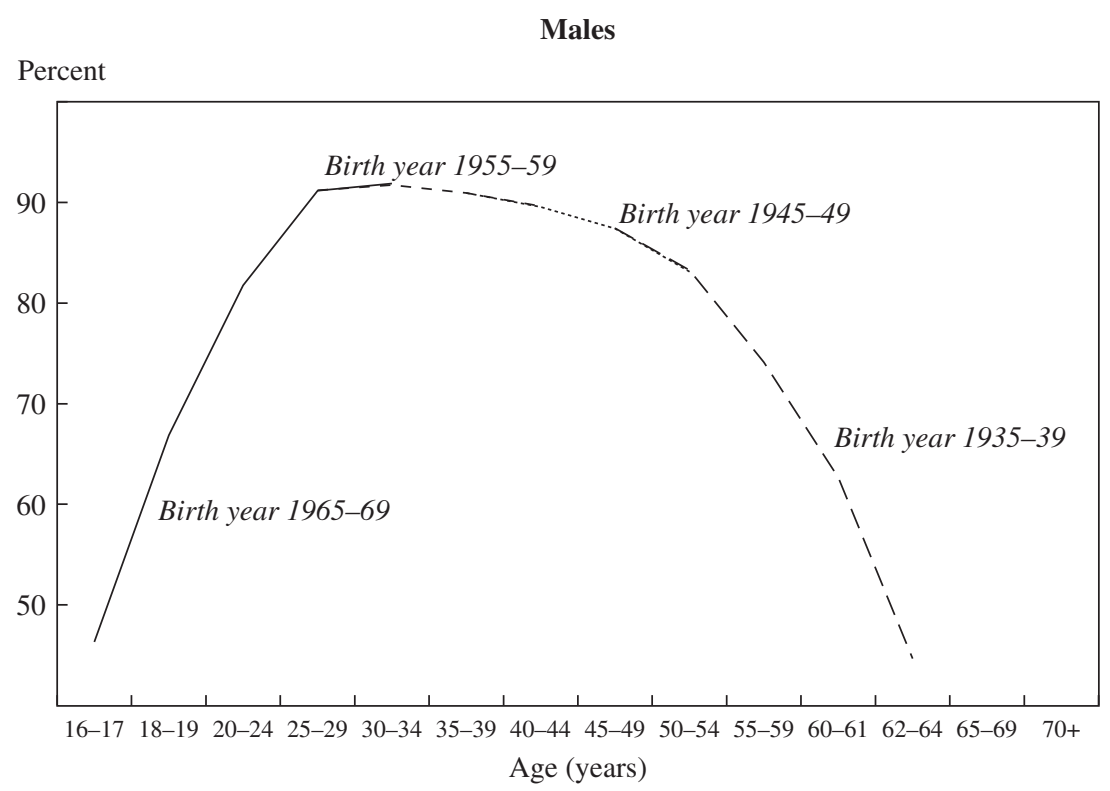

\section{Females}

\section{Percent}

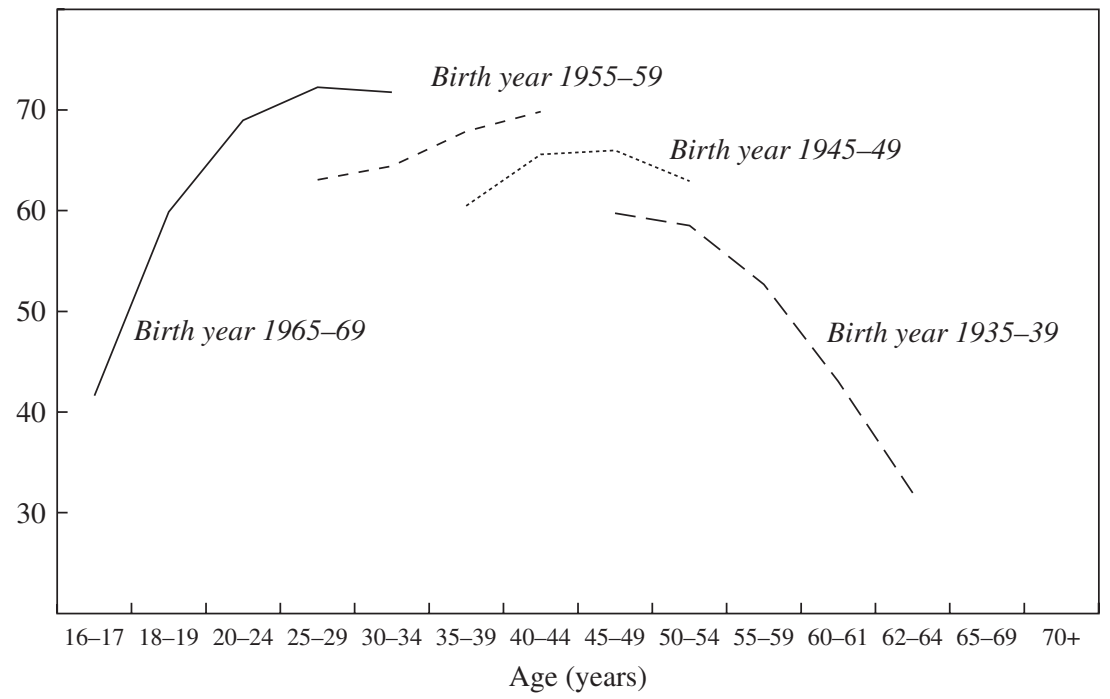

Source: Authors' calculations using data from the Bureau of Labor Statistics. 
The profiles for males have been remarkably stable. As the upper panel of figure 9 shows, the age profile segments for the various groups of birth cohorts lie on top of each other for those ages for which they overlap, suggesting that a single age profile applies to all cohorts in the sample. In contrast, the age profiles for females (in the lower panel) are disjoint, suggesting that they have evolved significantly over time. Most notably, more recent cohorts appear to have reached their peak rate of participation earlier in life. We cannot tell at what ages the participation rates of the oldest cohorts shown reached their maximum - the rate for cohorts born in the 1930s apparently peaks before age 45 , which is where their segment begins. However, participation rates for those born in the 1940s peak in their forties, whereas the rates for those born in the 1960s appear to peak in their late twenties or early thirties.

\section{The Aggregate Trend}

The estimated age and cohort effects and the contributions of the observable determinants, with the exception of the cyclical variables, can be weighted by the relevant population shares $S$ at each point in time and summed to produce an aggregate trend. We compute the trend as

$$
T L F P R_{t}=\sum_{\text {sex }} \sum_{g=1}^{14} S_{\text {sex }, g, t} \alpha_{\text {sex }, g} Z_{\text {sex }, g, t}^{\lambda_{\text {sex }},}\left(\prod_{b=1907}^{1989} \beta_{\text {sex }, b} c_{g, b, t}\right)^{\frac{1}{n_{g}}},
$$

where, again, $Z$ contains all the elements of $X$ except the cyclical variables. In other words, we calculate the trend participation rate for each age-sex group for each year from the estimates of the age effect, the cohort effects of the cohorts that appear in each age group in that year, and the right-hand-side variables that apply to that age-sex group in that year (or, equivalently, to that age group in that cohort). Then, weighted by the population shares of the age-sex group in each period, the rates are aggregated. Through the population weights, the model explicitly incorporates the more traditionally modeled demographic shifts in the age-sex distribution.

Figure 10 shows the model's estimated trend for the aggregate labor force participation rate, and figure 11 shows the estimated trends separately for males and females. (Here and below, the trends have been smoothed by taking three-quarter centered moving averages.) The aggregate trend follows the familiar pattern over most of history, but it peaks and begins to decline in 
Figure 10. Actual, Fitted, and Trend Labor Force Participation Rates, 1977-2005

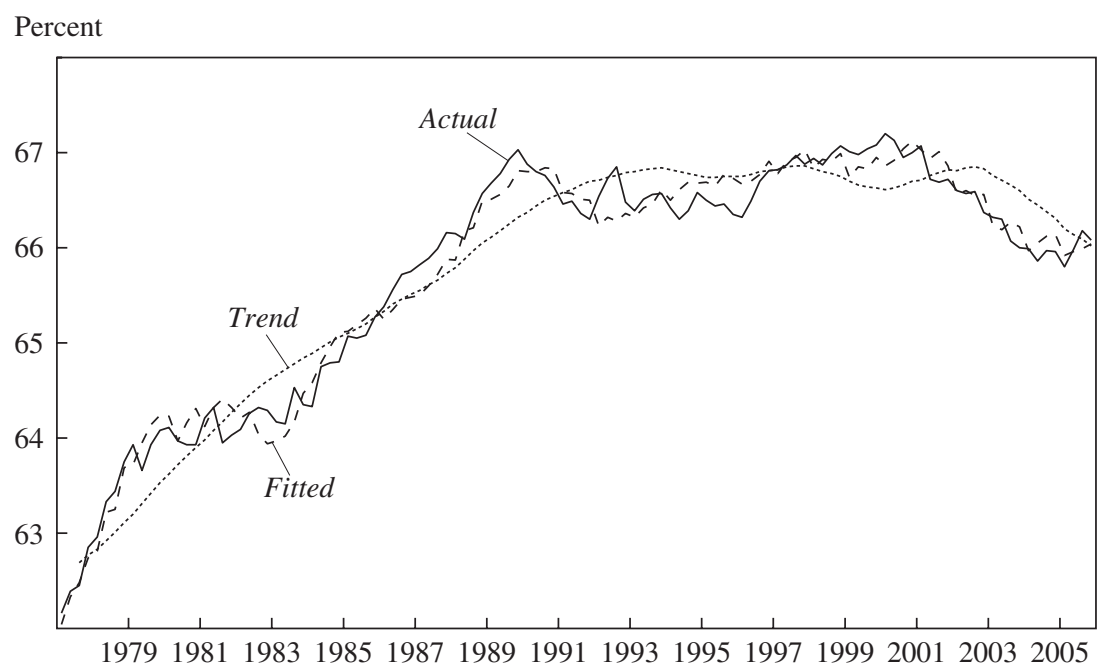

Source: Bureau of Labor Statistics and authors' calculations.

2002. More than half of the estimated decline in the trend between 2002 and 2005 is due to shifting demographic shares-the most important of which is the redistribution of baby-boomers from high-participation-rate ages to low-participation-rate ages. The remainder is due to the flattening of women's trend participation combined with the ongoing decline in men's participation, as shown in the two panels of figure $11 .{ }^{46}$

Table 4 shows how changes in specific explanatory variables, such as educational attainment or fertility, affect the estimate of the aggregate trend participation rate. Each row of the table reports the effect of a 1-standarddeviation increase in that variable on the aggregate trend participation rate, using 2005 population weights to aggregate the estimates from the twentyeight separate equations. Perhaps not surprisingly, the marriage rate is estimated to have the largest influence on the trend, in keeping with the increases in participation observed in recent decades as more couples

46. An unexpected feature is the dip in the aggregate trend in the late 1990s, which interrupts an otherwise easily characterized shape. Trends for women in particular age groups primarily account for the dip, which appears to be mostly attributable to some odd movements in marriage rates. This anomaly warrants further investigation, but for the moment we are inclined to smooth through this reduction in the estimated trend. 
Figure 11. Estimated Labor Force Participation Rate Trends by Sex, 1977-2005

Males

Percent

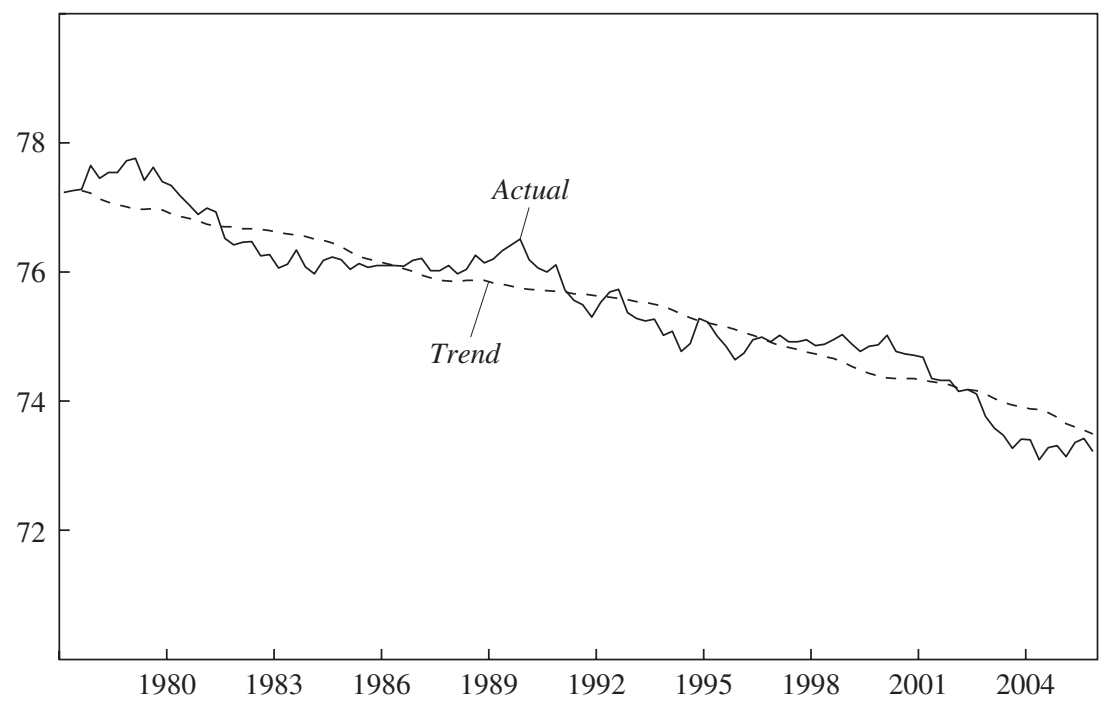

Females

Percent

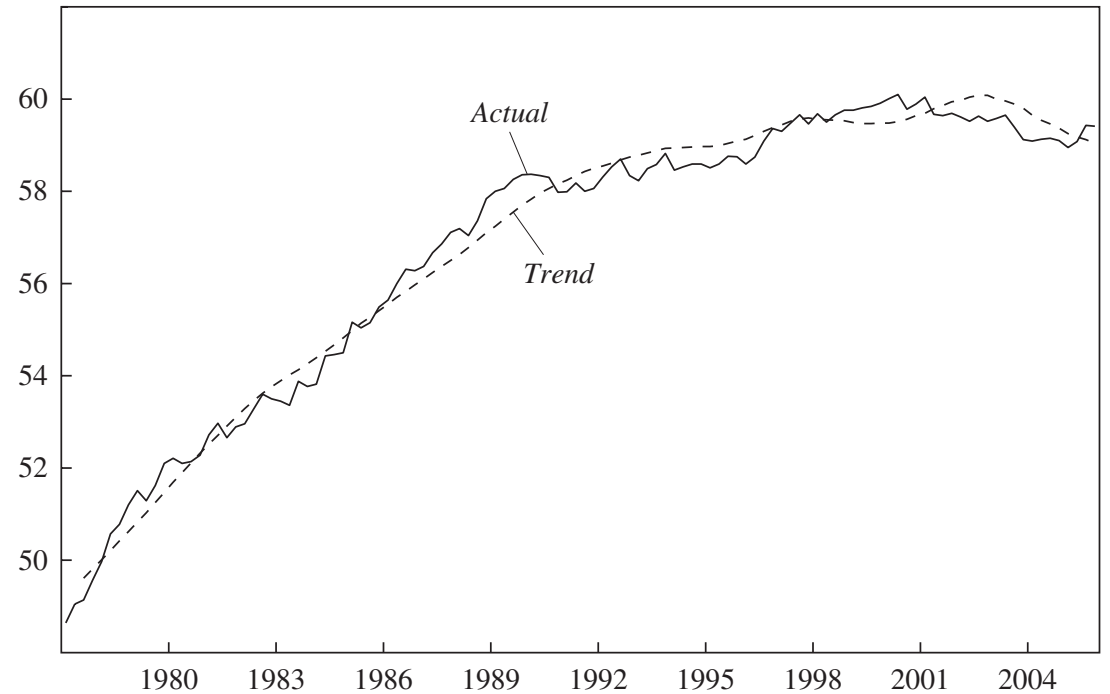

Source: Bureau of Labor Statistics and authors' calculations. 
Table 4. Effect of a One-Standard-Deviation Change in Explanatory Variables on the Aggregate Labor Force Participation Rate

\begin{tabular}{lc}
\hline Variable $^{\mathrm{a}}$ & Percentage points \\
\hline Returns to education & -0.088 \\
College completion rate & 0.352 \\
Life expectancy & 0.269 \\
Disability award rate & -0.014 \\
Generosity of early-retirement rules & -0.030 \\
Generosity of delayed retirement credit & 0.016 \\
Female-male earnings ratio & 0.253 \\
Marriage rate & -1.505 \\
Presence of children under 6 in family & -0.171 \\
\hline
\end{tabular}

Source: Authors' calculations.

a. See the text for definitions of the variables.

have postponed marriage or forgone it altogether. However, we view such a large change in this variable as unlikely in the foreseeable future. Higher returns to schooling, which should raise the demand for education, are estimated to lower the aggregate trend, whereas changes in Social Security retirement and disability benefits have, on net, relatively little influence. The prevalence of young children is estimated to lower the aggregate participation rate, and rising wages of women relative to men to raise it. Educational attainment and life expectancy-two influences that should increase career longevity - have positive estimated influences on the trend. However, the estimate for the effect of life expectancy does not incorporate the effect of the corresponding increase in the number of elderly individuals overall, which would tend to put downward pressure on the trend. (This effect is captured by the changing population weights.)

\section{Trend versus Cycle}

One striking feature in figure 10 is the gap between the level of the trend in 1989-90 and the peak in actual participation at that time. Figure 10 also shows the predicted participation rate from the model, which includes the effects of the employment gap and its lags. As the figure indicates, the model interprets most of the gap between the trend and the actual participation rate at the end of the 1980s expansion as a cyclical deviation from trend rather than as a residual. The same can be said of the late 1970s and the end of the 1990s. 
Table 5. Cyclical Elasticities from the Labor Force Participation Rate Model

\begin{tabular}{|c|c|c|c|c|}
\hline \multirow[b]{2}{*}{ Age (years) } & \multicolumn{2}{|c|}{ Males } & \multicolumn{2}{|c|}{ Females } \\
\hline & Elasticity $^{\mathrm{a}}$ & $p$-value & Elasticity $^{\mathrm{a}}$ & $p$-value \\
\hline $16-17$ & 2.88 & 0.00 & 2.33 & 0.00 \\
\hline $18-19$ & 0.78 & 0.00 & 0.63 & 0.00 \\
\hline $20-24$ & 0.29 & 0.00 & 0.29 & 0.00 \\
\hline $25-29$ & 0.14 & 0.00 & 0.46 & 0.00 \\
\hline $30-34$ & 0.18 & 0.00 & 0.53 & 0.00 \\
\hline $35-39$ & 0.03 & 0.55 & 0.43 & 0.00 \\
\hline $40-44$ & 0.06 & 0.18 & 0.39 & 0.00 \\
\hline $45-49$ & 0.07 & 0.02 & 0.12 & 0.51 \\
\hline $50-54$ & 0.08 & 0.40 & 0.25 & 0.02 \\
\hline $55-59$ & -0.01 & 1.00 & -0.17 & 0.06 \\
\hline $60-61$ & 0.38 & 0.03 & -0.53 & 0.09 \\
\hline $62-64$ & 0.53 & 0.19 & -0.96 & 0.00 \\
\hline $65-69$ & 0.62 & 1.00 & 0.70 & 1.00 \\
\hline 70 and over & 0.73 & 0.05 & -0.37 & 1.00 \\
\hline
\end{tabular}

Source: Authors' calculations.

a. Sum of the coefficients on the employment gap in the current period and two lags.

Indeed, more generally, the model estimates a fairly high degree of cyclicality in labor force participation. Table 5 summarizes the cyclical sensitivity of the various demographic groups by summing the coefficients on the employment gap and its two lags. For both sexes, the youngest group (those 16 and 17 years old) is by far the most sensitive to the business cycle. Among males this sensitivity declines quickly and becomes small for prime-age men. But participation rates for men aged 60 and above are again quite sensitive to business cycle conditions. Among females the pattern is less clear. The estimated cyclical sensitivity for women remains considerably higher than for men through their midfifties, but the estimates suggest that, with the marked exception of the 65-69 age group, women's participation is countercyclical at older ages. However, the cyclical coefficients for the older age groups are often imprecisely estimated.

Of course, the contribution of each group to the cyclicality of the aggregate participation rate depends upon its share in the population. For example, although men aged 35-44 exhibit only a small cyclical response, they account for $9 \frac{1}{2}$ percent of the working-age population, and so the table understates their contribution to aggregate cyclicality. In contrast, men aged 
65 and over account for only $6 \frac{1}{2}$ percent of the working-age population. However, as the age distribution of the population shifts toward these older age groups, the model's predictions for the cyclical responsiveness of the aggregate participation rate, in addition to its trend, will change.

Figure 12 focuses on the past ten years. Apart from the dip in the late 1990 s, the estimated trend in the aggregate participation rate is fairly flat until 2002, after which it declines steadily. The actual participation rate begins to decline sooner, near the beginning of the recession. The fitted line indicates that the model explains the initial drop in participation as a consequence of the economy's movement from the tight labor markets of the late 1990s to the looser labor market of 2001, and the further declines in 2002 and 2003 as the result of a combination of weak labor demand and the beginning of a downward trend. As hiring began to pick up in late 2003, the decline in participation subsided. However, the trend rate of participation continued to fall, and the recent improvement in labor market conditions only served to buoy the participation rate up toward its declining trend level. Indeed, by the end of the sample period, the aggregate participation rate was close to its estimated trend.

It is important to note that our estimate of the end-of-sample trend level of the aggregate participation rate is not very sensitive to assumptions about current cyclical conditions, because it is identified using variables (age effects, cohort effects, and the observed structural variables) that are not closely tied to the behavior of the actual participation rate at the end of the sample period. To illustrate this robustness, we reestimated the model under the assumption that the level of employment was still 1 percent below its trend level in 2005, rather than at trend as in our baseline estimate. This produced an estimated trend level of participation in 2005 of 66.2 percent, barely above our baseline estimate of 66.1 percent. A commensurately lower employment trend (leaving employment 1 percent above its trend level in 2005) reduced the estimated trend level of participation in 2005 to 66.0 percent.

We also experimented with several alternative cyclical controls, including the difference between capacity utilization and its long-run average, and an alternative procedure that used the $\mathrm{CBO}$ unemployment rate gap to extrapolate the cyclical variable after 2000. In each case the trend level of the participation rate at the end of the sample was little changed. Thus the model-based estimate of the aggregate trend participation rate appears robust to a broad range of cyclical conditions, and it currently seems to lie in a 
Figure 12. Alternative Simulations of Labor Force Participation Rate Trends, 1995-2015

\section{Adjusting age effects}

Percent

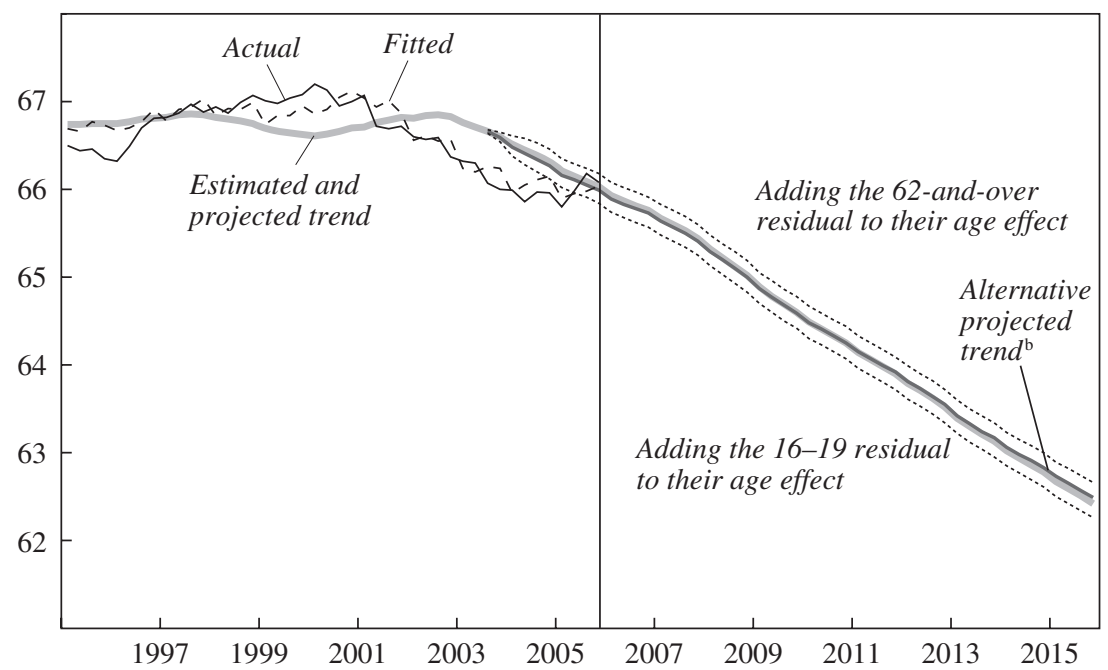

Adjusting cohort effects

Percent

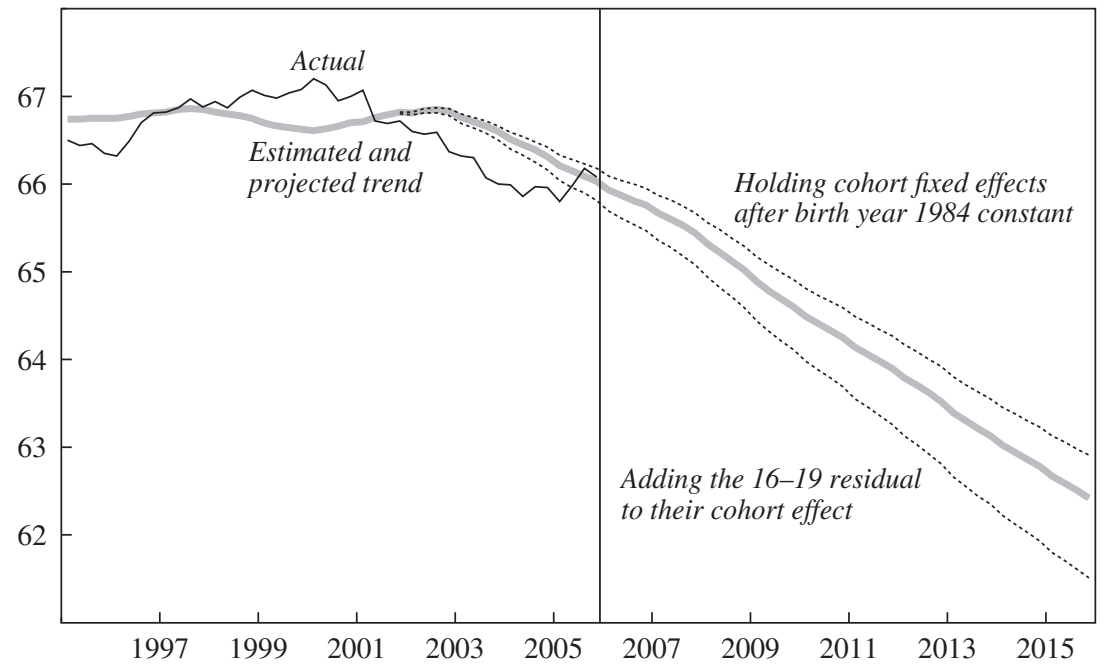

Source: Bureau of Labor Statistics and authors' calculations.

a. Points to the right of the vertical line are projections.

b. Alternative trend adds the residuals from the 62-and-over and 16-19 models to their respective age effects. 
narrow band bracketed by 66.0 and 66.2 percent. Moreover, our finding that recent levels of the aggregate participation rate are close to trend is neither an indication nor necessarily a consequence of an economy that is at full employment.

\section{Model Performance}

Figure 13 shows the participation rates, estimated trends, and fitted values of the model for teenagers (ages 16-19), young adults (20-24), primeage adults (25-61), and older adults (62 and over), built up from the more detailed demographic groups included in the model. These aggregates highlight the relatively good fit of the model for the broad range of middle age groups and illustrate our concerns about the deviation of actual observations from the model predictions for the youngest and the oldest age groups.

For the 16-19 age group, the model appears to have captured the general trends and turning points in participation rates, although for teenage males there have been long stretches where the model prediction deviated from the data. Most recently, the model has expected participation rates to recover back toward their trends. In fact, actual rates have remained well below trend; although this finding represents a failure of the model, it does mitigate the concern that endpoint bias may be dragging down the estimated trend. Note, however, that for ages 20-24 the model exhibits much smaller errors, which suggests that the model residuals for the teenage groups have not tended to be carried through to older age categories as these cohorts age, and thus that the changes affecting recent cohorts of teens are age specific rather than cohort specific.

For ages 25-61 the model fits well overall and is not surprised by the developments of the past few years. Notably, the model effectively captures the dramatic change in slope in the participation rate of prime-age women and the persistent downtrend in the participation rate of primeage men. In contrast, the actual participation rates for both older men and older women have exceeded the model predictions in recent years. The model also missed actual outcomes fairly uniformly across the older age groups in some earlier periods (for example, 1985-86), suggesting that we may have omitted some salient influence on retirement decisions from the model. For example, the errors in the most recent few years could be related to sizable movements in asset valuations, although, as 
Figure 13. Actual, Trend, and Fitted Labor Force Participation Rates by Sex and Age Group, 1977-2005

Males, ages 16-19

Percent

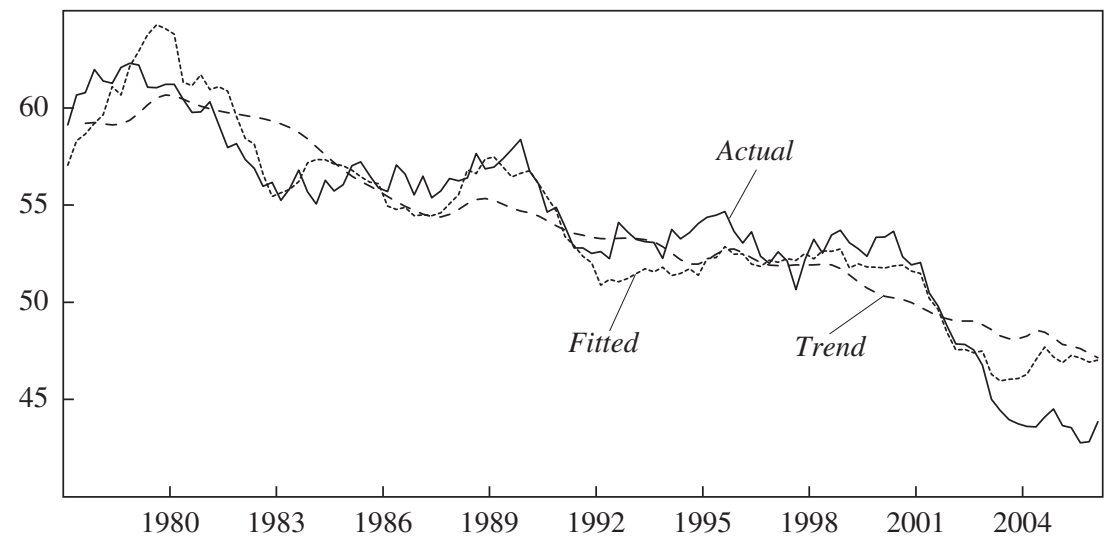

Females, ages 16-19

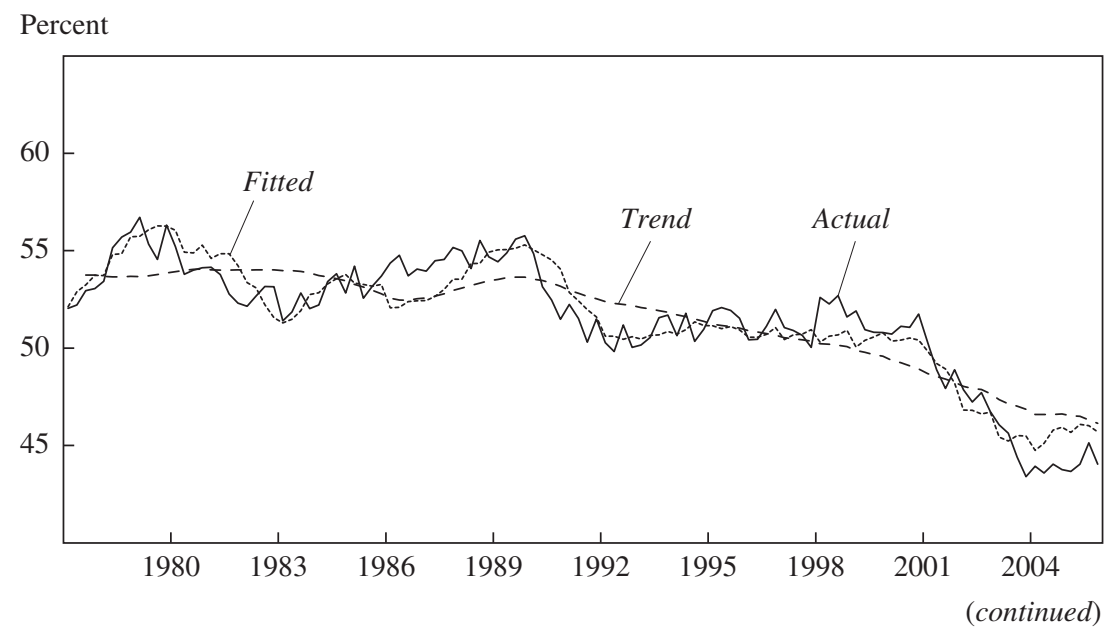


Figure 13. Actual, Trend, and Fitted Labor Force Participation Rates by Sex and Age Group, 1977-2005 (Continued)

Men, ages 20-24

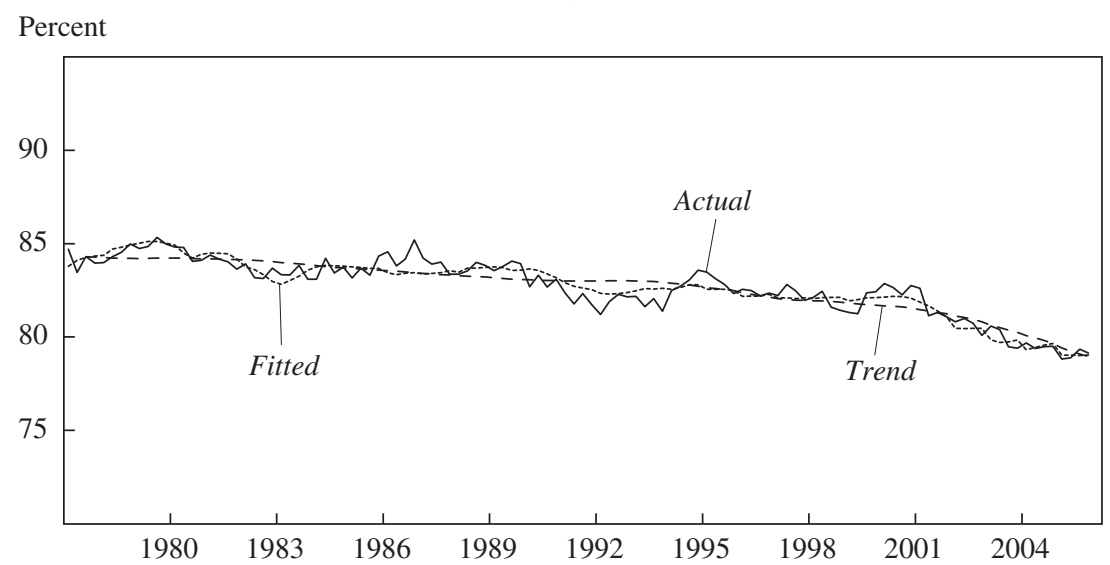

Women, ages 20-24

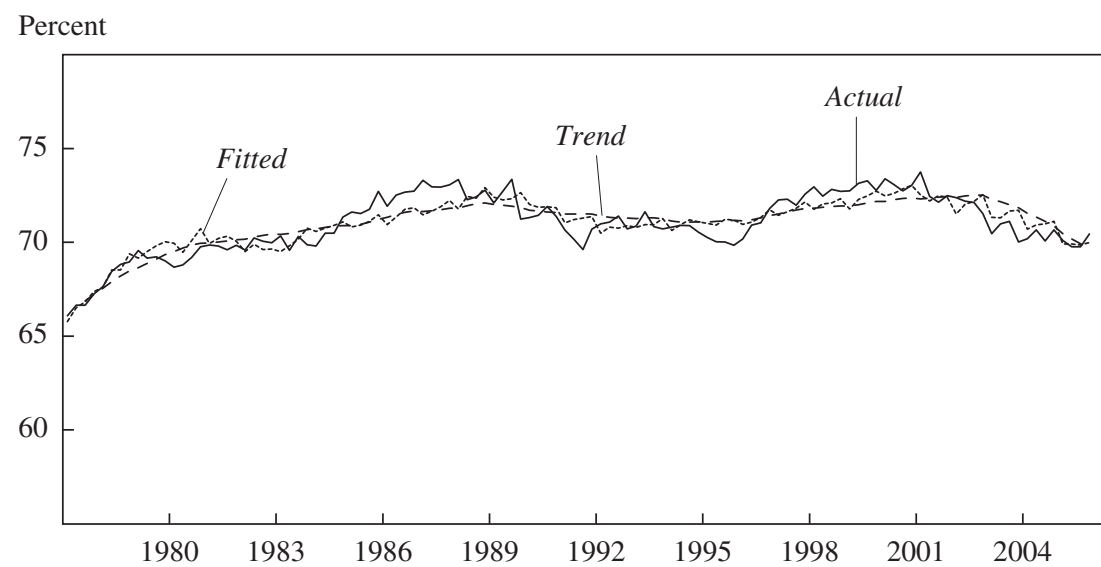


Figure 13. Actual, Trend, and Fitted Labor Force Participation Rates by Sex and Age Group, 1977-2005 (Continued)

Men, ages 25-61

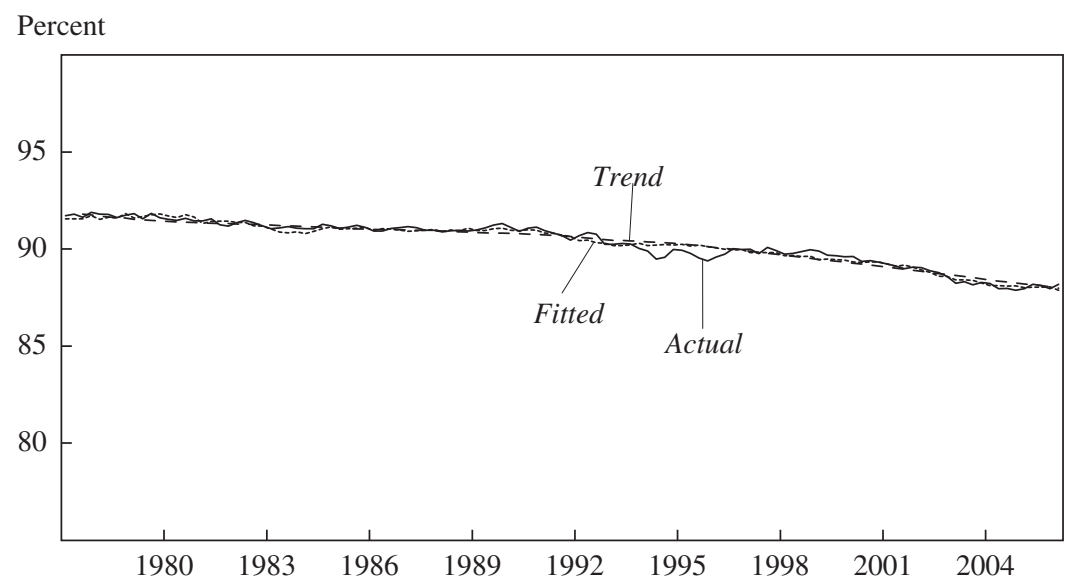

Women, ages 25-61

Percent

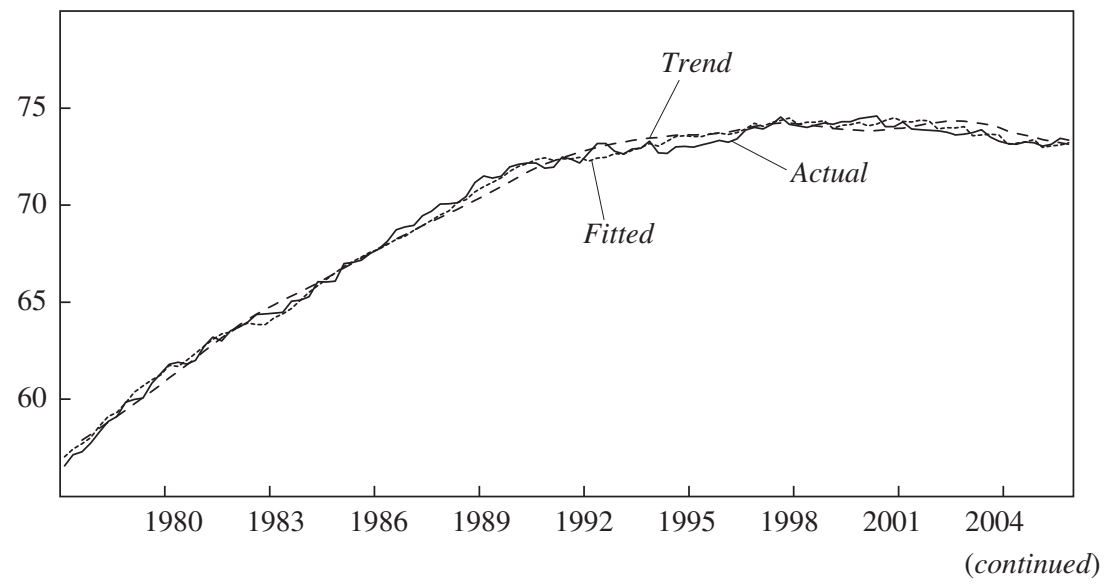


Figure 13. Actual, Trend, and Fitted Labor Force Participation Rates by Sex and Age Group, 1977-2005 (Continued)

Men, ages 62 and over

Percent

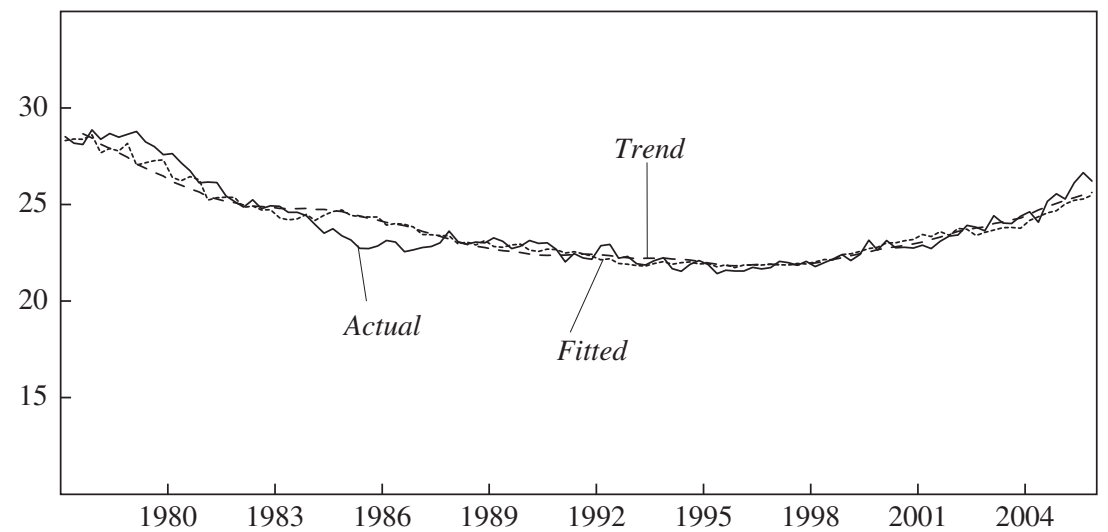

Women, ages 62 and over

Percent

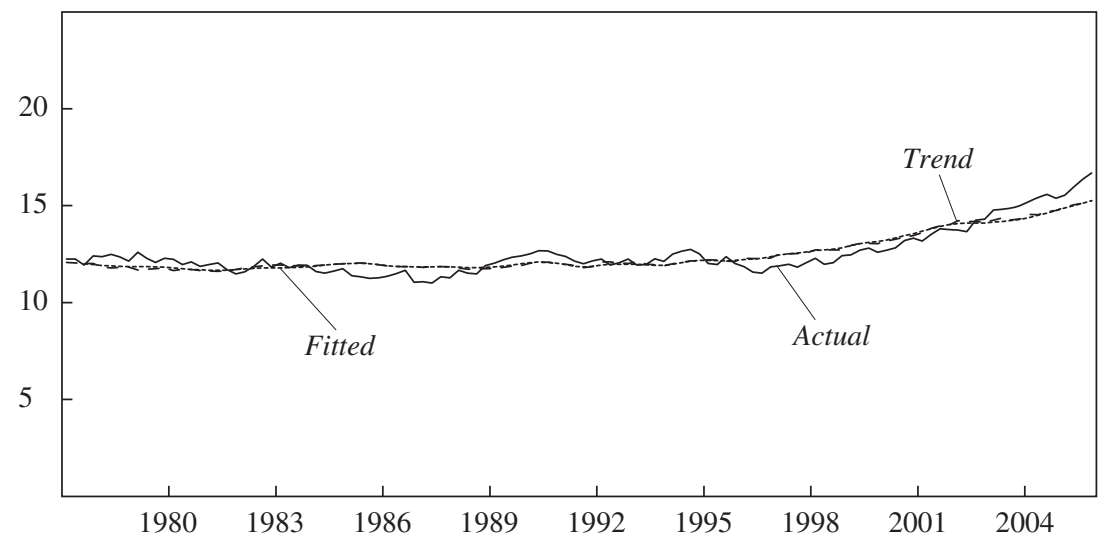

Source: Bureau of Labor Statistics and authors' calculations. 
noted above, we did not find variables representing wealth to be significant in the model. Nevertheless, the large and growing size of this group suggests that these errors represent a substantial risk to our estimated trend.

\section{Model Projections and Alternative Simulations}

We can also use the model to project how the trend in labor force participation will develop in coming years. To do this we employ the following procedure. For birth-year cohorts age 16 or above in 2005, we hold the cohort effects constant at their last values and essentially age these cohorts along the last observed age profile. ${ }^{47}$ For cohorts who had not yet entered the labor market by 2005 (so that we have no model estimate of their cohort effect), we assume that the cohort effect is constant at the average value of the last few cohorts and then age them along the last observed age profile.

As figure 12 shows, the model projects that the trend in the aggregate labor force participation rate will fall further over the next ten years; indeed, the projected decline from 2005 to 2015 is more than 3 percentage points, which is comparable to the increase over the first ten years of our estimation period, when female participation was rising so rapidly. About 2 percentage points of this decline reflects the projected changes in the age distribution of the population associated with the aging of the baby-boom cohort, and the remainder is due to the model's estimates of the trends in the age and cohort profiles over the next ten years.

In constructing this projection of the trend, we assumed that the sizable recent model errors for teenagers and for the oldest age groups were not a manifestation of changes in the trend. However, an alternative approach would be to interpret the errors as suggestive of a recent change in the age profiles at those ages. To examine how this alternative interpretation would change our projection of the trend, we added the average error over the last two years to the age effects for teenagers and for the 62-and-over age group. For the latter group, this change reduces the extent of the drop

47. This procedure effectively means that we hold most of the right-hand-side variables at their last observed values and keep the cohort and age effects fixed. There are two exceptions to this. First, we allow life expectancy at age 65 to evolve in line with census projections. Second, we assume that educational attainment for cohorts currently younger than 27 will continue to change at the rate exhibited by the five most recent cohorts for which we measure attainment. 
in the age profile for older ages and, as indicated in the top panel of figure 12 , raises the level of the projected trend by $1 / 4$ percentage point by 2015 . For teenagers this exercise steepens the age profile between youths and prime-age individuals and reduces the aggregate trend by $1 / 4$ percentage point. Hence, as it happens, carrying forward both sets of errors leaves the projected trend almost unaltered.

Alternatively, the recent errors in the teenage equations could indicate that the attachment of recent cohorts has fallen more sharply than allowed for in the baseline model. To simulate this possibility, we added the average recent errors among teenagers to their cohort effects and computed the effects on the aggregate trend as they age. This simulation, shown by the lower line in the bottom panel of figure 12, leads to a steeper projected decline in the aggregate trend and reduces the trend level by more than 1 percentage point in 2015. Of course, it also seems possible that these cohorts might eventually have greater labor force attachment than the model suggests. For example, if the additional schooling obtained by these cohorts boosts their participation rates throughout their lives, the baseline model would underestimate the aggregate trend. We approximated this influence by raising the cohort effects for cohorts born after 1984 to that of the 1984 birth cohort, rather than allowing any further decline (in effect raising the average participation rates of these cohorts later in life). This simulation, shown by the upper line in the figure, slows the decline in the trend noticeably and produces a trend level that is about $1 / 2$ percentage point higher in 2015 than that projected by the baseline model.

We also recognize that a steeper rise in the labor supply of older workers than predicted by the model is a realistic possibility, especially if the aging of the baby-boom cohort leads to changes to parameters of the Social Security program or to concerns about the viability of private pension plans or retiree health benefits. However, given the substantial downward pressure on the aggregate participation rate from other forces, participation rates among this group would need to rise dramatically to prevent future declines in the aggregate trend participation rate. For example, if participation among the remaining age groups turns out as the model predicts, the average participation rate of individuals 62 and over would need to double over the next ten years, from 20 percent to 40 percent, to hold the trend at its current level. Such a change would require a quickening of the pace of increase in this group's participation 
rate from roughly 0.1 percentage point a year recently to 2 percentage points a year. ${ }^{48}$ Given the projected increases in the number of individuals in this group who are over 80 years of age (and therefore unlikely to work), such a sharp acceleration seems unlikely.

\section{Additional Evidence}

Although the results are not directly comparable with those from the cohort-based model presented above, other aspects of recent patterns in labor force participation can provide independent evidence on the extent to which changes in the aggregate labor force participation rate in recent years are cyclical or structural in nature. Here we present several such related analyses, including a comparison of participation rate changes in different states, an examination of gross labor force flows, and changes in the duration and incidence of labor force participation.

\section{Cross-State Evidence}

Variation in participation rates across states is one alternative source of information about the potential sources of the post-2000 decline in the aggregate participation rate. In particular, if changes in participation during this period were driven largely by changing labor demand conditions, one would expect those states in which the labor market showed a relatively greater deterioration to also have experienced a larger relative drop in labor force participation rates. On the other hand, to the extent that the changes in participation were unrelated to fluctuations in labor demand, one would expect them to be uncorrelated with a state's cyclical condition.

To investigate this proposition, we regressed the annual participation rate in each state on a constant state-specific effect, a common linear trend as a measure of structural factors, state-specific cyclical conditions, and a dummy variable equal to zero before 1994 and one otherwise, to control for any effects of the CPS redesign. To capture possible changes both in the underlying trend rate of participation and in the responsive-

48. To put this change in perspective, the participation rate for prime-age women rose an average 1.5 percentage points a year between 1973 and 1983, the decade in which their labor supply increased the most rapidly. 
ness of the participation rate to the business cycle, we allow for a break in the coefficients on the trend and cycle terms after $2000 .{ }^{49}$ The full specification is as follows:

$$
\begin{aligned}
l f p r_{s, t}= & \alpha_{s}+\underset{\substack{0.091 \\
(0.03)}}{d 94}+\underset{\substack{0.021 \\
(0.92)}}{\gamma} \times t+\underset{\substack{-0.123 \\
(-2.58)}}{\delta^{t}} \times d 00 \times t \\
& +\underset{\substack{-0.243 \\
(-6.11)}}{\beta} \times c y c_{s, t}+\underset{\substack{-0.028 \\
(-0.97)}}{\delta_{c}^{c}} \times d 00 \times c y c_{s, t}+\varepsilon_{s, t},
\end{aligned}
$$

where $s$ indexes states, $t$ indexes time, lfpr is the participation rate, $c y c$ is the state unemployment rate (our measure of cyclical conditions), $d 00$ is a dummy variable equal to one beginning in 2001 and zero before that, and $d 94$ is the CPS redesign dummy. To control for spurious correlation between the unemployment rate and the participation rate due to measurement error, we instrument for the contemporaneous unemployment rate with a state's lagged unemployment rate and the contemporaneous percentage change in payroll employment. The model is estimated using population-weighted least squares and data from 1990 to 2005. The estimated coefficients (except for the state effects) are reported below each parameter, with $t$ statistics shown in parentheses.

If the post-2000 downward movements in the participation rate were associated with structural factors uncorrelated with changes in state-level labor demand, our estimates of $\delta^{t}$ should be negative. If, on the other hand, participation rate declines were caused only by changes in demand, with or without an increase in the cyclical sensitivity of the participation rate, our estimates of $\delta^{t}$ should be zero and our estimates of $\beta$ should be negative. If changes in cyclical sensitivity played an important role in the post-2000 behavior of the participation rate, our estimates of $\delta^{c}$ should be negative.

Overall, the estimation results suggest that both cyclical and structural factors played a role in the post-2000 decline. Estimates of $\delta^{t}$ and $\beta$ are both negative and statistically significant. On net, the point estimates imply that the break in the common trend accounts for about one-half of the 0.8-percentage-point decline in the participation rate between 2000 and 2005 , with the remainder accounted for by changes in cyclical condi-

49. We exclude state-specific time trends because the interpretation of coefficients is clearer without them. Results are qualitatively similar when they are included. 
tions. ${ }^{50}$ Although the estimate of $\delta^{c}$ is also negative, it is not statistically significant at conventional levels, suggesting little or no change in the cyclical sensitivity of the participation rate. Despite the differences in the information used to identify structural changes, these results are quite similar to those from our cohort-based model, which also estimates that about half of the decline in the participation rate since 2000 was due to structural forces.

\section{Gross Labor Force Flows}

Patterns of gross labor force flows may also be useful in discerning the reasons for the post-2000 drop in the participation rate, given a set of assumptions about the types of flows that would be expected to be associated with cyclical and structural changes in participation. In particular, one reasonable presumption is that withdrawal from the labor force as an unusually strong response to the weak job market in recent years should be reflected in an unusually large rate of flows out of unemployment into nonparticipation, as job seekers became discouraged. In contrast, the flow out of employment into nonparticipation arguably should be procyclical, because employed individuals, to the extent that they are worried about job prospects, would be reluctant to leave the labor force temporarily (for example, to go back to school) in a weak economy. As a result, any increase in this latter flow during and after the 2001 recession would likely be related to more structural factors.

Figure 14 shows the rates of flow out of employment and unemployment into nonparticipation. ${ }^{51}$ As expected, the flow rate from unemployment to nonparticipation tends to increase when the job market weakens, whereas that from employment to nonparticipation tends to decrease. This evidence suggests that we can use the deviations from these standard cyclical patterns as a test of whether the post-2000 decline in participation

50. When we include year dummies, so that identification derives from the deviation of state-level variables from average (across state) levels, the results are qualitatively similar. We also analyzed whether the effect of cyclical conditions is asymmetric. Results suggest an asymmetric response of the participation rate to cyclical conditions (with the response greater when the unemployment rate is above the state-specific mean) but reveal no evidence of a post-2000 break in this response; in addition, when we allow for an asymmetric response, the estimated contribution of a common trend to the post-2000 participation rate decline is qualitatively similar to the results discussed.

51. We thank Fran Horvath for providing us with the gross flow data. 
Figure 14. Flows Out of the Labor Force, 1980-2005

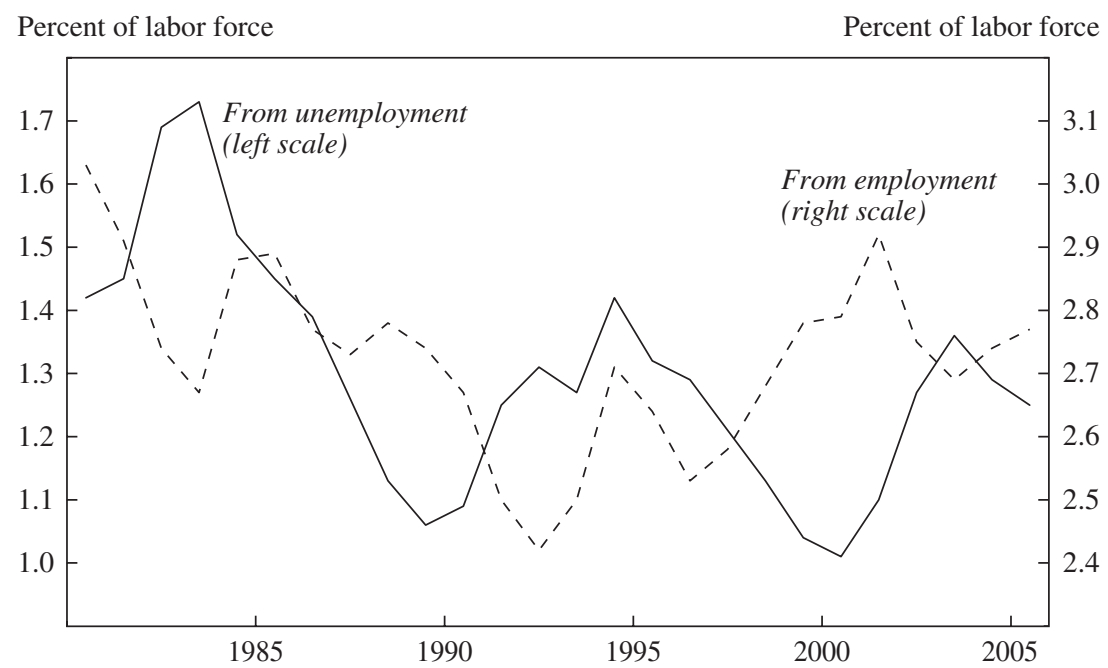

Source: Bureau of Labor Statistics.

was due to structural factors or to an unusually strong response to the cyclical deterioration in the labor market.

To implement this test, we first estimate the pre-2001 typical cyclical response using the following equations:

(6)

$$
u n n_{t}=\underset{\substack{0.005 \\(7.86)}}{\alpha^{u}}+\underset{\substack{0.003 \\(9.70)}}{\delta} \times d 94+\underset{\substack{0.12 \\(16.97)}}{\beta u} \times c y c_{t}+\underset{\substack{-0.00003 \\(-0.70)}}{\gamma_{1}^{u}} \times t+\underset{\substack{-0.000006 \\(-2.54)}}{\gamma_{2}^{u}} \times t^{2}+\varepsilon^{u}
$$

$$
e n_{t}=\underset{\substack{0.037 \\(26.66)}}{\alpha e}+\underset{\substack{0.0009 \\(1.38)}}{\delta} \times d 94+\underset{\substack{-0.0 .84 \\(-5.23)}}{\beta^{e}} \times c y c_{t}+\underset{\substack{-0.0007 \\(-6.96)}}{\gamma_{1}^{e}} \times t+\underset{\substack{0.00001 \\(2.95)}}{\gamma_{2}^{e}} \times t^{2}+\varepsilon^{e}
$$

where $u n$ is the rate of flow from unemployment to nonparticipation, en is the rate of flow from employment to nonparticipation, $c y c$ is a measure of the stage of the business cycle (we use the unemployment rate), $d 94$ is a dummy variable equal to one in 1994 and later and zero before 1994 (to control for the CPS redesign), and $t$ and $t^{2}$ are linear and quadratic trend terms, respectively. Coefficient estimates and $t$ statistics are reported below each parameter. Using the estimated $\beta s$, we then construct estimates of the flow rates, excluding cyclical effects, through 2005 as 


$$
\begin{aligned}
& e n_{t}^{a d j}=e n_{t}-\beta^{e} c y c_{t} \\
& u n_{t}^{a d j}=u n_{t}-\hat{\beta}^{u} c y c_{t} .
\end{aligned}
$$

Lastly, we regress these cyclically adjusted measures on quadratic time trends and a dummy variable ( $d 00)$ set equal to zero before 2001 and to one thereafter:

$$
\begin{aligned}
& e n_{t}^{a d j}=\underset{\substack{0.001 \\
0.245)}}{\delta_{94}^{e}} \times d 94+\underset{\substack{0.0006 \\
(-8.05)}}{\gamma_{1}^{e}} \times t+\underset{\substack{0.0 .0001 \\
(2.95)}}{\gamma_{2}^{e}} \times t^{2}+\underset{\substack{0.0023 \\
(3.19)}}{\delta_{0.02}^{e}} \times d 00+\varepsilon^{e} \\
& u n_{t}^{a d j}=\delta_{\substack{0.002 \\
0.63) \\
(6.34)}}^{\delta_{0}^{u}} \times d 94+\underset{\substack{-0.0001 \\
(-2.54)}}{\gamma_{1}^{u}} \times t+\underset{\substack{0.00000 \\
(0.28)}}{\gamma_{2}^{u}} \times t^{2}+\underset{\substack{0.0006 \\
(1.18)}}{\delta_{0.18}^{u}} \times d 00+\varepsilon^{u},
\end{aligned}
$$

This specification embodies our assessment that, through 2000, the underlying trend in both flow rates can be reasonably well described by a quadratic time trend. After 2000, however, we allow the average flow rates (excluding the typical cyclical response) to be freely estimated. In this way the average post-2000 fitted values will reflect both the presence of excessive cyclical responses and underlying structural change. Under our assumptions, a higher rate of flow from unemployment to nonparticipation (after controlling for the typical cyclical response) would support the excess cyclicality hypothesis, whereas a higher rate of flow from employment to nonparticipation would favor the structural change hypothesis.

Estimation results support the latter hypothesis. The mean value of the post-2000 flow rates of unemployment to nonparticipation (excluding the typical cyclical response) is slightly lower than the average flow rate from 1994-2000, but this difference is not statistically significant. In contrast, the difference between the mean post-2000 employment-to-nonparticipation flow rate and the average pre-2001 flow rate is substantial and positive, and this difference is statistically significant.

The magnitudes of the changes in cyclical and structural flows imply that all of the change in the participation rate since 2000 has been due to structural forces-a greater share than our cohort-based model would suggest. However, two important caveats limit the usefulness of the gross flows-based estimates. First, because we did not have strong priors about how structural and cyclical forces should affect flows into the labor force, our analysis excluded these flows. Second, the gross flows data generally 
have a difficult time capturing the procyclical movements in the participation rate. Flows out of the labor force impart a countercyclical influence (because the decline in flows out of employment in recessions dominates the increase in the flows out of unemployment), whereas flows into the labor force do not have a strong correspondence with the business cycle.

\section{Incidence versus Duration}

A final line of inquiry we undertake is to decompose the aggregate participation rate into the incidence of participation (the proportion of individuals who participate in the labor force at all during the year) and the duration of participation (the proportion of time individuals spend in the labor force over that year). This decomposition is potentially informative, because a decline in the incidence of participation may be an indication that the forces behind the decline in participation are more structural in nature, whereas a change in the duration of participation may be a more temporary development. ${ }^{52}$

Using data from the Annual Demographic Supplement to the CPS, we define the incidence of participation as the percentage of individuals who worked or looked for work in at least one week during the year, and the duration of participation as the number of weeks that individuals with a positive incidence spent working or looking for work during the year. The relevant data are available on an annual basis from 1975 to $2004 .{ }^{53}$

As figure 15 shows, the recent decline in the participation rate appears to be entirely driven by a decline in incidence. Duration flattened out a bit after 2002 but was still higher in 2004 than in the late 1990s. Judging from the early 1980s and early 1990s, incidence has historically exhibited larger cyclical fluctuations than duration, has tended to drop off slightly before the cyclical peak, and has continued to decline after the cyclical trough. In these respects the current episode fits the historical pattern. However, incidence has been much weaker in the current recovery, and it is difficult to say whether this pattern is cyclical or structural in nature. Interpreting the duration data is even more problematic, because they are affected by the selection of individuals who do not participate at all.

52. See, for example, Murphy and Topel (1987) and Juhn, Murphy, and Topel (1991).

53. These data were not directly affected by the redesign of the basic CPS questionnaire in 1994, although we cannot rule out that the redesign may have influenced individuals' answers to the supplement questions. 
Figure 15. Incidence and Duration of Labor Force Participation, 1975-2004

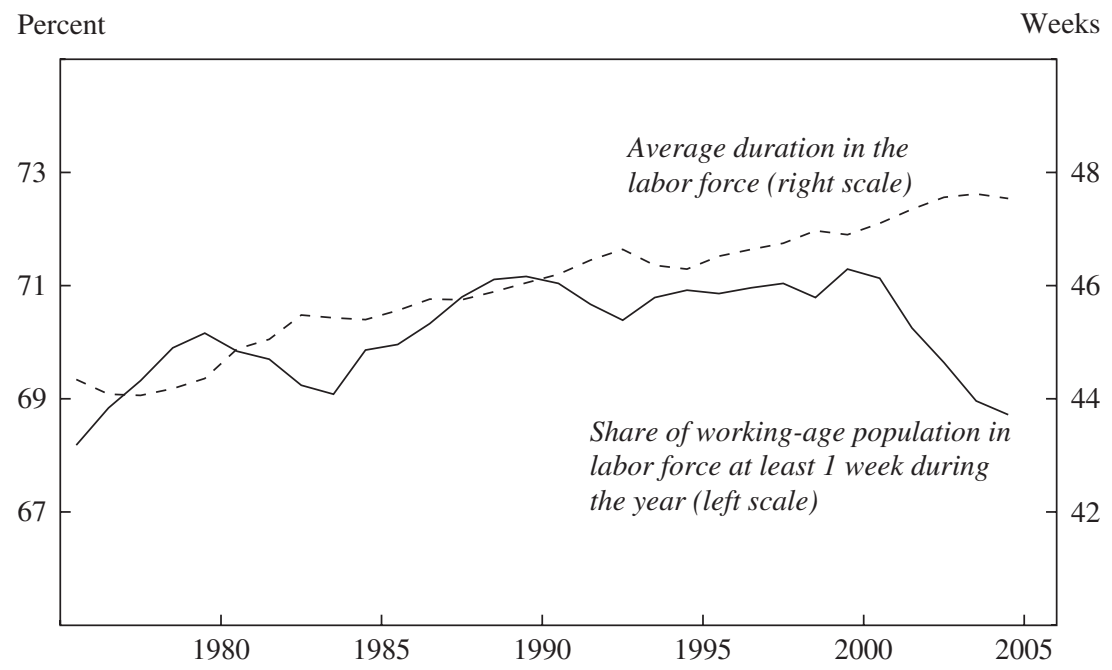

Source: Bureau of Labor Statistics.

\section{Implications for Potential Labor Input}

As we noted in the introduction, the underlying trend in the labor force participation rate is a key determinant of the potential supply of labor hours to the economy and thus has an important influence on potential output growth. Based on the estimates from our model, the downward trend in participation between 2000 and 2005 subtracted about 0.2 percentage point per year from growth in potential labor hours. By comparison, the rise in the aggregate participation rate between 1960 and 1995 contributed about 1/2 percentage point per year, on average, to labor input growth in that period.

Of course, from a growth accounting framework, changes in labor force participation represent only one component of the change in the total supply of hours. Two other aspects of the total supply of labor-the size of the working-age population and the average number of hours worked-also are important determinants of potential output. ${ }^{54}$

54. Changes in the natural rate of unemployment can also influence the potential supply of labor to the economy. Although we do not address that issue in this paper, the CBO assumes that the NAIRU has held steady at 5.2 percent since the mid-1990s. 
Figure 16. Average Weekly Hours, 1970-2005

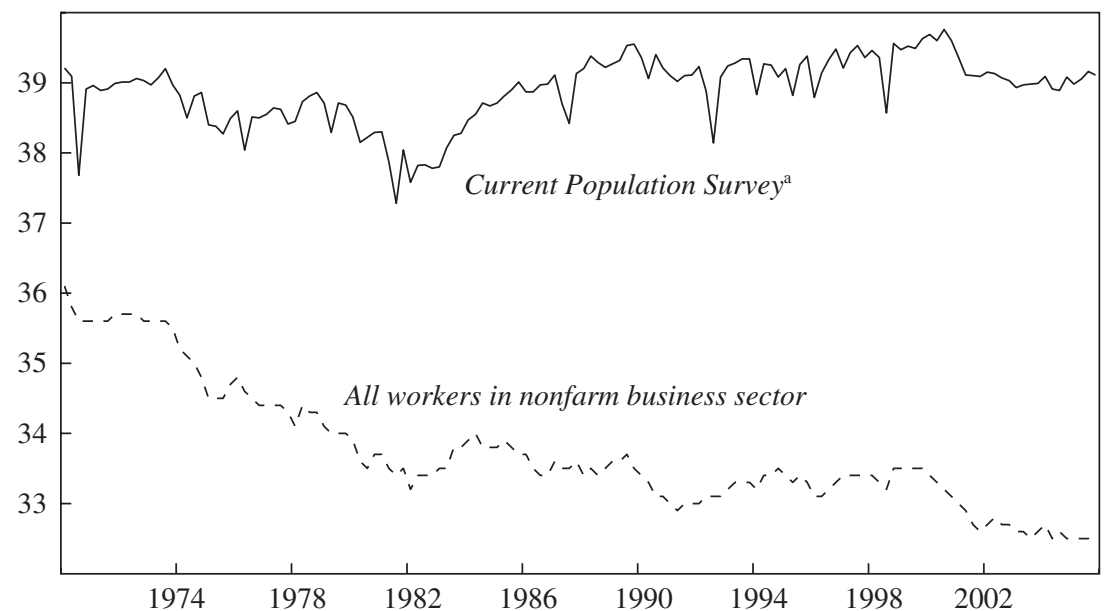

Source: Bureau of Labor Statistics.

a. Includes all workers in nonagricultural industries.

The working-age population has grown at a relatively steady pace of about 1.2 percent a year over the past decade or so. However, census projections point to a substantial but gradual slowing in this rate over the next decade, to about 0.9 percent a year by 2010 and to 0.8 percent a year by 2015. Of course, both current estimates of the population and projections of its growth are subject to considerable uncertainty. Indeed, when the 2000 decennial census population estimates were released, the count of the resident population was 6.8 million higher than the previous intercensal estimate. Net immigration is particularly difficult to estimate and project, and both the $\mathrm{CBO}$ and the Social Security Administration assume higher immigration flows than are incorporated into the census projections..$^{55}$

Figure 16 shows the average number of hours worked each week by individuals employed in the nonfarm business sector. Although this measure of the workweek is not the most widely recognized, we consider it to be the most relevant for purposes of estimating potential labor input because it includes hours of supervisory workers and the self-employed,

55. See the 2005 Old Age, Survivors, and Disability Insurance Trustees Report from the Social Security Administration. For more discussion of the relative merits of the Census Bureau population projections, see CBO (2004). 
Figure 17. Unweighted and Fixed-Weight Average Weekly Hours, 1991-2005

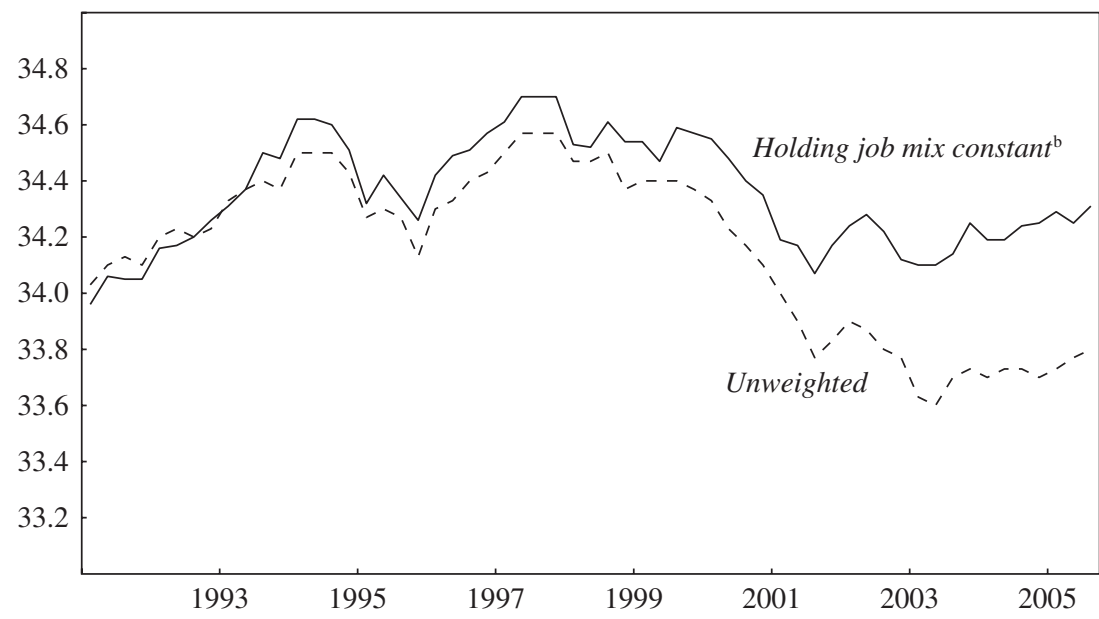

Source: Bureau of Labor Statistics, CES data.

a. Includes production or nonsupervisory workers.

b. The industrial composition of employment is held constant at January 1994 levels.

both of which are excluded from the more familiar workweek collected as part of the BLS Current Employment Statistics (CES) survey. ${ }^{56}$ As the figure shows, the nonfarm business sector workweek has trended downward over the past thirty years or so, perhaps with a slight lessening in that trend over the past decade.

One source, in an accounting sense at least, of this downward trend has been changes in the industrial composition of employment-most notably, the shift from manufacturing jobs, which were frequently full-time jobs and often included a substantial overtime component, to jobs in the service-producing sector. The influence of this change in industry composition on the workweek can be seen in figure 17, which plots the actual workweek from the CES against a constructed workweek that holds industry shares constant at their January 1994 levels. ${ }^{57}$ The gap between the two widened considerably during the 2001 recession, when manufacturing

56. Effectively, the BLS combines information from the CES survey on workweeks of production or nonsupervisory workers with information from the CPS on workweeks of supervisory workers and the self-employed. See Eldridge, Manser, and Otto (2004) for details.

57. We use the CES workweek for this exercise because of the availability of detailed data on industry-specific workweeks. 
employment fell especially sharply, and has remained wide ever since. Indeed, according to this measure, about three-quarters of the net decline in average hours between 2000 and 2005 was associated with changes in the industrial composition of employment.

Previous research also suggests that changes in laws regulating the operating hours of establishments (blue laws), as well as societal shifts toward eating out and all-hours shopping, have contributed to an increase in jobs with both shorter and nonstandard hours in recent decades. ${ }^{58}$ Changing demographics likely also influenced the average workweek in the 1970s and 1980s, although the effects were mixed. The increase in the population share of prime-age workers tended to increase the workweek,,$^{59}$ as did the growing desire for professional careers among prime-age women, whose workweeks rose over this period. On the other hand, a greater share of women among the employed would have put downward pressure on the workweek, because women work fewer hours, on average, than men.

Similarly, demographic changes probably have had little effect, on net, on the aggregate workweek over the past decade. ${ }^{60}$ In large part this reflects the age profile of average workweeks, which are relatively constant from age 25 to age 65 but considerably lower for youths and for workers older than 65 . For the post-2000 period the increase in the number of working older individuals has put downward pressure on the average workweek, but this effect has been largely offset by the declining number of working youths.

To empirically extract the trend in the workweek, we use a Kalman filter model that includes controls for the business cycle. That is, we assume that actual movements in the workweek follow the specification

$$
\begin{aligned}
h_{t} & =\alpha_{t}+\beta_{1} C y c_{t}+\varepsilon_{t} \\
\alpha_{t} & =\alpha_{t-1}+\gamma_{t} \\
\gamma_{t} & =\gamma_{t-1}+v_{t},
\end{aligned}
$$

where $\alpha$ and $\gamma$ are the unobserved trend components and the errors are

$$
\begin{aligned}
& \varepsilon_{t}=\rho \varepsilon_{t-1}+\eta_{t}, \quad \eta \sim \text { iid } \\
& v_{t} \sim N\left(0, \sigma_{v}^{2}\right) .
\end{aligned}
$$

58. Kirkland (2000).

59. Rones, Ilg, and Gardner (1997).

60. Demographic detail on average weekly hours is available only from the CPS. 
Figure 18. Actual and Trend Average Weekly Hours in the Nonfarm Business Sector, 1979-2005

Hours

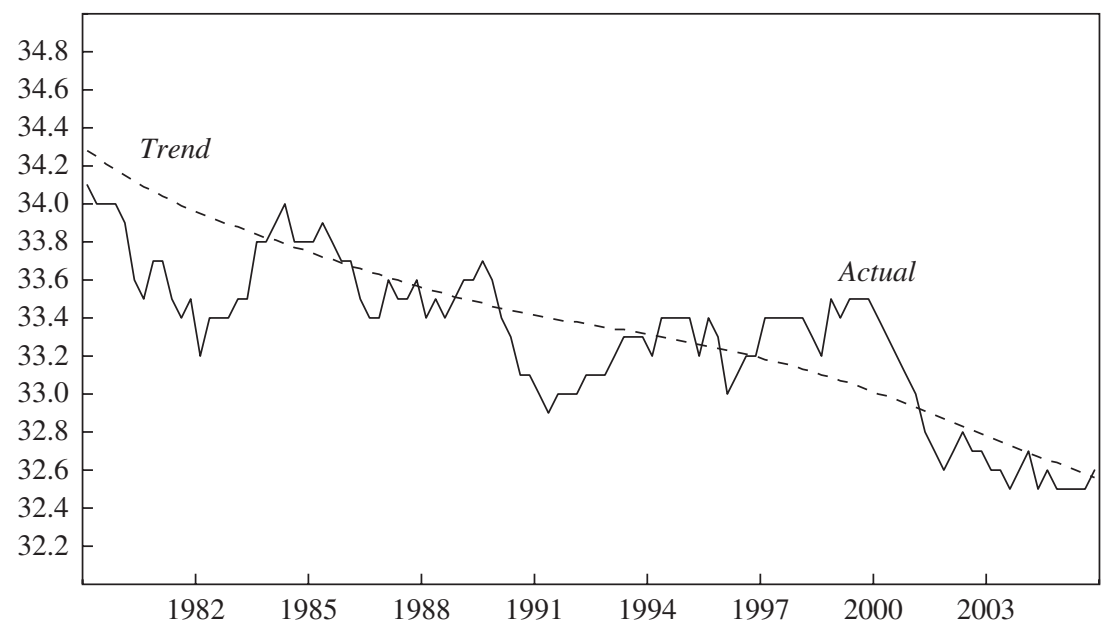

Source: Bureau of Labor Statistics and authors' calculations.

We estimate this trend-cycle decomposition on the workweek in the nonfarm business sector with quarterly data from 1970 to 2005 , using the unemployment rate to control for the business cycle and the first difference in the percentage change in real GDP to account for our expectation that the workweek responds more quickly than other inputs to abrupt changes in demand.

Interestingly, the picture looks quite similar to that for the labor force participation rate. As figure 18 shows, the model estimates that the trend workweek has fallen, on net, over the past five years, from about 33.0 hours in 2000 to 32.5 hours in 2005. In addition, the model views some of the decline in the workweek over the past five years as cyclical, with the workweek rising above its trend in the late 1990s, falling below trend in 2001 and 2002, and subsequently moving back toward trend by 2005 . The model's estimate of the trend decline between 2000 and 2005 subtracts about 0.2 percentage point a year from the growth in potential hours over that period.

An important caveat to this analysis is that we rely on the nonfarm business workweek, which incorporates payroll data for production or nonsupervisory workers from the CES survey. An alternative measure can be constructed using data solely from the CPS, which includes self- 
reported workweeks for all classes of workers. As also shown in figure 16, average weekly hours in the CPS are significantly higher than the BLS figure for the nonfarm business sector. In part, this difference stems from a difference in definitions, with the CPS including hours worked at all jobs. But even adjusting for this and other differences in their construct, the CPS workweek exceeds the measured nonfarm business sector workweek. ${ }^{61}$

In addition, the two measures of the workweek seem to exhibit different longer-run trends. In particular, whereas the nonfarm business workweek has shown a gradual downward trend over the past thirty years, the CPS workweek has held steady, or even increased a bit on net, over that period. That said, both the CPS and NFB workweeks fell sharply during the 2001 recession and have remained at this lower level ever since. And, on net, both workweeks currently stand about $1 / 2$ hour lower than their level at the most recent business cycle peak.

\section{Comparisons with Other Projections}

Several government agencies regularly develop their own projections of labor force growth, and it is informative to compare the implications from our model of labor force participation with these other forecasts. Table 6 compares the labor force projections from our model with those constructed by the CBO, the BLS, and the Social Security Administration (SSA). ${ }^{62}$ Notably, the decline in the participation rate projected by our model over the next ten years is more than twice that projected by any of these agencies, although all of them do anticipate a noticeable downtrend. Similarly, the projections for the level of the labor force that we obtain by combining the model's participation rate forecast with the Census' population projections show trend labor force growth slowing to roughly 0.3 percent a year between 2010 and 2015. By contrast, both the CBO and the SSA project that labor force growth will slow to about $1 / 2$ percent a year by 2015 , and the BLS projections show labor force growth slowing to $3 / 4$ percent a year in ten years.

61. See Aaronson and Figura (2005).

62. We thank David Brauer of the CBO, Karen Smith of the Social Security Administration, and Mitra Toossi of the BLS for providing us with the agency projections shown in the table. The projections are not strictly comparable across agencies because of conceptual differences in their constructs. For example, the CBO and the BLS project participation rates consistent with an economy at full employment, whereas the Social Security Administration projects actual participation rates. 
Table 6. Comparisons of Projected Trend Labor Force Participation Rates and Trend Labor Force Growth

\begin{tabular}{ccccc}
\hline Year & $\begin{array}{c}\text { Authors } \\
\text { model }\end{array}$ & $\begin{array}{c}\text { Congressional } \\
\text { Budget Office }\end{array}$ & $\begin{array}{c}\text { Bureau of } \\
\text { Labor Statistics }\end{array}$ & $\begin{array}{c}\text { Social Security } \\
\text { Administration }\end{array}$ \\
\hline \multicolumn{4}{c}{ Labor force participation rate (percent) } \\
2004 & 66.4 & 66.5 & n.a. & \\
2005 & 66.1 & 66.5 & 66.0 & 66.2 \\
2006 & 65.8 & 66.5 & 66.0 & 66.3 \\
2007 & 65.6 & 66.5 & 65.9 & 66.5 \\
2008 & 65.2 & 66.4 & 65.9 & 66.5 \\
2009 & 64.7 & 66.3 & 65.9 & 66.5 \\
2010 & 64.4 & 66.2 & 65.8 & 66.4 \\
2011 & 64.0 & 65.9 & 65.8 & 66.3 \\
2012 & 63.7 & 65.7 & 65.7 & 66.2 \\
2013 & 63.3 & 65.4 & 65.6 & 66.0 \\
2014 & 62.9 & 65.2 & 65.6 & 65.8 \\
2015 & 62.5 & 65.0 & n.a. & 65.5 \\
& & & & \\
2004 & 0.8 & Labor force growth (percent a year) & \\
2005 & 0.8 & 1.2 & n.a. & 0.6 \\
2006 & 0.8 & 1.2 & n.a. & 1.3 \\
2007 & 0.6 & 1.2 & 1.2 & 1.5 \\
2008 & 0.4 & 1.1 & 1.1 & 1.1 \\
2009 & 0.4 & 1.0 & 1.0 & 1.1 \\
2010 & 0.4 & 0.9 & 1.0 & 0.9 \\
2011 & 0.4 & 0.8 & 0.9 & 0.8 \\
2012 & 0.3 & 0.5 & 0.9 & 0.8 \\
2013 & 0.2 & 0.6 & 0.8 & 0.7 \\
2014 & 0.2 & 0.6 & 0.7 & 0.5 \\
2015 & 0.2 & 0.5 & n.a. & 0.5 \\
\hline
\end{tabular}

Source: Authors' calculations and projections from the indicated agencies. n.a., not available.

\section{Conclusion}

This paper has reviewed an array of evidence on the sources of the persistent decline in the aggregate labor force participation rate since 2000. In broad terms this evidence suggests that the business cycle initially played an important role in the decline, contributing to the sharp run-up in labor force participation in the late 1990s and to the subsequent drop-off during the 2001 recession and the ensuing period of weak labor market performance. However, the evidence also highlights a number of more structural 
factors that have contributed to a potentially longer-lasting downtrend in labor force participation.

To assess the relative importance of these influences, we developed and estimated a model that attempts to coherently combine what we observe about labor force attachment for particular age-sex groups with what we know about demographic changes in the population. Although the model we use is clearly of a reduced form, this basic specification appears to provide a valuable structure for estimating and interpreting aggregate developments in labor force participation. Using the model, we estimated that most of the decline in participation between 2000 and 2003 reflected cyclical influences. In 2004 and 2005, however, the participation rate moved toward its (declining) longer-run trend, ending in late 2005 close to trend.

These results have two important implications for the assessment of current macroeconomic conditions. First, the fact that the model finds that the current low rate of labor force participation is close to its trend rate suggests that it is not artificially masking the extent of unemployment (or at least no more than usual); rather, the unemployment rate is providing a reasonably accurate picture of the state of the labor market. Of course, that is not to say that the participation rate might not move above its trend level with a further strengthening in labor demand, as apparently happened in the late 1990s. But the model would view such an increase as cyclical rather than as a sustainable increase in the participation rate.

Second, our estimate of a downward trend in the participation rate has implications for the longer-run growth potential of the U.S. economy. In particular, the model results point to a continuation of this declining trend, which, coupled with the slowdown in population growth projected by the Census Bureau and a possible further downtrend in average weekly hours, would depress the increments to aggregate labor supply over the coming decade. Absent a pickup in the underlying pace of productivity growth, such a slowing in labor input would, in turn, reduce the sustainable rate of economic growth relative to the robust pace experienced over the past decade or so. ${ }^{63}$

63. Aaronson and Sullivan (2001) argue that demographic changes may also contribute to slower potential output growth by reducing slightly the contribution to growth from changes in the average quality of the workforce. 
Although our analysis is incomplete in a number of ways, we would emphasize, in particular, three important caveats to this interpretation of recent developments in labor force participation. First, our cohort-based model of participation generally had difficulty capturing the extent of the decline in the labor force attachment of teenagers. If the unexplained shortfall in participation for this group reflects a downward shift in the age profile for teenagers rather than a temporary deviation, the participation rate trend may be lower than our model suggests. Alternatively, to the extent that the decline in the labor force participation rate of youths results from these cohorts spending more time in school, this additional investment in human capital may increase labor market attachment for such individuals in their prime working years, given the higher wages and greater opportunities associated with more education.

Second, the model projections may overlook potential factors that determine labor force participation, including some that may respond endogenously to the downward pressures on participation themselves. In particular, we do not consider how policy changes might alter the baseline path of participation projected by the model. This limitation of our forecasting apparatus may be particularly relevant for projections of labor force attachment among older individuals - another group for which the recent performance of the model has been problematic. This age group is large and growing, and a steeper uptrend in the participation rates of the elderly associated with, for example, movements in relative wages, changes in the parameters of the Social Security or Medicare programs, or concerns about the availability of pension income and retiree health benefits could contribute significantly to movements in the aggregate participation rate in the future. Moreover, longevity and health are particularly difficult variables to forecast, and positive innovations in those determinants of participation could be potent as well. As noted above, however, any increase in labor force participation rates for the older age groups would have to be quite sharp to offset the downward pressures from demographics more broadly.

Finally, rates of immigration that differ from those assumed by the Census Bureau could have important implications for our projected trend in labor supply. Most directly, increased immigration would lead to faster population growth. However, it would also be expected to provide a persistent boost to the aggregate labor force participation rate, both because 
the immigrant population tends to be concentrated in age groups with relatively high participation rates and because immigrants tend to have greater labor force attachment than native-born individuals of the same age.

In the end, however, it seems unlikely that these influences will be enough to offset the significant downward pressures associated with the aging of the baby-boom generation and the other factors that we highlight in this paper. Thus, although the exact magnitude of the projected decline in the labor force participation rate is subject to considerable uncertainty, the future direction of the trends in the participation rate and labor force growth seems less open to question. 


\section{Comments and Discussion}

Gary Burtless: The recovery from the 2001 recession pushed the unemployment rate down to a level that would have seemed low by the standards of the two decades that ended in 1995. By March 2006 the civilian unemployment rate was just 4.7 percent. GDP growth between 2001 and 2005 was moderate, and improvements in after-tax incomes fueled a substantial rise in personal consumption.

Two aspects of the recovery sparked concern, however. First, employment growth was exceptionally slow in comparison with that in all previous postwar recoveries. Fifty-eight months after the business cycle peak in March 2001, payroll employment was only 1.8 percent higher than it had been at the peak. In the average previous postwar expansion lasting at least fifty-eight months, payroll employment increased more than 9 percent. Even in the weakest previous postwar expansion, employment grew 6.8 percent. $^{1}$

Second, five years into the expansion there was little evidence of recovery in the before-tax incomes of median- and low-income households. Real wages and compensation earned by people holding jobs either improved or declined only slightly, depending on the wage benchmark used. But because households on average had fewer earners or had breadwinners who earned paychecks for fewer weeks in a year, real household income for families with average or below-average income remained lower in 2005 than it had been at the peak of the last expansion. Even though gross income per person was higher in 2005 than it had been in 2000, a large fraction of the before- and after-tax income gains were captured by a small fraction of households.

1. According to data from the Bureau of Labor Statistics and calculations by the Economic Policy Institute (2006). 
This paper by Stephanie Aaronson and her coauthors assesses one possible explanation for some of the peculiarities of the recent recovery. One reason that employment gains may have been modest in an environment of low and declining unemployment is that the labor force participation rate has been unusually depressed. The BLS estimates that between 2000 and 2005 the overall participation rate fell 1.0 percentage point. The rate among males 16 and older fell 1.5 percentage points, and the rate among females fell 0.7 percentage point. With declining participation rates, it is conceivable that the unemployment rate did not provide a reliable signal of job market distress. If potential job seekers dropped out the labor force instead of looking for jobs, both the unemployment rate and the labor force participation rate would have been lower than in previous economic expansions. For example, if all of the decline in labor force participants were added to the ranks of unemployed job seekers, the unemployment rate in 2005 would have been 6.5 percent instead of 5.1 percent. Of course, it is very unlikely that all of the drop in participation between 2000 and 2005 was traceable to job seekers' distress over their labor market prospects. But if dropping out of the labor force was exceptionally common after 2001, it provides a partial explanation for the combination of slow employment growth and a low unemployment rate.

Among the questions posed by the authors are these:

- How much of the 2000-05 decline in labor force participation is explained by predictable demographic factors, such as the aging of the population?

- How much is explained by normal cyclical factors?

- How much can be explained by an examination of trend influences on age-specific participation rates, such as lower fertility, changing retirement incentives, and a bigger payoff to staying in school?

- How much of the decline in participation remains unexplained?

The authors' summary of their analytical findings seems to me sound. Most of the drop in participation between 2000 and 2003 was due to normal cyclical factors, and the partial recovery of participation since 2003 brings it close to the trend line that one would expect given the shifting age composition of the population. The long-term trend in participation is downward, as the large baby-boom generation moves toward retirement and begins its withdrawal from the workforce. In early 2006 the overall participation rate was about where one would expect if age-specific participation rates had remained unchanged after the mid-1990s. What changed 
between 1995 and 2005 were the weights of the different age-sex groups in the population. As the authors' figure 3 shows, groups with low participation rates grew in importance, while groups with high participation rates shrank.

The authors' apparatus for distinguishing between trend effects and cyclical effects on the participation rate is rather complicated, but their basic conclusions can be checked fairly easily. Start with the simple but crude assumption that labor market tightness is reliably indicated by the reported unemployment rate of people who have participation rates that are relatively insensitive to the business cycle. For simplicity, assume that this population consists of men and women between 25 and 54 years old. In 2005 the unemployment rate of this group was 4.1 percent. The last time the unemployment rate of 25- to 54-year-olds was at approximately this level was in 1996-97, when the jobless rate also averaged 4.1 percent. At that time the participation rate for all persons aged 16 and over was 66.9 percent, whereas in 2005 it was 66.0 percent, or 0.9 percentage point lower. According to my back-of-the-envelope calculations, if nothing changed between 1996-97 except the age and sex composition of the population 16 and older, the overall participation rate would have fallen almost 0.6 percentage point, about two-thirds of the decline actually observed. In other words, roughly two-thirds of the decline in participation rates between 1996-97 and 2005 can be explained by demography alone. If there was an unexpected drop in the participation rate between those years, it was at most about a third of a percentage point.

The authors account for most of this small mystery by including other trend variables in their explanatory model. Contrary to the assumption of the previous paragraph, age- and sex-specific participation rates have not remained constant over time. Even though demographic changes-that is, shifting population weights - apparently explain much of the ten-year trend in overall participation, participation rates within major demographic groups have moved in offsetting directions. In some age-sex groups the changes have been nontrivial, a fact that is obvious in the authors' table 3 .

My figure 1 shows the basic pattern of participation rate changes by five-year age group for both males and females. The top panel shows changes between 1996-97 and 2000, and the bottom panel shows changes between the business cycle peak in 2000 and 2005. Focusing first on the bottom panel, one sees immediately that the big changes in participation rates have been concentrated at the ends of the age spectrum. The patterns 
Figure 1. Changes in Labor Force Participation Rates by Age Group and Sex, 1996-97 to 2005

1996-97 to 2000

Percentage points

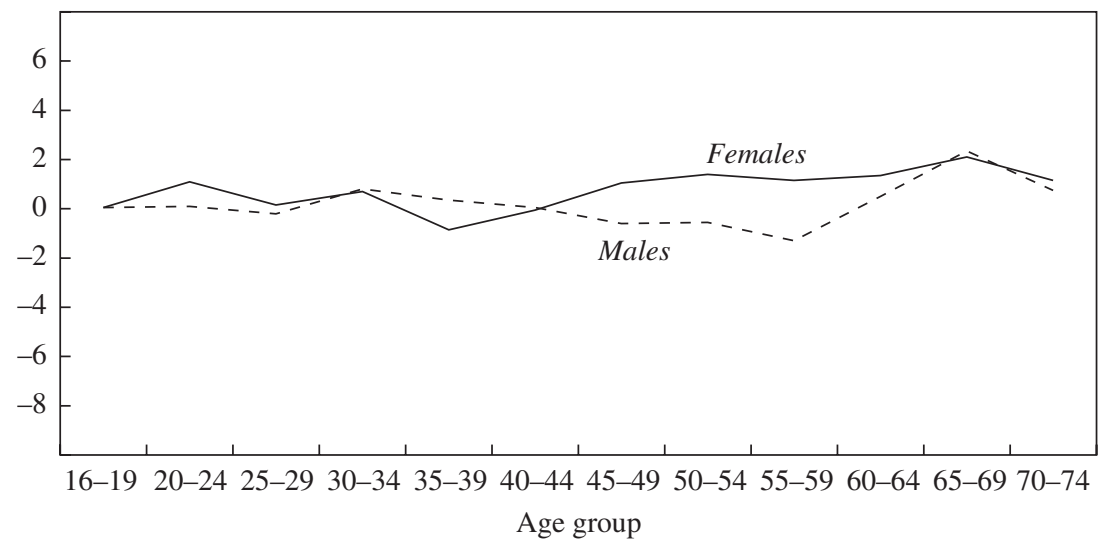

2000 to 2005

Percentage points

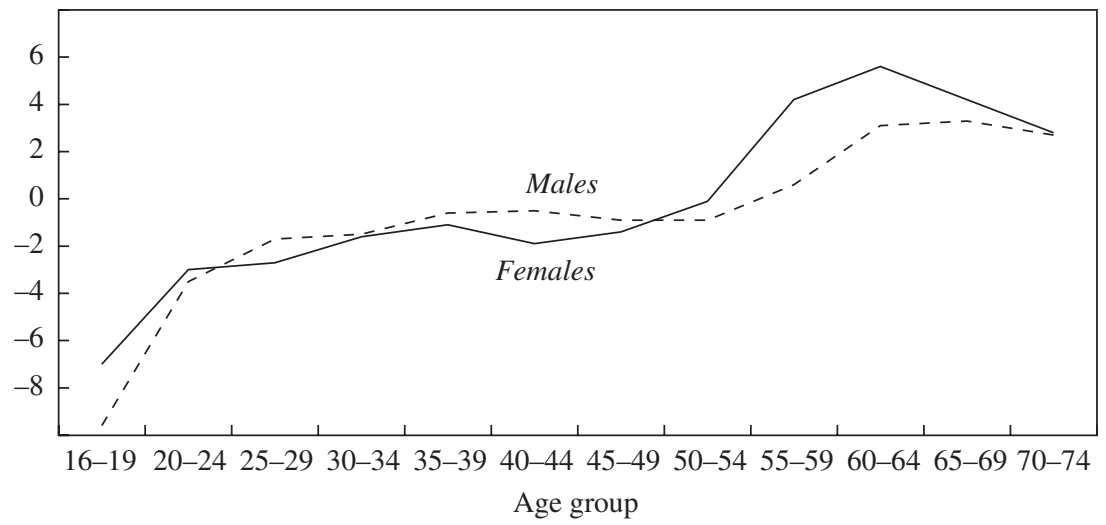

Source: Bureau of Labor Statistics data.

for men and women are broadly similar: young people experienced big reductions in participation; older people experienced noticeable increases. To a large extent, the recent increase in older Americans' participation rate represents a continuation of a trend that was well under way in the 1990s. Note in the top panel of figure 1 that participation rates for women 
past age 45 and men past age 60 were rising in the late 1990s. Among men and women 55 and older, this trend did not slow down in the postrecession period. In fact, it probably accelerated. At the other end of the age scale, the fall in participation rates among young adults was not foreshadowed in the prerecession era: participation rates among the young were stable during the second half of the 1990s.

Most of the big changes in the participation rate between 1996-97 and 2005 took place in the 2001 recession and in the subsequent expansion. The changes that occurred between 1996-97 and 2000 were comparatively modest. Although the unemployment rate was virtually the same in 1996-97 as in 2005, participation among young adults was sharply lower in the later year, and participation among those past age 55 or 60 was sharply higher.

The authors' empirical model accounts for these developments through some combination of birth-year cohort effects and the effects of changes in returns to schooling, life expectancy, disability and retirement rules, and marriage and fertility changes. The crucial question is whether their parameter estimates can be taken seriously - that is, whether they can be used to make a reliable forecast of future participation rates. The question is important, because both the government and private companies use such forecasts to predict potential GDP growth. Government agencies also use the forecasts to make predictions of future tax revenue as well as future benefit claims under large public programs such as Social Security. The Social Security actuaries are unlikely to abandon their current forecasting method for one based on the model estimated here. They have invested heavily over many years in developing methods for making and adjusting their labor force forecasts, and they will not discard those methods without powerful evidence that a new method can produce more reliable predictions. Other potential users may find the authors' forecasts more useful.

An issue that the study leaves unresolved is how to account for the observed rise in participation at older ages and the sharp decline in participation among the young. Turning first to the young, the authors' model includes returns to schooling and rates of eventual college completion. It certainly makes sense that young people would invest more in schooling if they thought the payoffs from this investment were increasing. Since people in school have less time to work, their labor force participation rates are below those of people the same age who do not attend school. As the authors show, however, participation rates have fallen among the young 
Figure 2. Years Enrolled in School from Age 16 to 24 by Sex, 1975-2004

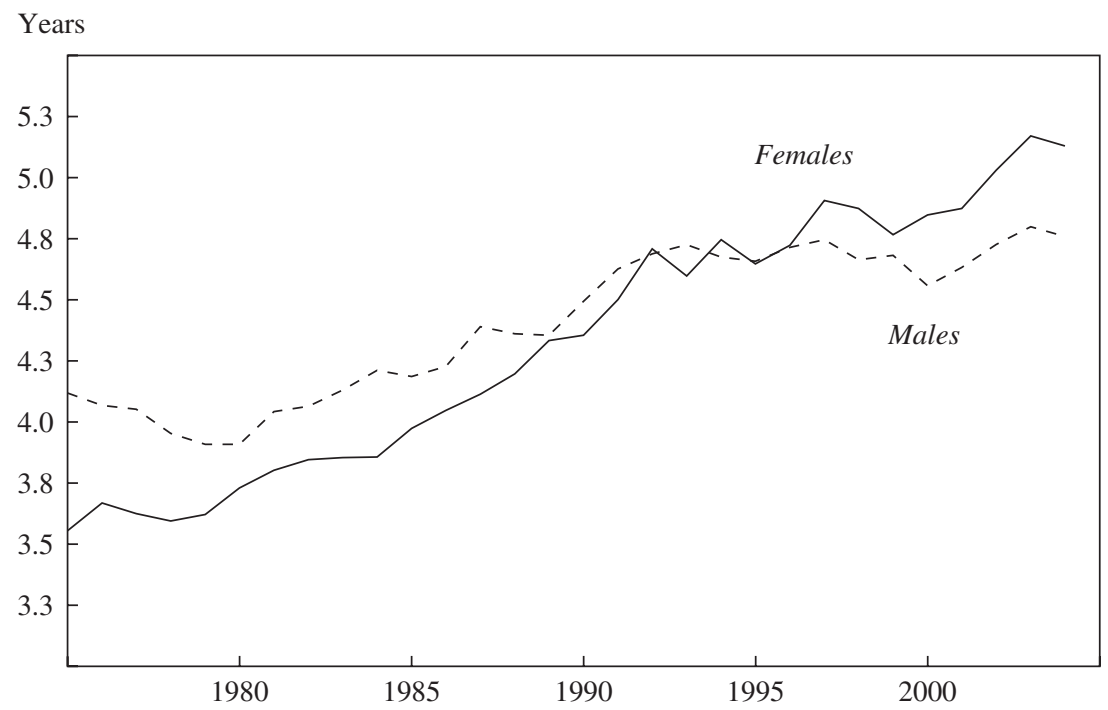

Source: Census Bureau data and author's calculations.

a. Expected years of schooling is calculated assuming a person has an enrollment rate at each age from 16 through 24 equal to the Census Bureau's estimate of the enrollment rate at that age in the indicated year.

whether or not they attend school. The recent increase in the percentage of young people enrolled in school has had a modest effect on the participation rate of the young, but this is swamped by the effects of lower participation among young adults both in school and out of school.

My reading of the evidence is that lifetime returns from schooling have increased substantially since the mid-1970s. The big increase in college pay premiums occurred between the mid-1970s and the mid-1990s, but it followed a lengthy period from the late 1940s to the mid-1970s during which the premium was constant or slightly declining. My figure 2 shows trends in years of schooling over the postwar era for both men and women. Although average years of schooling has risen in successive birth cohorts, it is not easy to see a simple connection between the trend in pay premiums just described and the pattern of change in years of enrollment. What is particularly puzzling is the contrasting patterns for men and women. Years of schooling has risen steadily for women, but recent schooling gains among men have been much smaller and more erratic. This contrast is especially puzzling because the extra payoff to schooling in the past two decades has 
been about as large for men as for women. Perhaps young women are more farsighted or apply a lower discount rate to the income gains they will achieve as a result of attending high school or college. Rising returns to schooling almost certainly boosted school enrollment rates and reduced young people's participation rates in the three decades after 1975. But recent changes in the returns to schooling do not offer a plausible explanation for the big drop in young people's participation rates that took place in the half decade after 2000.

The steady rise in participation rates among people older than 55 or 60 has been obvious to specialists for about two decades. In the case of older men, the participation gains occurred after a century-long period in which men tended to withdraw from the labor force at younger and younger ages. ${ }^{2}$ Labor and public finance economists who study retirement and pension acceptance behavior point to five main explanations for rising participation in this group.

The first explanation is noted in this paper. Women who are now reaching their late fifties and sixties have had much higher employment rates over their careers than did women born in earlier decades. If their participation rates at age 45 were 10 percentage points higher than rates at that age among women born twenty years earlier, their rates will probably be higher at ages 55 and 65 as well, assuming the retirement patterns of the two groups are similar. This is the cohort effect that the paper identifies.

The next two explanations focus on work incentives built into the Social Security old-age benefit program. A crucial point is that Social Security is no longer becoming more generous for successive generations of retirees. Compared with the three decades before 1980, when the generosity of retirement benefits grew considerably, this represents a major change. A second crucial change is that the Social Security formula is now more ageneutral than it was in the past. Before the 1980s, workers who postponed claiming a pension until after age 62 or 65 lost lifetime pension wealth as a result of the delay. Nowadays, the average worker can continue to work after the age of 62 or 65 without any loss of pension wealth. Before the 1980s, many workers had to give up their jobs if they wanted to claim a Social Security pension. But in a sequence of reforms beginning in the 1970s, the work penalty was first reduced and then eliminated. Workers

2. Burtless and Quinn (2001). 
can now earn substantial wages and receive a Social Security pension at the same time. Those who continue to work past the benefit-claiming age suffer no penalty in terms of lower lifetime Social Security benefits.

A fourth explanation for delayed retirement is connected to changes in the private pension system. The authors mention the shift from definedbenefit pensions toward defined-contribution pensions. Between 1981 and 2003 the fraction of workers who were exclusively covered by a definedcontribution plan rose from less than 20 percent to 60 percent of all pensioncovered workers. ${ }^{3}$ The authors focus on the total pension wealth that workers have accumulated in their plans. This factor is undoubtedly important, although the authors could not reliably detect any effect of the changed accumulation on labor force participation rates. Pension wealth accumulation may be less important than the differences in retirement incentives provided by the two kinds of pension plan, however. A defined-benefit pension usually penalizes workers who delay retirement past the plan's early or normal pension-claiming age. In many such plans, it is advantageous for workers to quit their jobs and accept a pension as soon as they reach the critical pension-claiming age. Workers may hold no other job after they decide to claim a pension from their main lifetime job. In contrast, a defined-contribution plan is usually age-neutral in its retirement incentives. So long as a worker remains employed under a plan, regardless of age, the employer, the worker, or both can continue to make contributions to the plan. The contributions usually remain the same percentage of the worker's money wage, regardless of the worker's age. Because defined-contribution pensions provide little incentive to retire at one age rather than another, farsighted workers might choose to remain in their career jobs in order to continue building up their retirement wealth.

A final explanation for higher participation rates at older ages is linked to changes in the nation's employer-provided health insurance system. The percentage of current workers who are offered insurance under an employersponsored health plan is shrinking very slowly, but the percentage of workers who will be covered by an employer-sponsored health plan after they retire has shrunk dramatically. The Kaiser Family Foundation and the Health Research and Educational Trust regularly survey firms with 200 or more employees about their health insurance benefits. Between 1988 and 2005 the percentage of these firms offering retiree health insurance to their

3. Buessing and Soto (2006). 
active workers fell by approximately half. ${ }^{4}$ Consider the retirement incentives faced by a 61-year-old worker who is employed by a firm that offers health insurance to its active workers but does not provide health insurance coverage to new retirees. If the worker leaves her job, she loses her health insurance. She will not qualify for Medicare until she turns 65 . Under these circumstances it may make sense to stick with the job until age 65 in order to maintain coverage in a group health plan. The very large decline in the percentage of workers covered by retiree health plans - and the increased importance of group health insurance coverage for people who are between 55 and 64-mean that a growing percentage of the older workforce may be staying in jobs to preserve their health coverage.

Lawrence F. Katz: Stephanie Aaronson and her coauthors have produced a thoughtful, comprehensive, and insightful assessment of recent trends in labor force participation both overall and by demographic group. They focus on understanding the decline in aggregate labor force participation since its all-time peak in early 2000. From 67.3 percent of the working-age population then, the participation rate fell to 65.8 percent in early 2005 before rebounding slightly to around 66.1 percent in early 2006. Even with the rebound, this is the largest decline in the labor force participation rate in over forty years.

The authors do a very good job of showing that most of the initial decline in labor force participation, from 2000 to 2003, reflected cyclical factors: following the unusually strong labor market of the late 1990s, the 2001 recession had a substantial impact on the labor market, from which it has recovered only weakly. But the authors also convincingly demonstrate that these cyclical developments masked important long-term structural factors that are now operating to impart a downward trend in the participation rate. The authors conclude that labor force participation is now back at its trend level and that low participation today is consistent with a labor market operating close to its potential (that is, near the natural rate of unemployment).

The lower labor force participation rate today than in 2000 (and even than in the mid-1990s) represents a distinct contrast to the pattern of rapidly rising labor force participation from the early 1960s to the early 1990s. The authors' analysis shows that two key structural factors largely

4. Kaiser Family Foundation (2005, chart 13). 
account for these contrasting trends. The first involves changes in the age composition of the working-age population: the aging of the baby-boom cohorts is now reducing rather than increasing the share of the population in the peak working ages (25-44 years) and increasing the share aged 45-64 years. The second involves changes in the labor force participation of female workers: the engine behind the rising aggregate participation rate from the 1960s to the 1990s was rapidly rising female participation, driven by large between-cohort increases in labor force commitment. The authors present much evidence suggesting that this process of progressively higher female participation with each successive birth cohort ended over the last decade or so.

The authors document two other salient recent developments in labor force participation: a particularly sharp decline in teen participation in the last recession and the current recovery, and rising participation by men and women 55 years and older since 2000, in the face of falling participation by prime-age individuals. One other unusual feature of recent labor market trends, which the authors do not emphasize, is that labor force participation among those 25 and older who did not finish high school has increased sharply, from 40.0 percent in 1995 to 45.5 percent in 2005 (and continued to increase even after 2001), even as participation has declined (particularly since 2000) for the more educated groups.

Although I could raise a few quibbles about the authors' cohort-based labor force participation model (for example, the differences in their treatment of children for women in their twenties compared with women in their thirties, and their modeling of the impact of disability benefits), I find their approach largely sensible and their conclusions rather compelling. Instead, therefore, I will discuss some tangential issues related to labor force participation trends and speculate on the interpretation of some of the authors' findings.

The role of rising disability rolls. Another possible factor in the recent slowdown and decline of the labor force participation rate is the tremendous rise in the disability rolls of the last fifteen years, especially in the weak labor markets of the early 1990s and the 2001 recession. David Autor and Mark Duggan document that the share of adults aged 25-64 receiving Social Security Disability Insurance (SSDI) benefits increased from 2.4 percent in 1990 to 3.4 percent in 2000 and 4.1 percent in $2005 .{ }^{1}$

1. Autor and Duggan (2005). 
The present authors consider and largely dismiss any significant impact of SSDI. I would place a bit more emphasis on this factor.

Autor and Duggan present some striking evidence of an increase in the responsiveness of SSDI application rates to labor market cyclical conditions over the past two decades, as well as a large rise in the number of individuals of peak working age (30-54) getting SSDI benefits. ${ }^{2}$ A substantial number of individuals with "marginal" (but real) disabling medical conditions who have tended to stay in the workforce in the past now leave the labor force permanently and join the disability rolls during recessions and weak labor market recoveries. This pattern creates a downward hysteresis effect in labor force participation, with each cyclical downturn permanently increasing the share of the potential workforce receiving SSDI. This rise in the SSDI rolls reflects a liberalization of screening practices since the early 1990s and the fact that disability benefits are related to past earnings, so that the disability insurance replacement rate has risen as real wages have declined for many less-educated and displaced workers. I speculate that the failure of Congress to extend unemployment insurance benefits during the weak labor market of 2001-03 reinforced this process by encouraging job losers with some health problems who had exhausted their unemployment benefits to abandon their labor force attachment and try to qualify for SSDI. The cracks in the nation's health insurance system for job losers and low-wage workers further make SSDI, which gives recipients access to Medicare benefits, an attractive health insurer of last resort for those who are able to work but have real medical problems.

The recent reform of SSDI (the Ticket-to-Work program), intended to encourage recipients to work, has had little implementation, almost no takeup, and no impact. ${ }^{3}$ Meanwhile the rise in SSDI is a fiscal crisis in the making (SSDI was already a $\$ 78$ billion program by 2004), and given that little can be done to encourage exit from the program, the key is to discourage entry by creating better labor market and health insurance options for those on the margin of applying for SSDI. The aging of the baby-boomers means that the growth of SSDI is likely to be an even larger issue in the coming decade. One possible major reform would make the disability insurance system more like the Department of Veterans Affairs' Disability Compensation program; that program provides a graduated disability scale in which

2. Autor and Duggan (2003, forthcoming).

3. Autor and Duggan (forthcoming). 
benefits are not intended to fully replace labor market earnings and are not conditioned on labor force nonparticipation.

Participation trends of certain subgroups. Several points are worth noting regarding trends in labor force participation among some of the subgroups of the working-age population. First, the authors emphasize the dramatic decline in youth labor force participation since 2000 and find it difficult to fully capture this phenomenon in their model. A key issue in assessing the decline in youth employment is the extent to which it is leaving young people disconnected from both the labor market and school. The authors find a rise in youth enrollment rates and declines in labor force participation both for enrollees and nonenrollees. This raises the question of whether the share of youth who are idle (neither working nor in school) has risen in recent years. My tabulations from the Current Population Survey Outgoing Rotation groups indicate that the idleness rate for persons aged 16-19 did not rise with the large decline in employment for this group since 2000 . The teen idleness rate actually declined in the 1990s' boom, from 14.6 percent in 1995 to 12.3 percent in 2000, and it remained at 12.4 percent in 2005 .

Second, the most important factor in the much slower growth (and then decline) in aggregate labor force participation since 1990, relative to the rapid growth of the 1960s to the 1980s, has been the cessation of crosscohort growth in adult female labor force participation. Of course, the rate of increase in female labor force participation from the 1960s to the 1980s could not be sustained as women approached the male level of participation. But I think it remains an open question whether the growth in female labor force participation rates has truly ended. Claudia Goldin makes the point that the decline over the last decade in participation among women aged 35-39 is not that surprising, given the rise in age of first marriage and an increase of the share of women in this age group (especially college graduates) with young children. ${ }^{4}$ But the decline in participation for women in their late twenties remains puzzling given their rising education levels, lower marriage rates, and lower probability of having young children than for previous cohorts. This raises the issue of whether the labor market may still be cyclically weak today for young, well-educated workers. Furthermore, the life-cycle pattern of female labor force participa-

4. Goldin (2006). 
tion appears to be changing. The increasing average delay of marriage and childbearing means that many women leaving the workforce in their thirties may be back again when their children are older. Thus a new surge in the labor force participation rate for women 45 and older may be on the horizon, one that would not have been predicted by the historical lifecycle patterns of female labor force activity used in the authors' model.

Third, another puzzling aspect of recent labor market performance has been changes in labor force participation (and employment) rates by education group. The behavior of less educated workers has typically been more cyclical than that of other groups: their participation has declined the most during downturns. But among workers 25 years and older, in the standard BLS published tabulations, one finds that the participation rate has risen sharply since 1995 for dropouts (those who did not finish high school); their participation, in fact, continued rising in the downturn and slow labor market recovery of 2001-05. Meanwhile the participation rate has fallen for persons with at least a high school diploma, and the decline has been the largest for the college-educated. From 2000 to 2005 the participation rate of dropouts increased from 43.4 percent to 45.5 percent, while it declined for those with at least a high school diploma from 71.9 percent to 70.8 percent. Welfare reform played some role in the late 1990s for dropout women, but the same pattern is seen for dropout men. Some have speculated that the strong construction and housing boom of recent years has contributed to growth in labor demand for less educated workers.

It turns out that the rise in the labor force participation rate for dropouts since 2000 is an immigrant-driven phenomenon. The participation rate of U.S.-born dropouts has not increased: it was 37.6 percent in 2000 and 37.6 percent in 2005 . Immigration has driven the increase in dropout participation both through a composition effect (the immigrant share of dropouts is rising, and, among dropouts, immigrants have higher participation rates than natives) and through rising participation among immigrants. The immigrant share of dropouts (again those aged 25 and older) increased from 21 percent in 1995 to 27 percent in 2000 to 33 percent in 2005, and the participation rate among dropout immigrants rose from 59.1 percent in 2000 to 61.2 percent in 2005. Adult U.S.-born dropouts have done better than expected in terms of employment in the recent economic cycle, but the rising immigrant share is a significant factor. Thus future immigration trends not only are important for the size of the U.S. adult population but may also be crucial for forecasting participation rates. 
Is the labor market operating at potential? The authors conclude that the labor market by 2005 (and certainly by early 2006) was back to operating at "potential." This seems to be the general consensus of much macroeconomic modeling and is consistent with the growth in the BLS productivity program's comprehensive measure of real compensation per hour, which, for 2005, shows a growth rate of 2.8 percent (using the GDP implicit price deflator) that is similar to productivity growth of 2.7 percent. But other wage and compensation series still suggest a weak labor market in 2005. Real compensation per hour for civilian workers declined in 2005 (on a December-to-December basis) when the CPI-U is used as the deflator, and barely increased when the GDP deflator is used. The real hourly earnings of the median worker, according to Current Population Survey data, showed no growth in 2004 and declined by 1.3 percent in 2005, even in the face of reasonably rapid productivity growth. ${ }^{5}$ Real compensation growth seems to be accruing only to workers above the 90th percentile of the wage distribution. This fits a longer-term pattern of rising wage inequality, driven by workers in the top part of the distribution persistently widening the gap between themselves and other workers. ${ }^{6}$

This pattern appears consistent with two interpretations. The first is that the labor market still has some slack, so that participation rates could recover a bit and unemployment could fall further without setting off inflationary forces. The second is that the structural factors (technological change, outsourcing and international trade, eroding bargaining power of nonelite workers) driving rising wage inequality and the polarization of job opportunities (a declining demand for workers in the middle of the skill and wage distribution) are such that gains from productivity growth do not seem to "trickle down" to the typical worker except when the labor market is overheating as it was in the late 1990s.

General discussion: William Brainard noted that the authors' demographic breakdowns did not distinguish among ethnic and racial groups, some of which are known to have very different labor force participation rates than others. Changes in the racial composition of the labor force could have a measurable impact on the overall participation rate, and accounting for such changes could explain some of the observed variation in participation and provide a better basis for extrapolating its trend. Robert Gordon added that

5. Allegretto and Bernstein (2006); Allegretto, Bernstein, and Shapiro (2005).

6. Autor, Katz, and Kearney (2005, 2006); Dew-Becker and Gordon (2005). 
the increasing population share of Hispanics relative to African-Americans in the population was especially important, since almost all undocumented Hispanic immigrants are in the labor market whereas African-American men have relatively low participation rates. By contrast, African-American women have higher participation rates than Hispanic women.

Turning to immigration more generally, Richard Cooper pointed out that the Census Bureau projections used by the authors predict a gradual decline in the number of legal immigrants over the next seven decades. However, these numbers, which derive from the Census Bureau's injunction to reflect U.S. policy, do not include undocumented immigrants, and this fact has enormous implications for population and Social Security projections, since many undocumented workers pay Social Security taxes. Gordon agreed with Cooper and added that the effect is magnified in the longer run by the fact that immigrants tend to have more children than the average for the population. In Gordon's own projections in his 2003 Brookings Paper, which were based on a moderately conservative slowdown in the growth of immigrants, population growth remains at 1 percent a year over seventy-five years rather than declining to 0.2 percent a year as the Social Security Trustees' report projects.

Some participants commented on the decline in average weekly hours over the authors' data period, which they project to continue. Gordon noted that the substantial decline in average hours in nonfarm business from 1970 to 1980 is largely explained by the increase in female labor participation, especially in part-time jobs. He wondered whether there was any obvious explanation for the rapid decline in average hours between 1999 and 2002. Andrew Figura replied that it can be largely explained by composition effects, in particular the loss of 3 million jobs in manufacturing, where workweeks are relatively long. Figura noted that the Bureau of Labor Statistics' chain-weighted hours index that controls for changes in industry employment shares shows a much smaller decline since 2000. Alan Blinder noted that the declining hours figures could reflect the steady shift of jobs to occupations where hours are measured very imprecisely, such as in the financial and legal professions. He suggested that participants in these sectors might work many more hours than are recorded, and he noted that the alternative hours measure based on the Current Population Survey shows little trend. Katherine Abraham replied that economists at the BLS used information from the CPS to plug gaps in the data from other sources but found that this had little effect on the official averages. 


\section{References}

Aaronson, Daniel, Kyung-Hong Park, and Daniel Sullivan. 2006. "The Decline in Teen Labor Force Participation.” Economic Perspectives (Federal Reserve Bank of Chicago) 2006(1): 2-18.

Aaronson, Daniel, and Daniel Sullivan. 2001. "Growth in Worker Quality." Economic Perspectives (Federal Reserve Bank of Chicago) 2001(4): 53-74.

Aaronson, Stephanie, and Andrew Figura. 2005. "How Biased Are Measures of Cyclical Movements in Productivity and Hours?" Finance and Economics Discussion Series Working Paper 2005-38. Washington: Board of Governors of the Federal Reserve System (September).

Allegretto, Sylvia, and Jared Bernstein. 2006. "The Wage Squeeze and Higher Health Care Costs." EPI Issue Brief 218. Washington: Economic Policy Institute (January).

Allegretto, Sylvia, Jared Bernstein, and Isaac Shapiro. 2005. "The Lukewarm 2004 Labor Market.” Washington: Economic Policy Institute and Center on Budget and Policy Priorities (February).

Autor, David H., and Mark G. Duggan. 2003. "The Rise in the Disability Rolls and the Decline in Unemployment." Quarterly Journal of Economics 118(1): 157-205.

. Forthcoming. "The Growth in the Social Security Disability Rolls: A Fiscal Crisis Unfolding." Journal of Economic Perspectives.

Autor, David H., Lawrence F. Katz, and Melissa S. Kearney. 2005. "Trends in U.S. Wage Inequality: Re-Assessing the Revisionists.” Working Paper 11627. Cambridge, Mass.: National Bureau of Economic Research (September).

2006. "The Polarization of the U.S. Labor Market." American Economic Review 96(2): 189-94.

Becker, Gary S. 1993. Human Capital: A Theoretical and Empirical Analysis with Special Reference to Education. University of Chicago Press.

Benhabib, Jess, Richard Rogerson, and Randall Wright. 1991. "Homework in Macroeconomics: Household Production and Aggregate Fluctuations." Journal of Political Economy 99(6): 1166-87.

Berger, Mark C. 1983. "Changes in Labor Force Composition and Male Earnings: A Production Approach.” Journal of Human Resources 18(2): 177-96.

Blau, Francine D., and Lawrence M. Kahn. 2005. "Changes in the Labor Supply Behavior of Married Women: 1980-2000." Working Paper 11230. Cambridge, Mass.: National Bureau of Economic Research (March).

Bosworth, Barry, and Gary Burtless. 1992. "Effects of Tax Reform on Labor Supply, Investment, and Saving." Journal of Economic Perspectives 6(1): 3-25.

Bound, John. 1989. "The Health and Earnings of Rejected Disability Insurance Applicants." American Economic Review 79(3): 482-503. 
Bound, John, and Timothy Waidmann. 1992. "Disability Transfers, Self-Reported Health, and the Labor Force Attachment of Older Men: Evidence from the Historical Record." Quarterly Journal of Economics 107(4): 1393-1419.

Bradbury, Katharine. 2005. "Additional Slack in the Economy: The Poor Recovery in Labor Force Participation during This Business Cycle." Public Policy Brief 05-2. Federal Reserve Bank of Boston (July).

Buessing, Marric, and Mauricio Soto. 2006. "The State of Private Pensions: Current 5500 Data." Issue in Brief 42. Center for Retirement Research at Boston College (February).

Burtless, Gary. 1999. “An Economic View of Retirement.” In Behavioral Dimensions of Retirement Economics, edited by Henry J. Aaron. Brookings.

Burtless, Gary, and Joseph F. Quinn. 2001. "Retirement Trends and Policies to Encourage Work among Older Americans." In Ensuring Health and Income Security for an Aging Workforce, edited by Peter P. Budetti and others. Kalamazoo, Mich.: W. E. Upjohn Institute for Employment Research.

Coile, Courtney C., and Phillip B. Levine. 2006. "Bulls, Bears, and Retirement Behavior." Industrial and Labor Relations Review 59(3): 408-29.

Congressional Budget Office. 2004. CBO's Projections of the Labor Force. Washington (September).

Coronado, Julia L., and Maria Perozek. 2003. "Wealth Effects and the Consumption of Leisure: Retirement Decisions during the Stock Market Boom of the 1990s." Finance and Economics Discussion Series Working Paper 2003-20. Washington: Board of Governors of the Federal Reserve System (May).

Dellas, Harris, and Plutarchos Sakellaris. 2003. "On the Cyclicality of Schooling: Theory and Evidence." Oxford Economic Papers 55(1): 148-72.

Devereux, Paul J. 2004. "Changes in Relative Wages and Family Labor Supply." Journal of Human Resources 39(3): 696-722.

Dew-Becker, Ian, and Robert J. Gordon. 2005. "Where Did the Productivity Growth Go? Inflation Dynamics and the Distribution of Income." BPEA, no. 2: 67-127.

Economic Policy Institute. 2006. "Jobs Picture: Steadily Improving Job Market, but Little Sign of Inflationary Pressure.” Washington. www.epi.org/content.cfm/ webfeatures_econindicators_jobspict_20060407.

Eissa, Nada, and Hilary W. Hoynes. 2004. "Taxes and the Labor Market Participation of Married Couples: The Earned Income Tax Credit." Journal of Public Economics 88(9-10): 1931-58.

2005. "Behavioral Responses to Taxes: Lessons from the EITC and Labor Supply.” Working Paper 11729. Cambridge, Mass.: National Bureau of Economic Research (November).

Eldridge, Lucy P., Marilyn E. Manser, and Phyllis Flohr Otto. 2004. “Alternative Measures of Supervisory Employee Hours and Productivity Growth." Monthly Labor Review 127(4): 9-28. 
Goldin, Claudia. 2006. “The Quiet Revolution That Transformed Women's Employment, Education, and Family." American Economic Review, Papers and Proceedings 96(2): 1-21.

Grant, James H., and Daniel S. Hamermesh. 1981. "Labor Market Competition among Youths, White Women, and Others." Review of Economics and Statistics 63(3): 354-60.

Greene, William H., and Terry G. Seaks. 1991. "The Restricted Least Squares Estimator: A Pedagogical Note.” Review of Economics and Statistics 73(3): 563-67.

Gustman, Alan L., and Thomas L. Steinmeier. 2002. "Retirement and the Stock Market Bubble." Working Paper 9404. Cambridge, Mass.: National Bureau of Economic Research (December).

Hausman, Jerry A. 1985. "Taxes and Labor Supply." In Handbook of Public Economics, vol. 1, edited by Alan Auerbach and Martin Feldstein. Amsterdam: North-Holland.

Haveman, Robert, Philip de Jong, and Barbara Wolfe. 1991. "Disability Transfers and the Work Decision of Older Men." Quarterly Journal of Economics 106(3): 939-49.

Himmelberg, Charles, and Margaret M. McConnell. 2006. "How Much Labor Market Slack: The Importance of Adjusting for Trend Participation Rates." Unpublished paper. Federal Reserve Bank of New York (January).

Hotchkiss, Julie L. 2005. "What's Up with the Decline in Female Labor Force Participation?" Working Paper 2005-18. Federal Reserve Bank of Atlanta (August).

Jaeger, David A. 1997. "Reconciling the Old and New Census Bureau Education Questions: Recommendations for Researchers." Journal of Business and Economic Statistics 15(3): 300-09.

Juhn, Chinhui. 1992. "Decline of Male Labor Market Participation: The Role of Declining Market Opportunities.” Quarterly Journal of Economics 107(1): 79-121.

Juhn, Chinhui, and Kevin M. Murphy. 1997. "Wage Inequality and Family Labor Supply." Journal of Labor Economics 15(1, part 1): 72-97.

Juhn, Chinhui, Kevin M. Murphy, and Robert H. Topel. 1991. "Why Has the Natural Rate of Unemployment Increased over Time?” BPEA, no. 2: 75-126. no. 1: 79-116.

. 2002. "Current Unemployment, Historically Contemplated." BPEA,

Kaiser Family Foundation. 2005. Employer Health Benefits 2005 Annual Survey. Menlo Park, Calif.: Kaiser Family Foundation and Health Research and Educational Trust. www.kff.org/insurance/7315/sections/upload/7375.pdf.

Killingsworth, Mark, and James Heckman. 1986. "Female Labor Supply: A Survey." In Handbook of Labor Economics, vol. 1, edited by Orley Ashenfelter and Richard Layard. Amsterdam: Elsevier North-Holland. 
Kirkland, Katie. 2000. "On the Decline in Average Weekly Hours Worked." Monthly Labor Review 123(7): 26-31.

Kominski, Robert, and Paul M. Siegel. 1993. "Measuring Education in the Current Population Survey." Monthly Labor Review 116(9): 34-38.

Loughran, David S., and Steven Haider. 2005. "Do the Elderly Respond to Taxes on Earnings? Evidence from the Social Security Retirement Earnings Test." Labor and Population Working Paper WR-223. Santa Monica, Calif.: RAND Corporation (January).

Mulligan, Casey B., and Yona Rubinstein. 2006. "Specialization, Inequality, and the Labor Market for Women." Unpublished paper. Alfred P. Sloan Center for the Study of Working Families, University of Chicago (January).

Murphy, Kevin M., and Robert H. Topel. 1987. "The Evolution of Unemployment in the United States: 1968-1985." In NBER Macroeconomics Annual 1987, edited by Stanley Fischer. MIT Press.

Parsons, Donald O. 1980. "The Decline in Male Labor Force Participation." Journal of Political Economy 88(1): 117-34.

Pencavel, John. 1986. "Labor Supply of Men: A Survey.” In Handbook of Labor Economics, vol. 1, edited by Orley Ashenfelter and Richard Layard. Amsterdam: Elsevier North-Holland.

Pension Benefit Guaranty Corporation. 2005. An Analysis of Frozen Defined Benefit Plans. Washington (December).

Perry, George. 1971. "Labor Force Structure, Potential Output, and Productivity." BPEA, no. 3: 533-65.

Polivka, Anne E., and Stephen M. Miller. 1998. "The CPS after the Redesign: Refocusing the Economic Lens." In Labor Statistics Measurement Issues, edited by John Haltiwanger, Marilyn E. Manser, and Robert H. Topel. University of Chicago Press.

Polivka, Anne E., and Jennifer M. Rothgeb. 1993. "Overhauling the Current Population Survey: Redesigning the CPS Questionnaire." Monthly Labor Review 116(9): 10-28.

Rones, Phillip L., Randy E. Ilg, and Jennifer M. Gardner. 1997. "Trends in Hours of Work Since the Mid-1970s." Monthly Labor Review 120(4): 3-14.

Sevak, Purvi. 2005. "Wealth Shocks and Retirement Timing: Evidence from the Nineties." Unpublished paper. Hunter College. urban.hunter.curry.edu/ psevak/ research/wealthshocks_july05.pdf.

Shimer, Robert. 1999. "Why Is the U.S. Unemployment Rate So Much Lower?" In NBER Macroeconomics Annual 1998, edited by Ben S. Bernanke and Julio J. Rotemberg. MIT Press.

Social Security Administration. 2004. Annual Statistical Report on the Social Security Disability Insurance Program, 2003. SSA Publication 13-11826. (August).

Toossi, Mitra. 2005. "Labor Force Projections to 2014: Retiring Boomers." Monthly Labor Review 128(11): 25-44. 
Venti, Steven F., and David A. Wise. 2001. "Aging and Housing Equity: Another Look." Working Paper 8608. Cambridge, Mass.: National Bureau of Economic Research (November).

Wachter, Michael L. 1977. "Intermediate Swings in Labor Force Participation." $B P E A$, no. 2: 545-74.

Watson Wyatt Worldwide. 2005. "More Companies Froze, Terminated Pension Plans in 2004, Watson Wyatt Analysis Finds.” Press release. Rochelle Park, N.J. (June 22).

Welch, Finis. 1979. "Effects of Cohort Size on Earnings: The Baby Boom Babies' Financial Bust." Journal of Political Economy 87(5, part 2): S65-S97.

1997. "Wages and Participation." Journal of Labor Economics 15(1, part 2): S77-S103. 